\title{
A Low-Cost and Scalable Synthesis of a Cyclohexanone-Related Bifunctional Building Block
}

Qinghong Zha, Xiaosheng An, Ze-Jun Xu, Wei-Bo Han, and Yikang Wu*

State Key Laboratory of Bioorganic and Natural Products Chemistry, Center for Excellence in Molecular Synthesis, Shanghai Institute of Organic Chemistry, Chinese Academy of Sciences, 345 Lingling Road, Shanghai 200032 China.

E-mail: yikangwu@sioc.ac.cn

Table of Contents

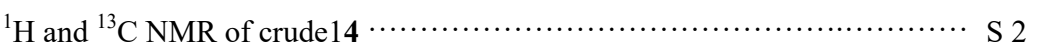

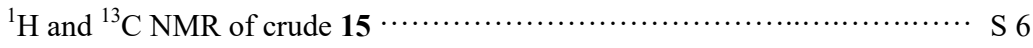

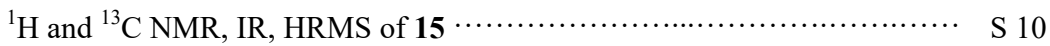

${ }^{1} \mathrm{H}$ and ${ }^{13} \mathrm{C}$ NMR of 7 (1:1 mixture of cis and trans isomers) $\cdots \cdots \cdots \cdots \cdots \cdots \cdots \cdots \cdots \cdots$

${ }^{1} \mathrm{H}$ and ${ }^{13} \mathrm{C}$ NMR, IR, HRMS of cis-7 …............................. S 20

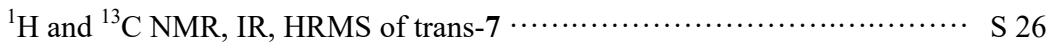

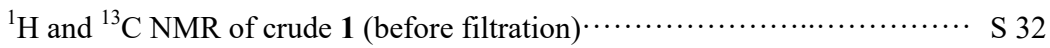

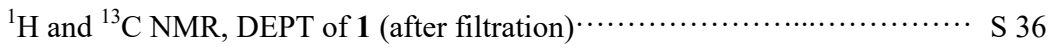

COSY, HSQC, HMBC of 1 (after filtration) $\cdots \cdots \cdots \cdots \cdots \cdots \cdots \cdots \cdots \cdots \cdots \cdots \cdots \cdots \cdots \cdots \cdots \cdots \cdots \cdots$ 


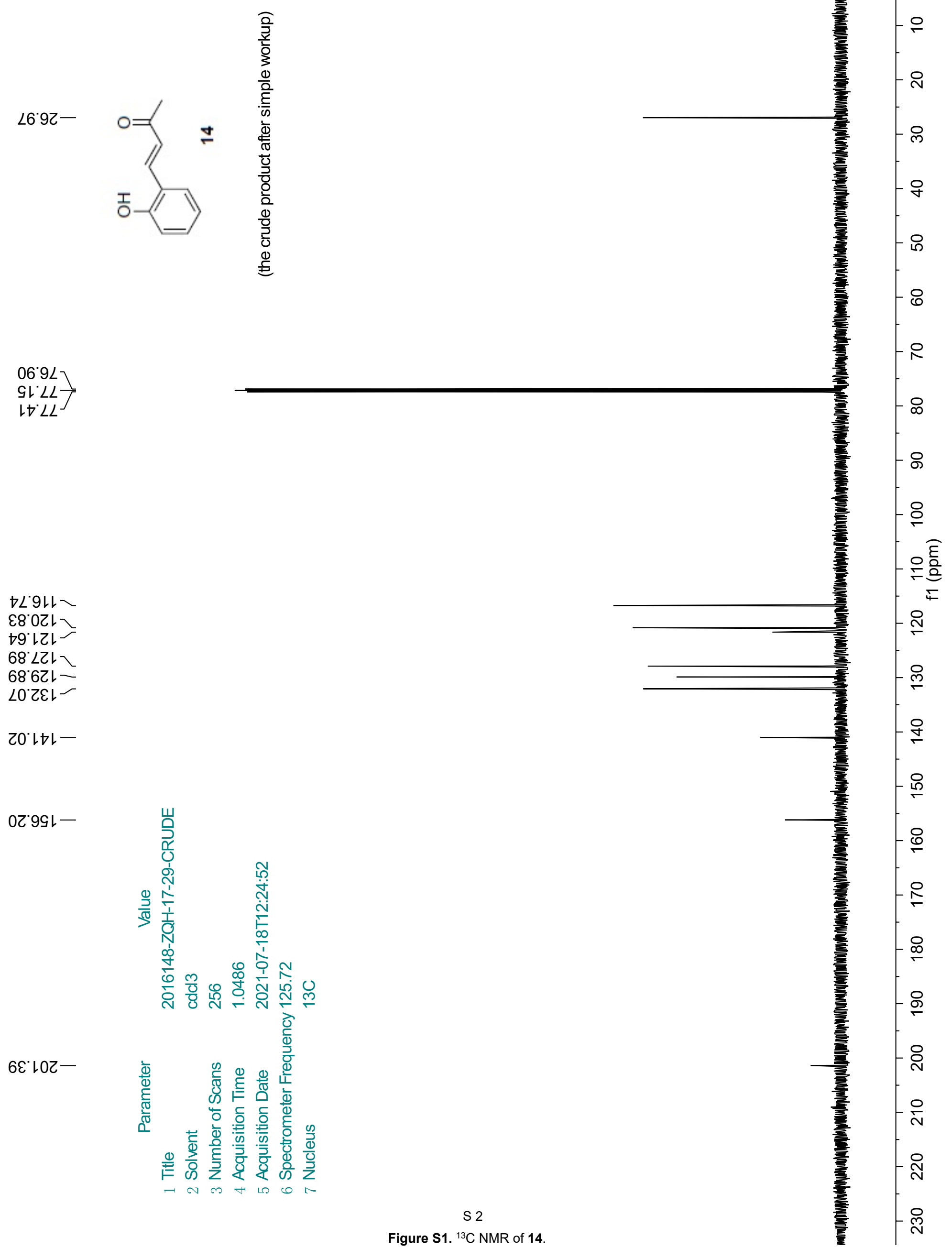


06.92

GL'LL

†L9ルレー

ع8.0Zレ -

†゚レてレー

68' LZL-

68'6Zレ-

$\angle 0^{\circ} Z \varepsilon \perp-$

て゚เナレー

OZ'9G -

6E'LOZ-
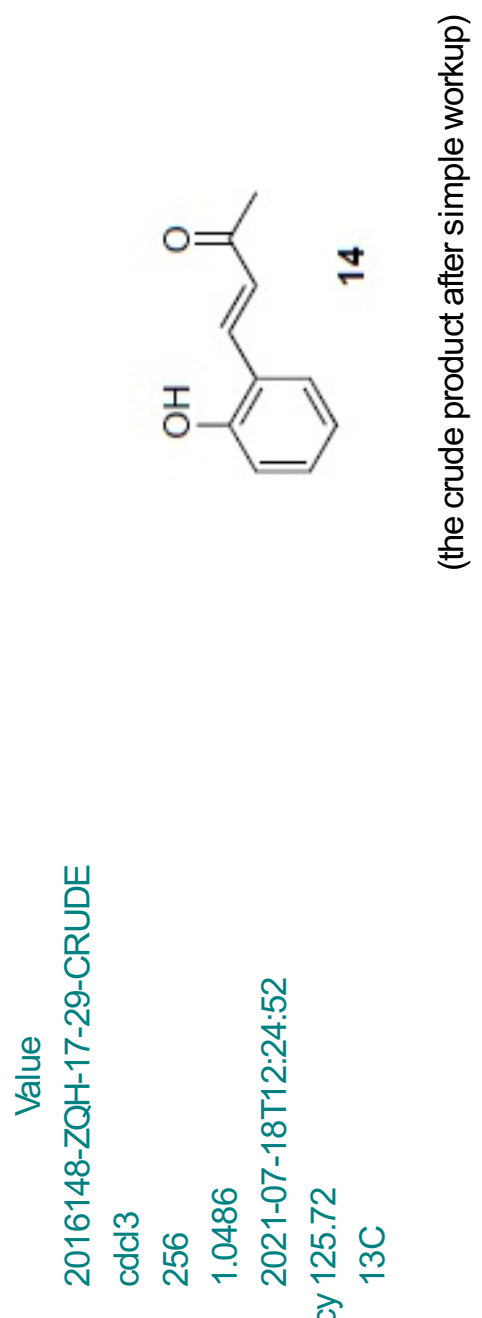

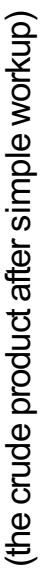

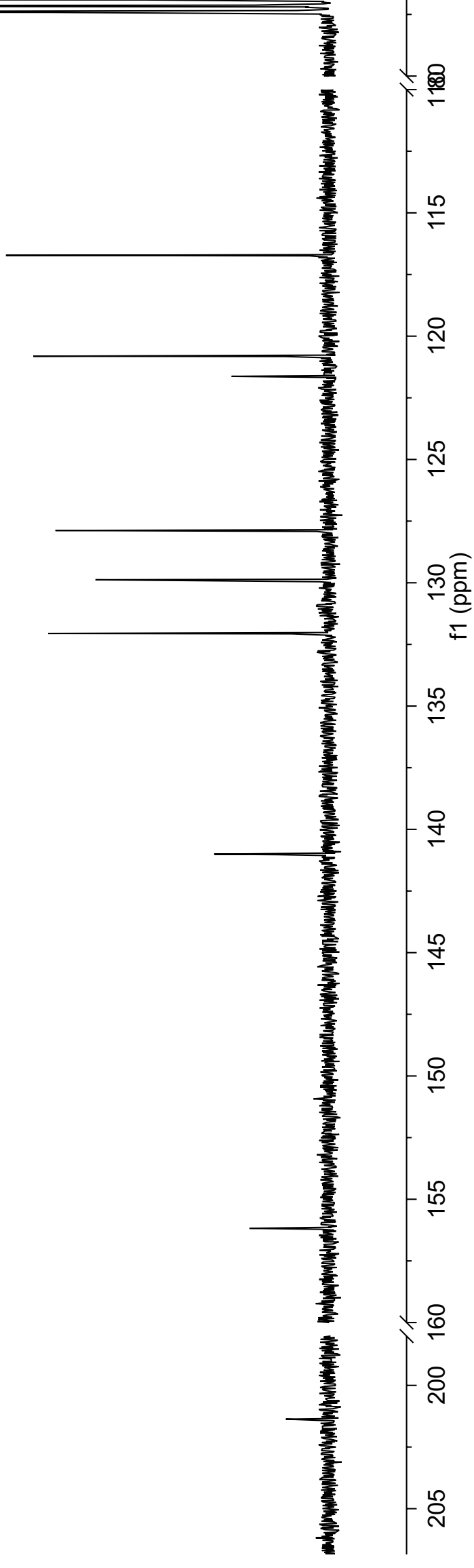




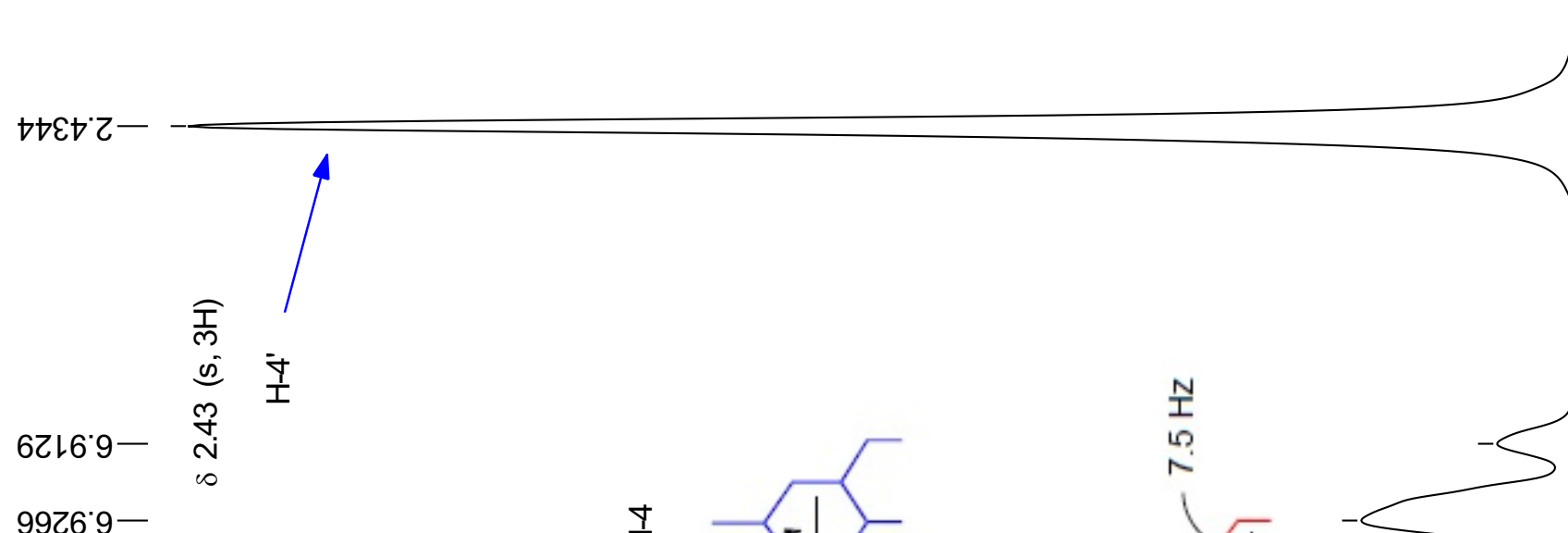

$60+6.9-$

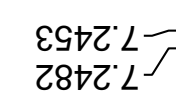

L6GZ L -

9E9Z L

19LZ $L$

E6LZ L -
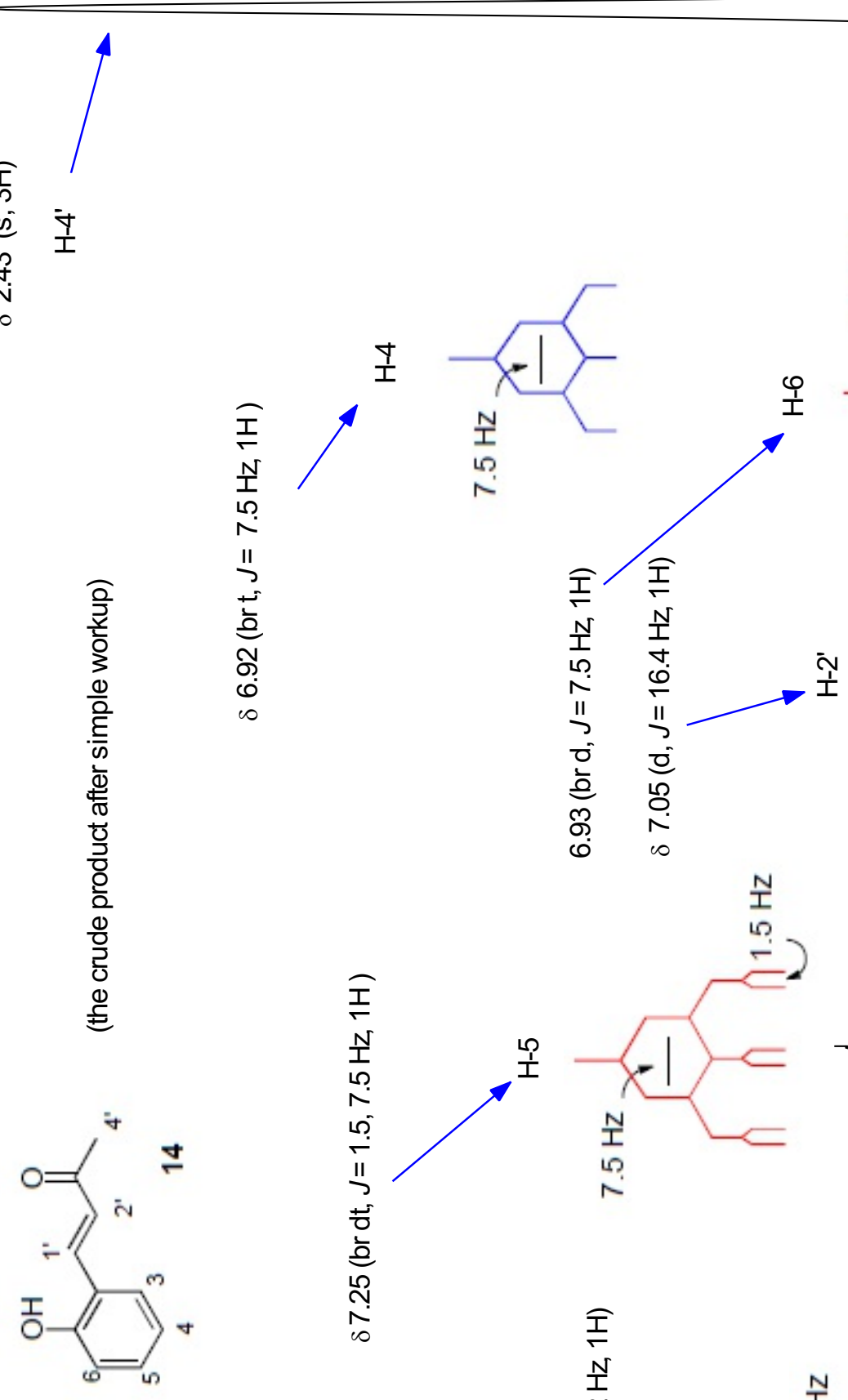

ZE9t L

$6+9 t^{\circ} L$

$88 \angle T^{\circ} L$

Z18大'L

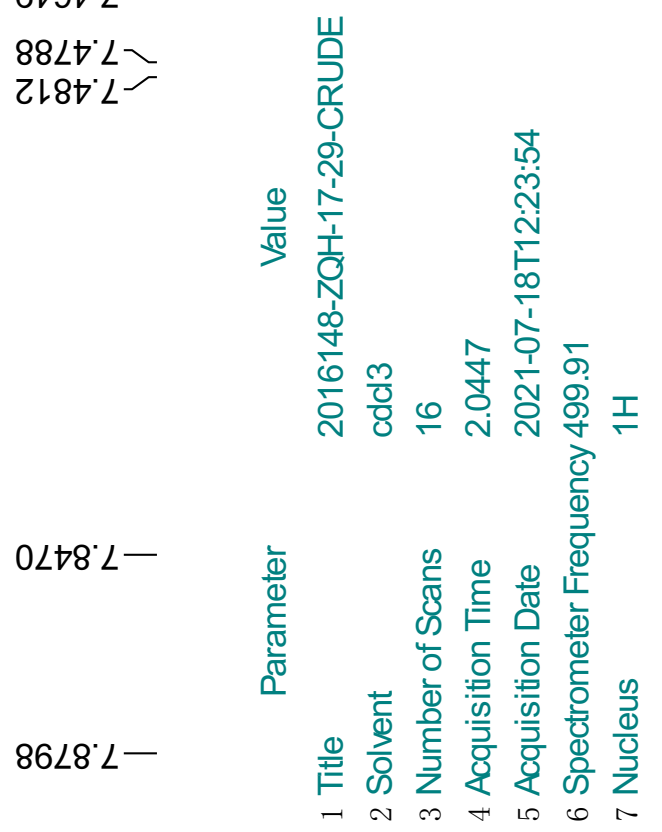

86L8 L-
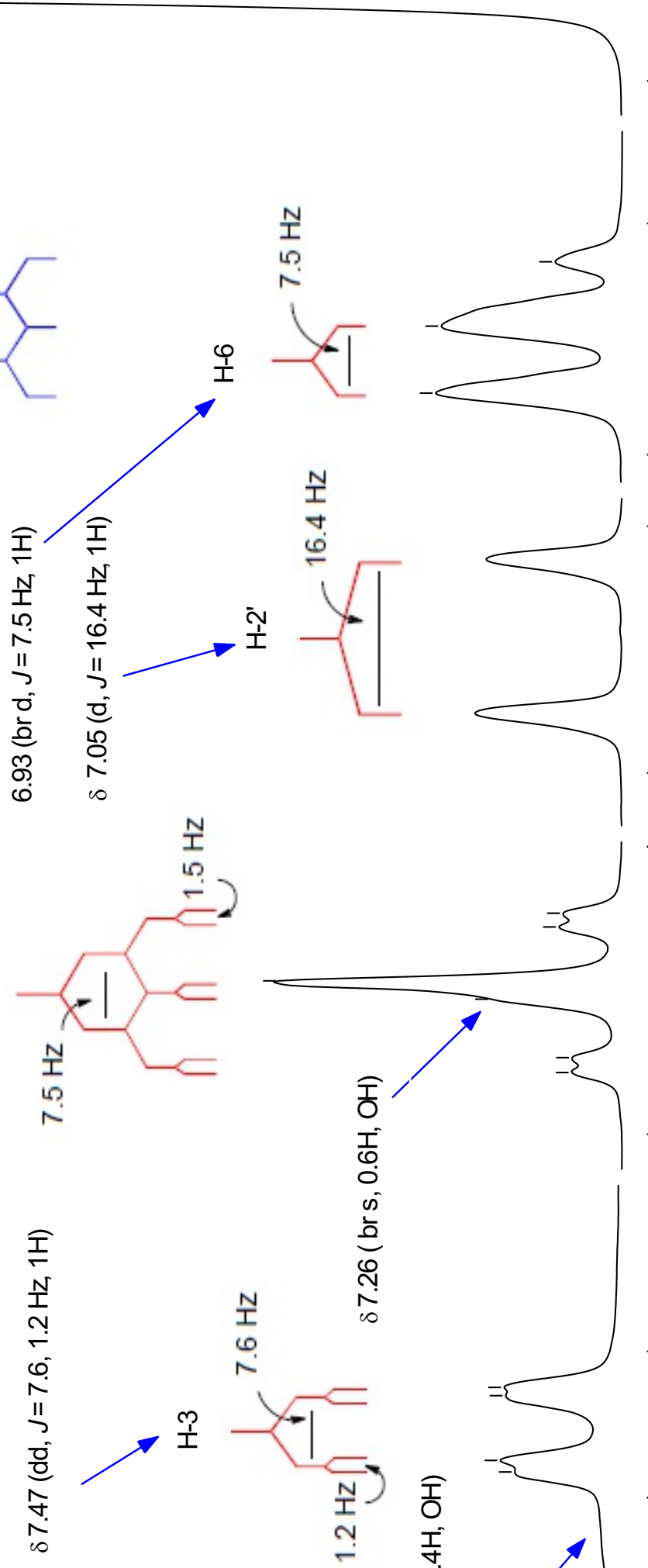

논
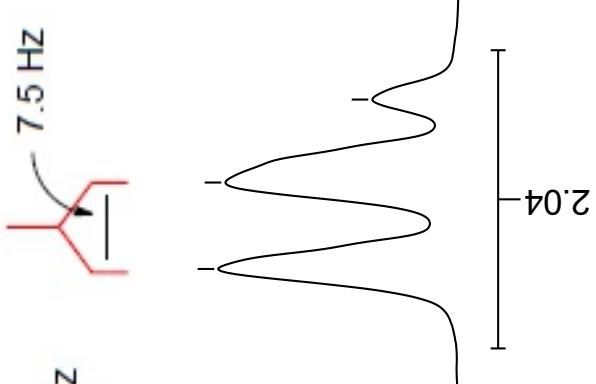

ڤొ

?.

$-00^{\circ} \mathrm{L}$

8,

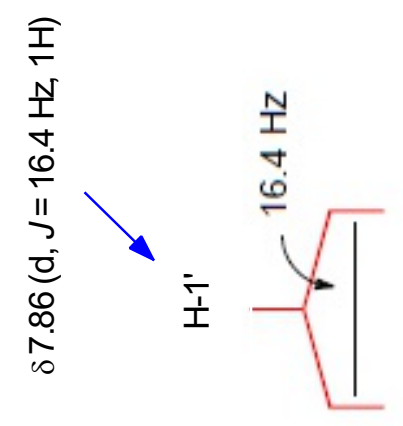




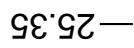

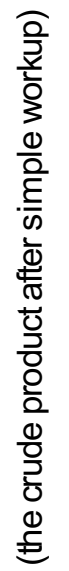

$\varepsilon L^{\circ} \triangleright 9-$

$06.9 L$

GL $L L \frac{}{0} \angle L=$

レレ80レー

80.9レL

Z6.0ZL

$69^{\circ}+Z L$

$86^{\circ} \angle Z L$

$80.621-$

†6.0عL-

9S'ยงレ -

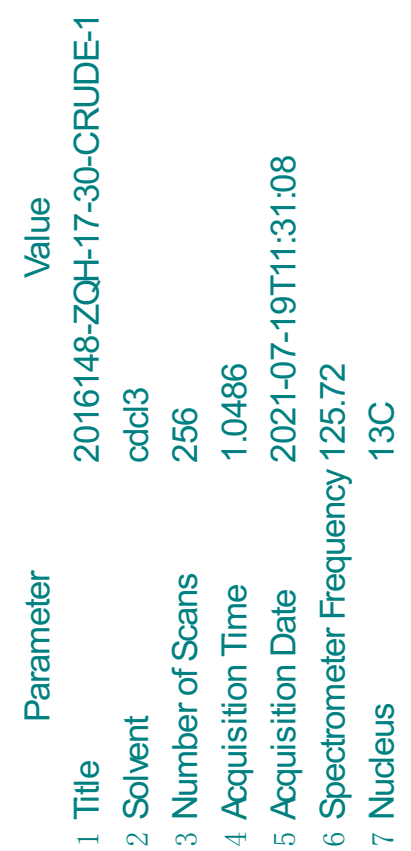


$06.9 \angle 入$

SL'LL-
$0 t \angle L C$

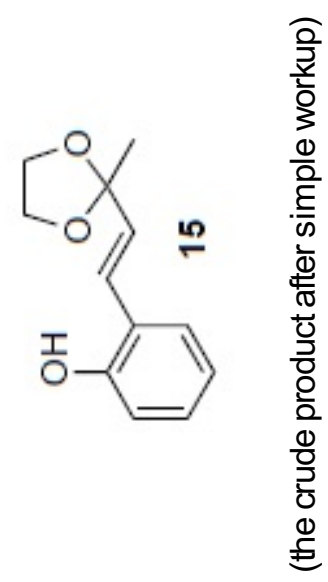

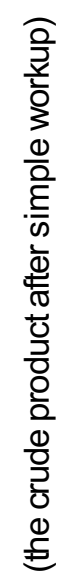

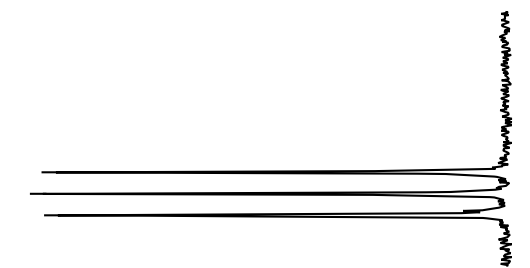

80.9ルー

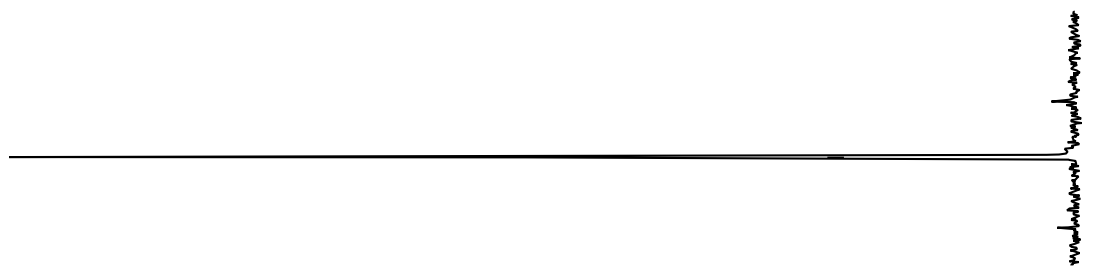

เL:80レ-

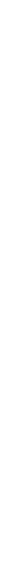

86 レZLー $80^{\circ} 6$ レー ๑6.0عเ-
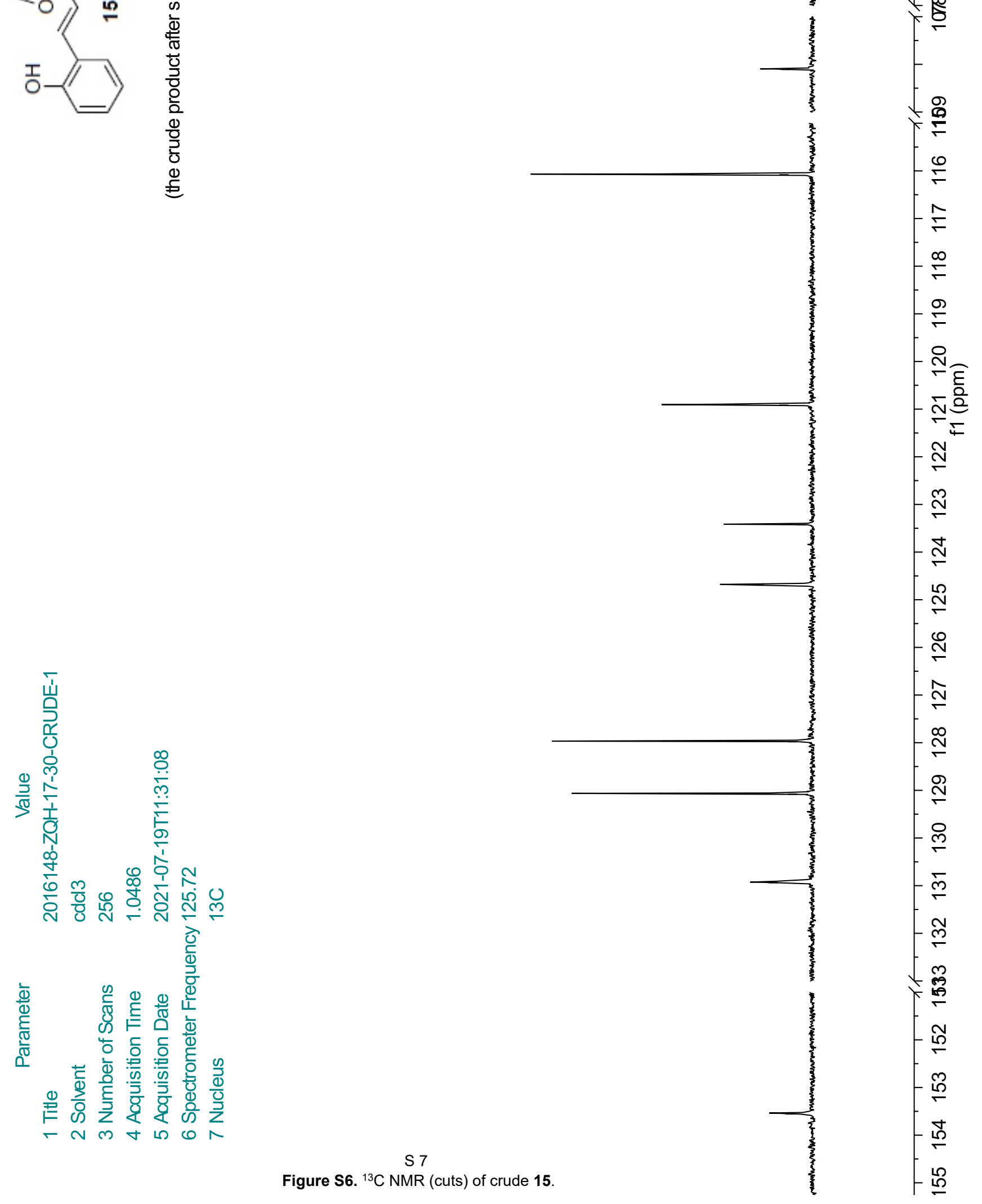



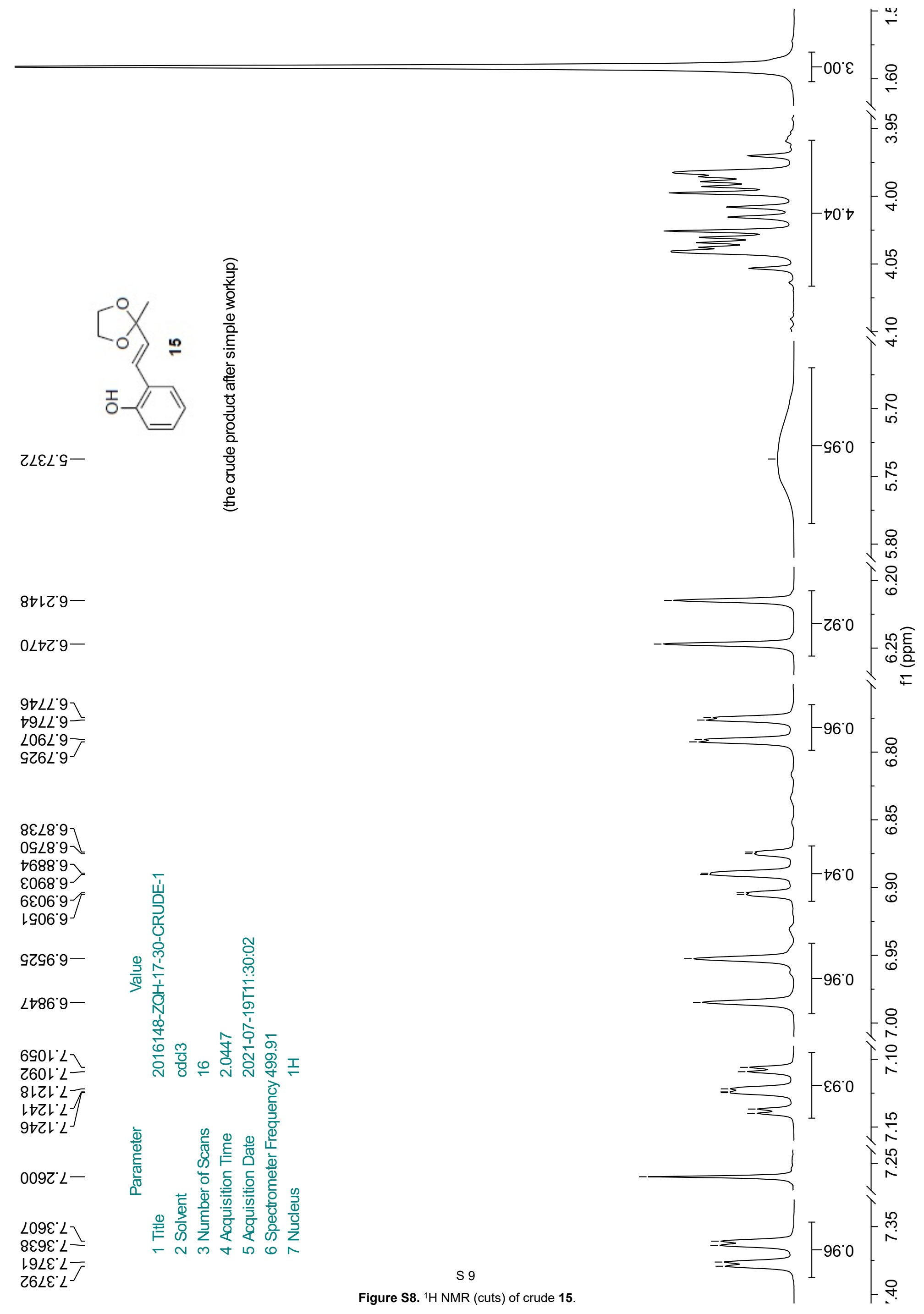


$09+9$

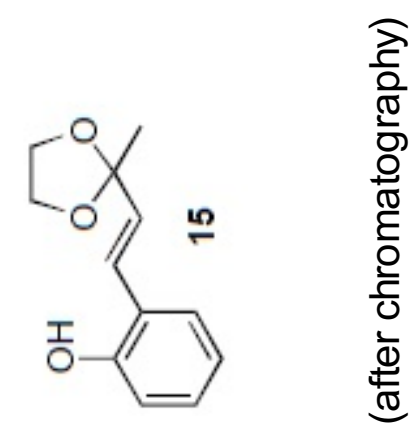

$9 \angle 9 L$

$\angle C^{\circ} \angle L \frac{I}{J}$

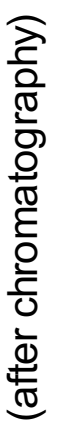

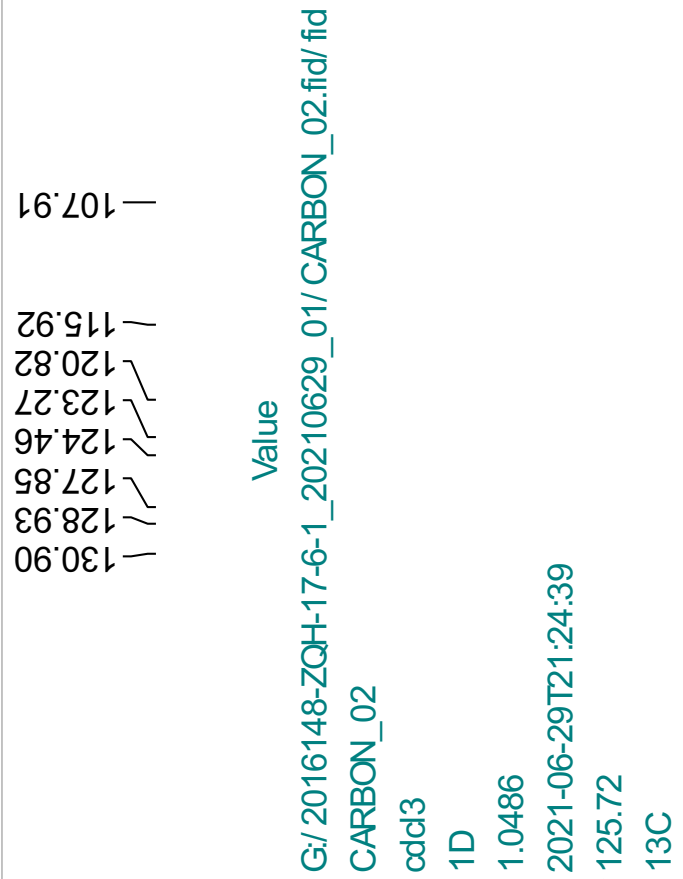

เยะรเ-

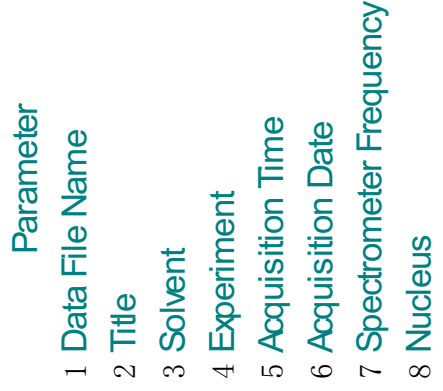



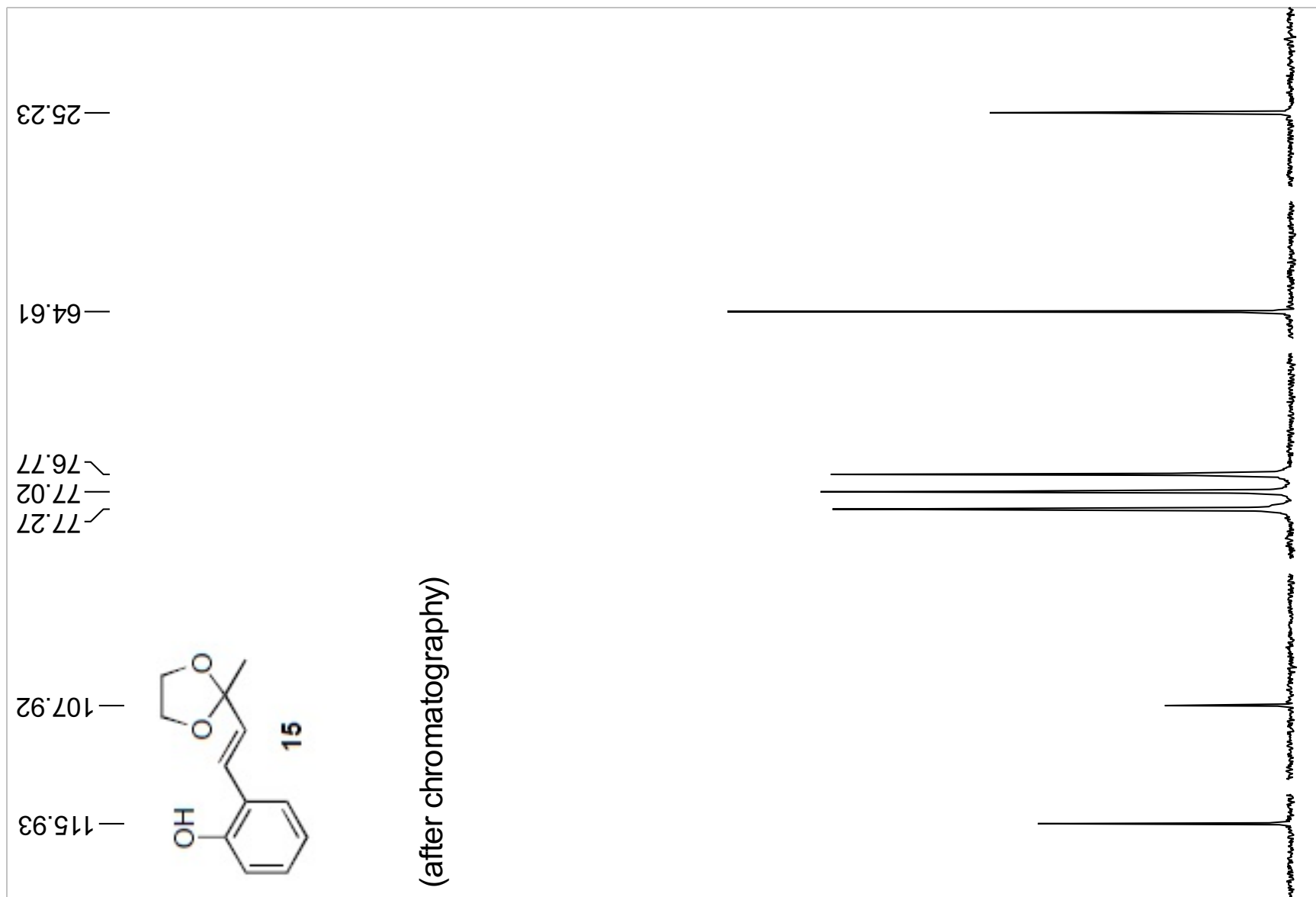

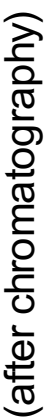

๕8・0Zレ-
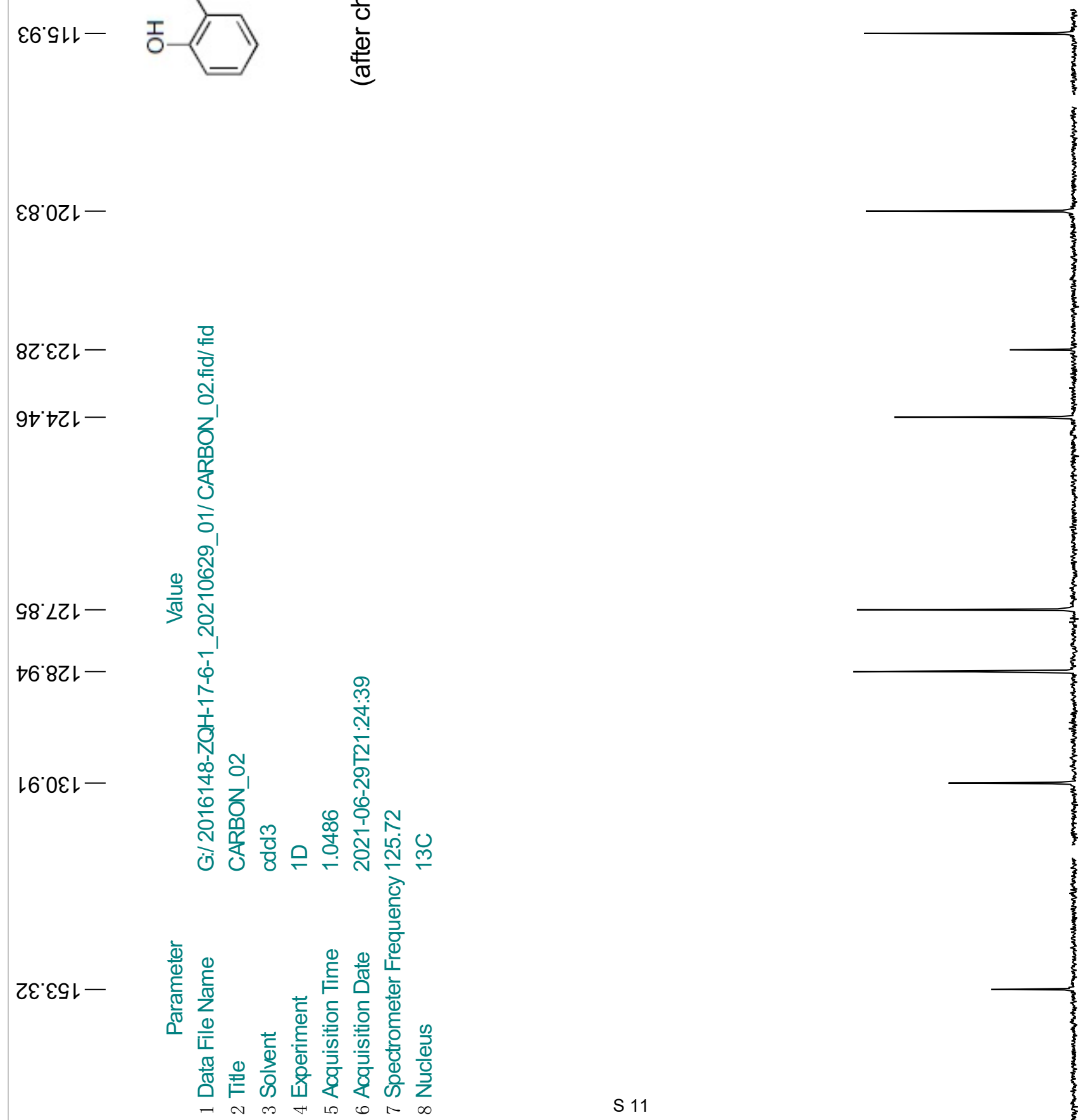

$\div$

$+\frac{9}{=}$

ำ

뜨를

$\stackrel{\text { M }}{\stackrel{9}{*}}$

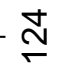

$\stackrel{\sim}{\stackrel{2}{\sim}}$

$\stackrel{\circ}{\stackrel{N}{\sim}}$

N

$\stackrel{\infty}{\sim}$

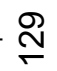

음

함

ผ

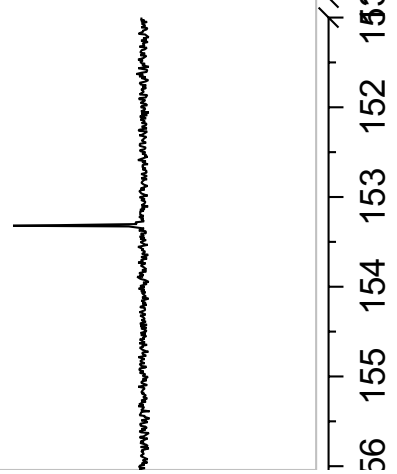




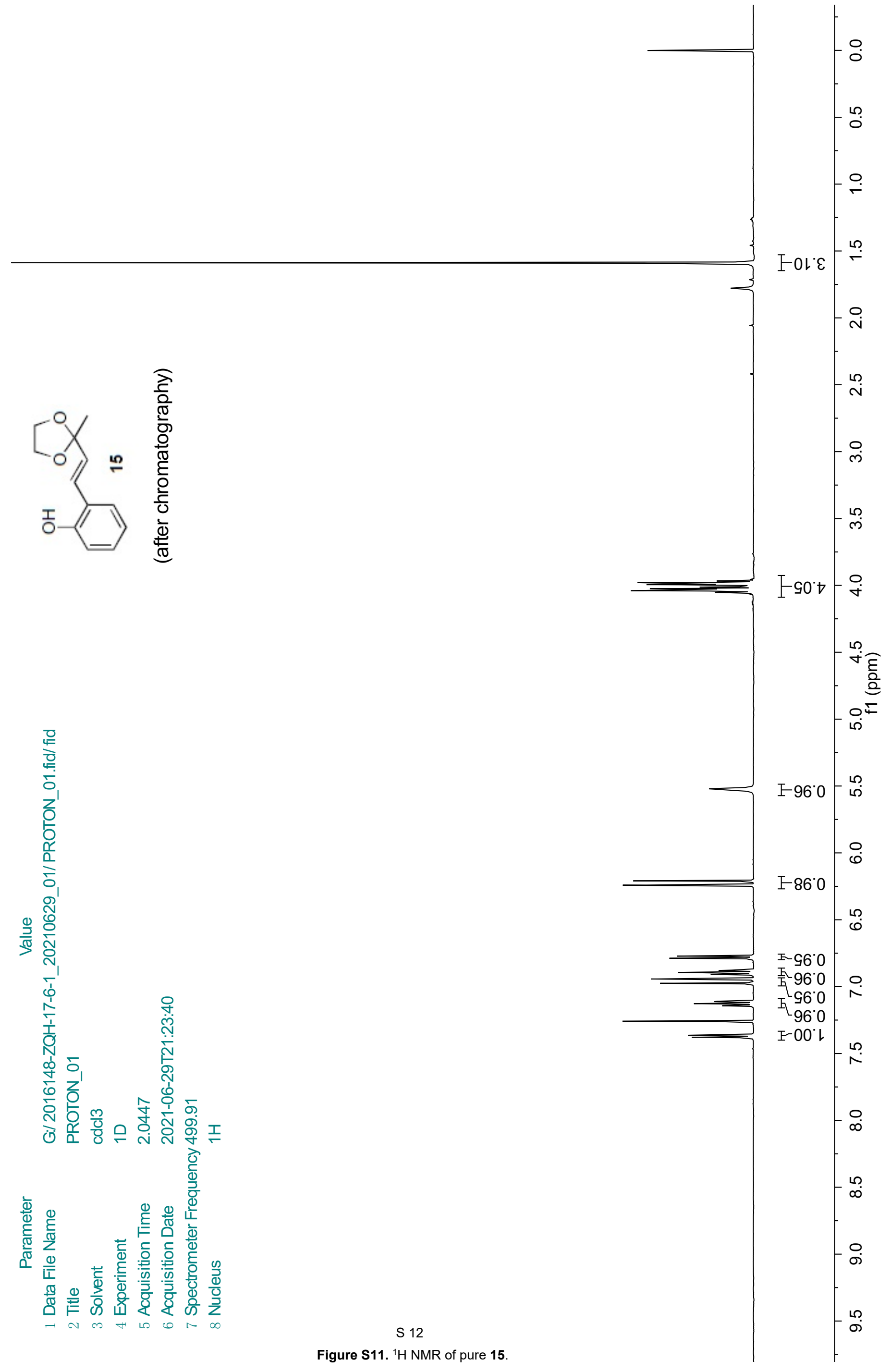


0889' ᄂ

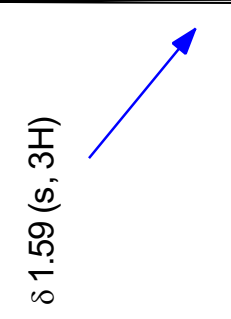

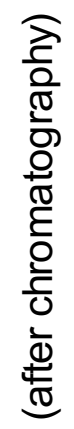

เ602'9-

ยเレで9-

9LLL'9-

9L8L'9-

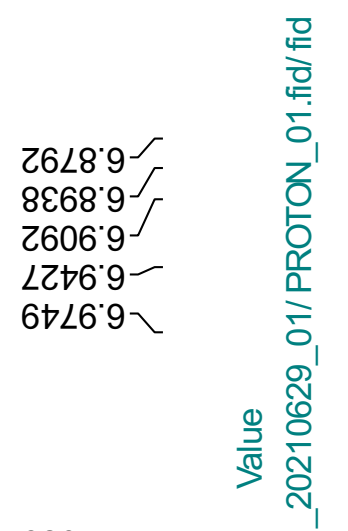

$680 L^{\circ} L$
LCLL]

StCL:L LLCL' $L$ $\angle 6 E L^{\circ} \angle-$

LETLL

989Z L-
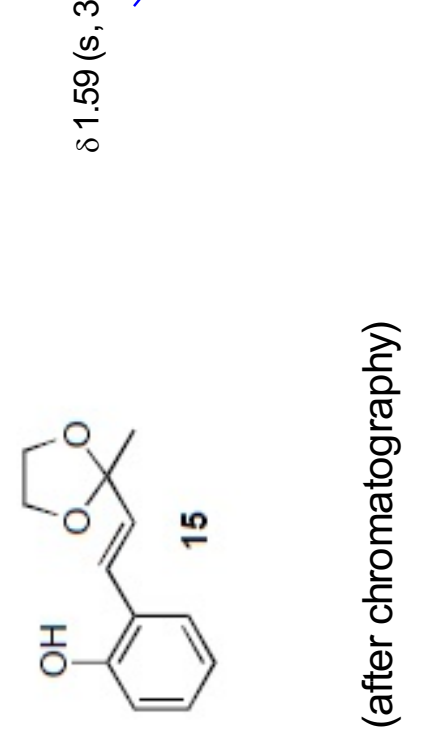

ELZG'S-

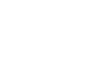




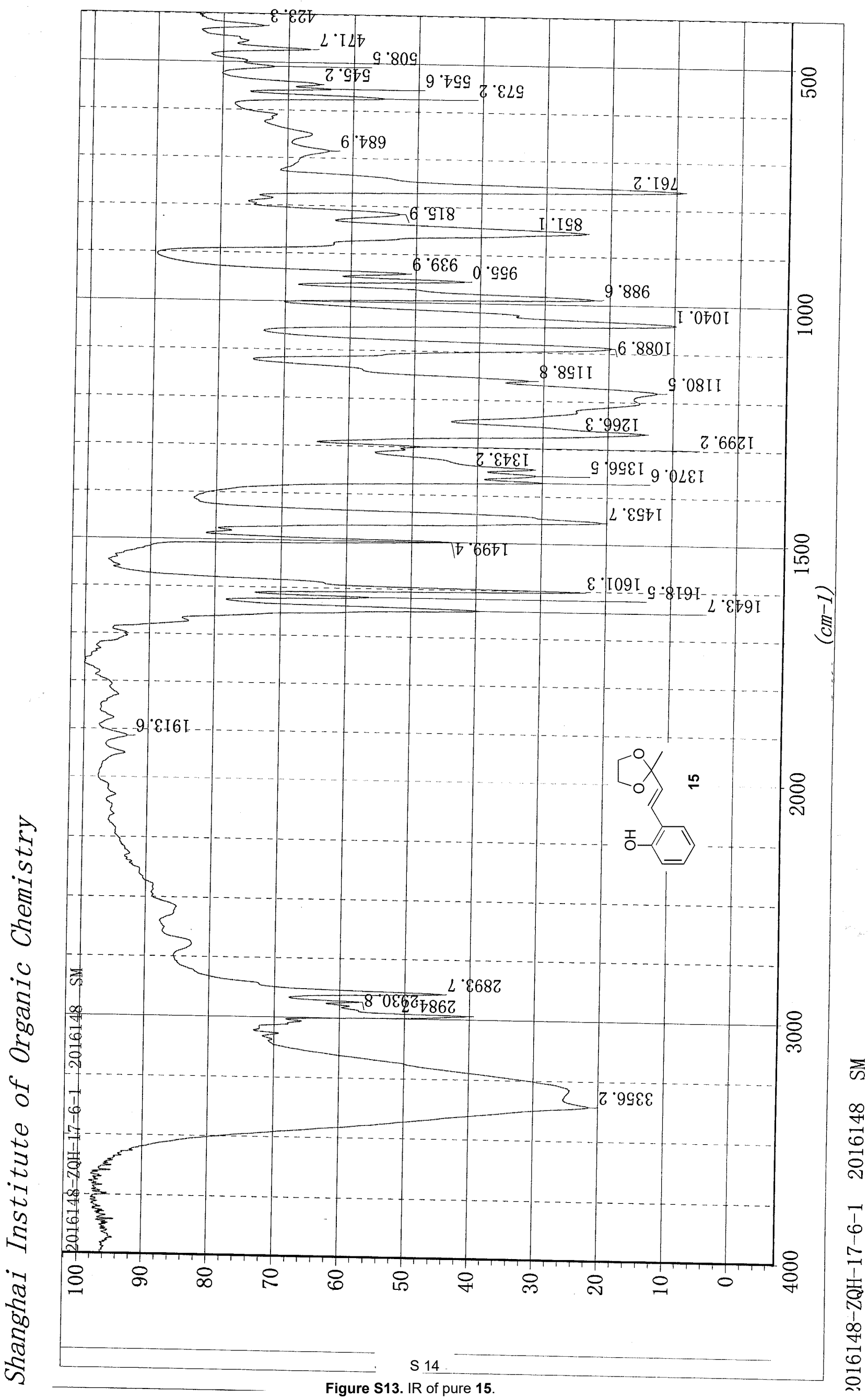


National Center for Organic Mass Spectrometry in Shanghai

Shanghai Institute of Organic Chemistry

Chinese Academic of Sciences

High Resolution EI-MS Report

Low Resolution EI-MS Report

Instrument:

Waters Premier GC-TOF MS

Operation Mode:

EI Positive Ion Mode

(Electron Energy: 70eV)

Card Serial Number: $\quad$ GCT-P-EI-T21-2061

Sample Serial Number: 2016148-ZQH-17-6-1

Operator:

$\mathrm{Li}$

Date:

$2021 / 07 / 07$

\begin{tabular}{|c|c|c|c|c|}
\hline $\mathrm{m} / \mathrm{z}$ & $\begin{array}{c}\text { Theo. } \\
\text { Mass }\end{array}$ & $\begin{array}{l}\text { Delta } \\
\text { (ppm) }\end{array}$ & $\begin{array}{c}\text { RDB } \\
\text { equiv. }\end{array}$ & Composition \\
\hline 206.0941 & 206.0942 & -0.65 & 1.5 & $\mathrm{C}_{9} \mathrm{H}_{17} \mathrm{O}_{2} \mathrm{~N} \mathrm{Cl}$ \\
\hline & 206.0937 & 1.72 & 6.0 & $\mathrm{C}_{12} \mathrm{H}_{14} \mathrm{O}_{3}$ \\
\hline & 206.0947 & -3.01 & -3.0 & $\mathrm{C}_{6} \mathrm{H}_{2} 0 \mathrm{ON}_{2} \mathrm{Cl}_{2}$ \\
\hline & 206.0934 & 3.31 & -10.0 & $\mathrm{CH}_{2} \mathrm{ON}_{2} \mathrm{Cl}_{2} \mathrm{~F}_{4}$ \\
\hline & 206.0949 & -3.83 & 2.0 & $\mathrm{C}_{9} \mathrm{H}_{15} \mathrm{O}_{4} \mathrm{~F}$ \\
\hline
\end{tabular}

T-337

GCT.P.EI-T21-337 $785(13.018) \mathrm{Cm}(783: 785-(776: 777+769: 770))$

100

191

TOF MSEI+

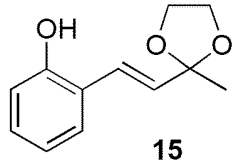

15

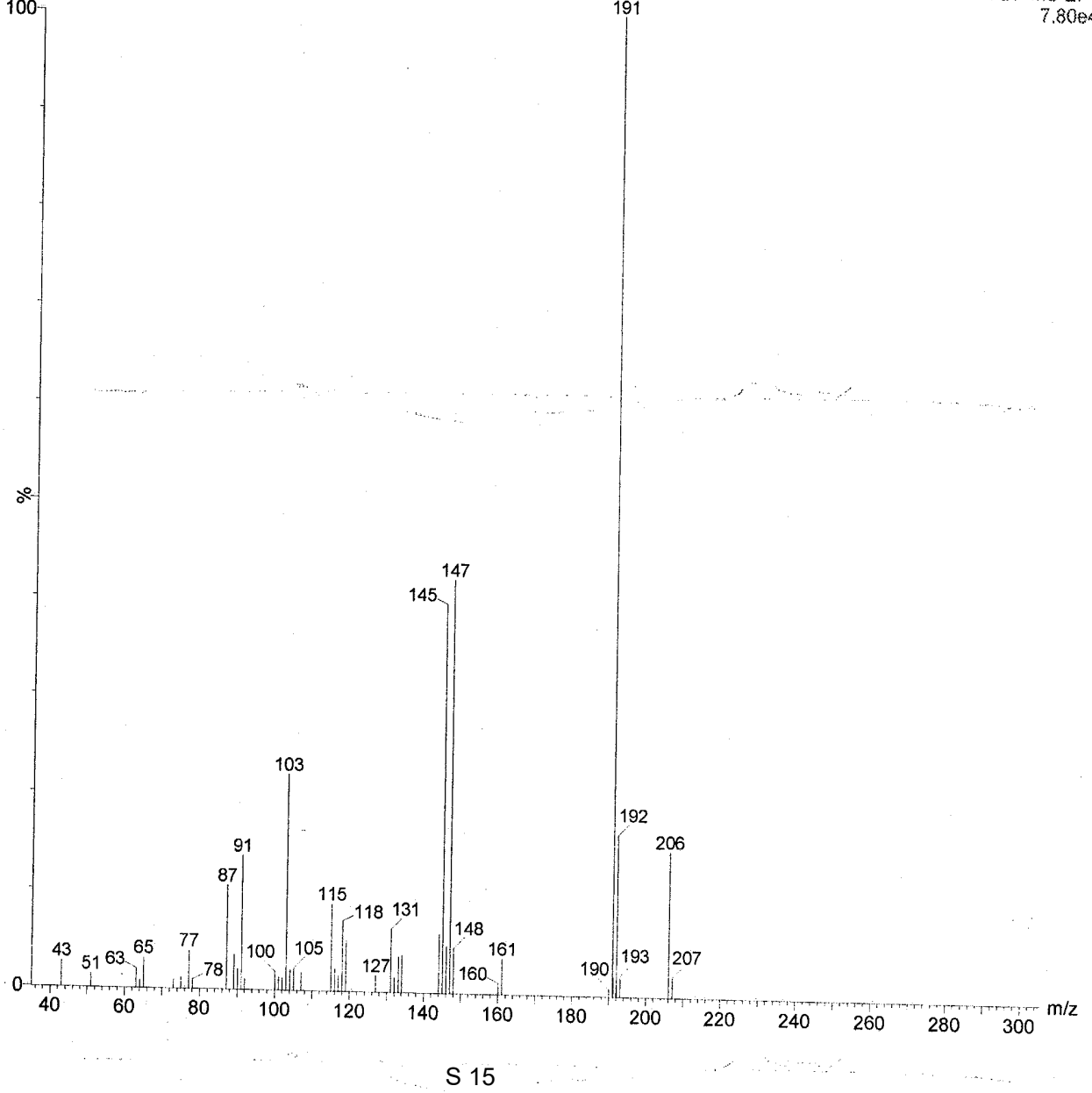

Figure S14. HRMS of 15. 

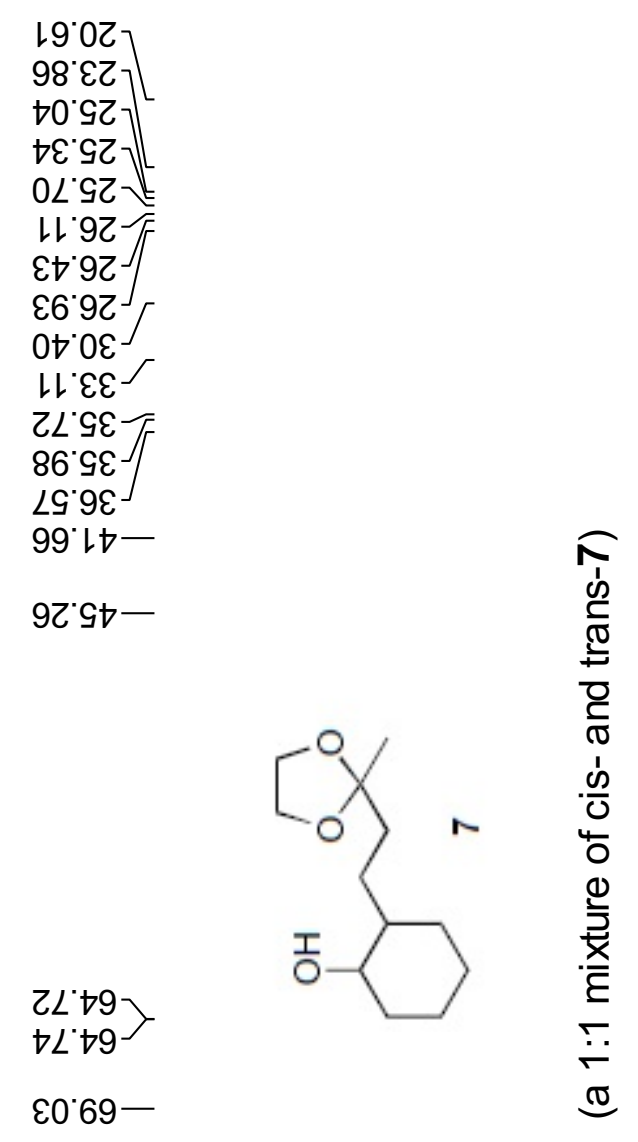

$89^{\circ} \nabla L \backslash$

$06.92]$

$G L L L \frac{L}{J}$
$L V L$

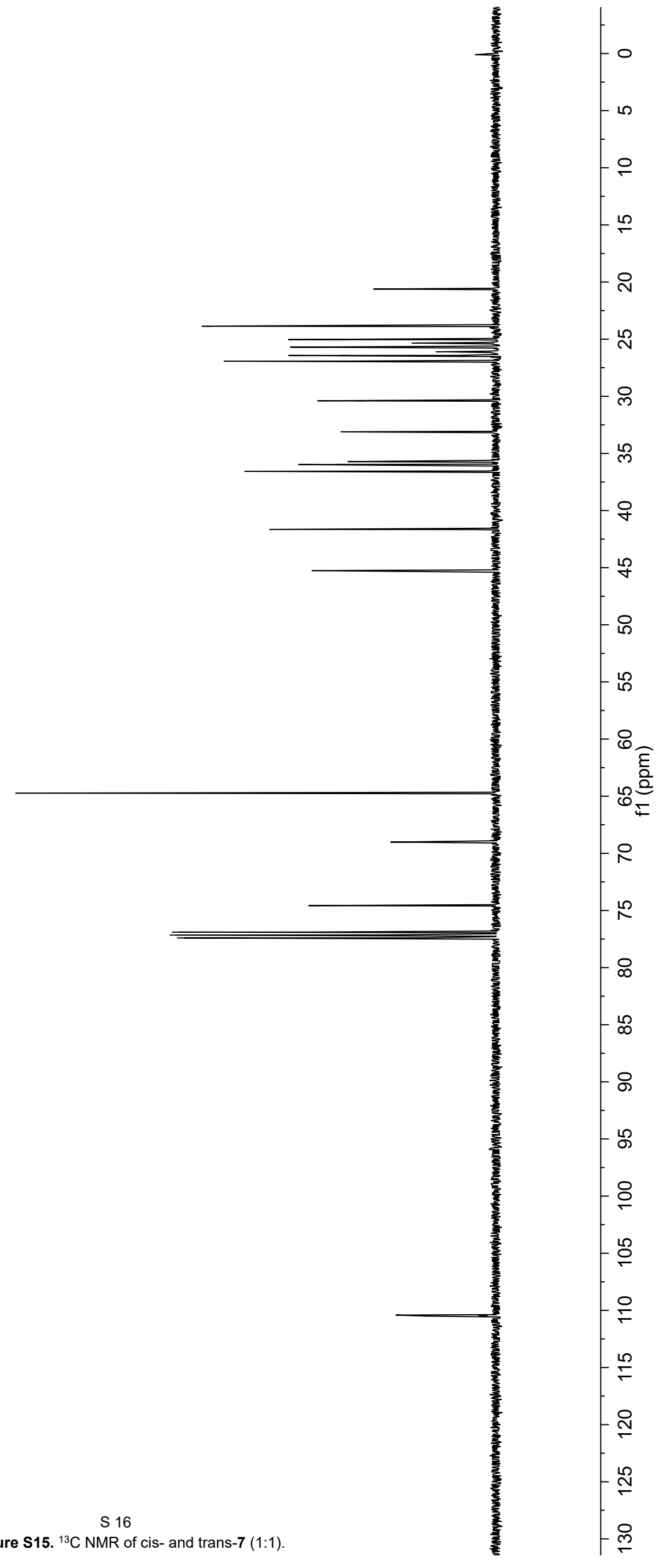

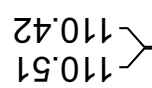

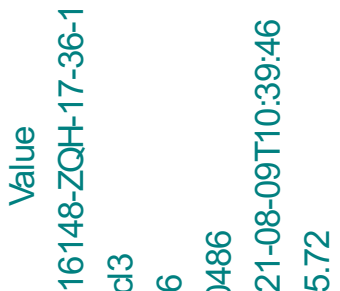

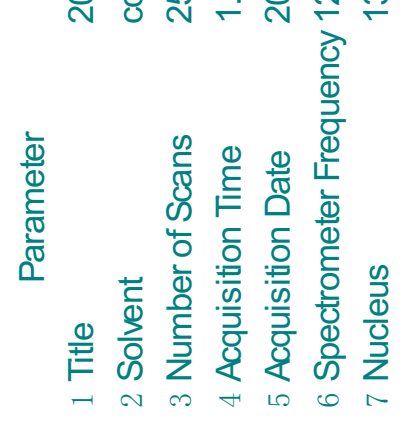


レ゚ยะー

ZL'SE 86. $9 \varepsilon^{-}$ $\angle \mathcal{C}^{\circ} 9 \mathcal{E}^{-}$ 99เレー $9297-$ $2 L \circ+9$ $\varepsilon 0.69-$ $89^{\circ} \nabla L-$ $06.9<>$ GLLLZガ0レレ

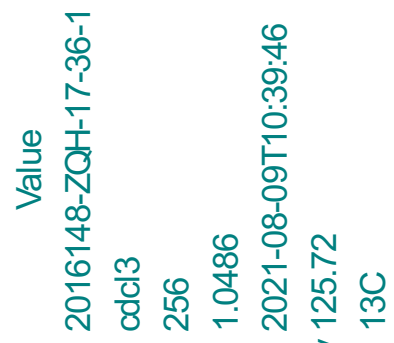<smiles>CC1(CCC2CCCCC2[O])OCCO1</smiles>

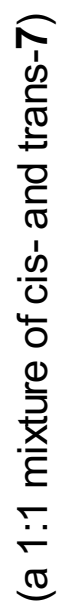

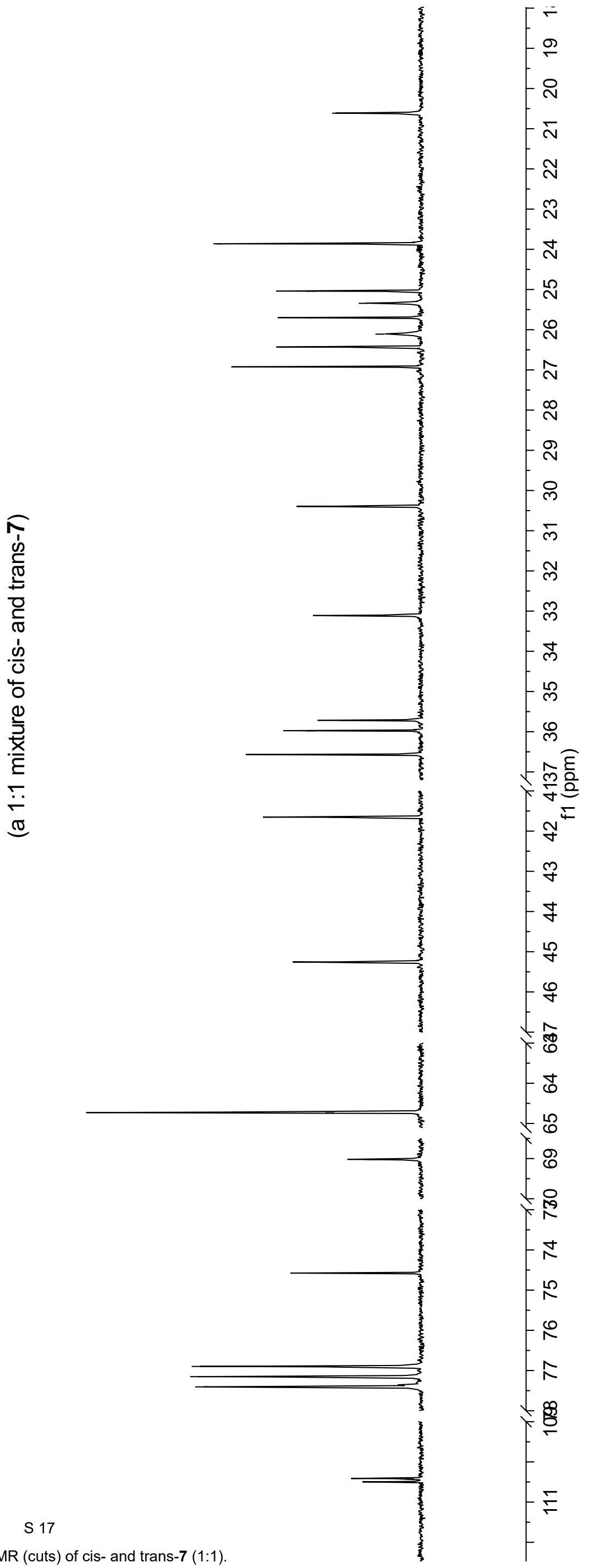




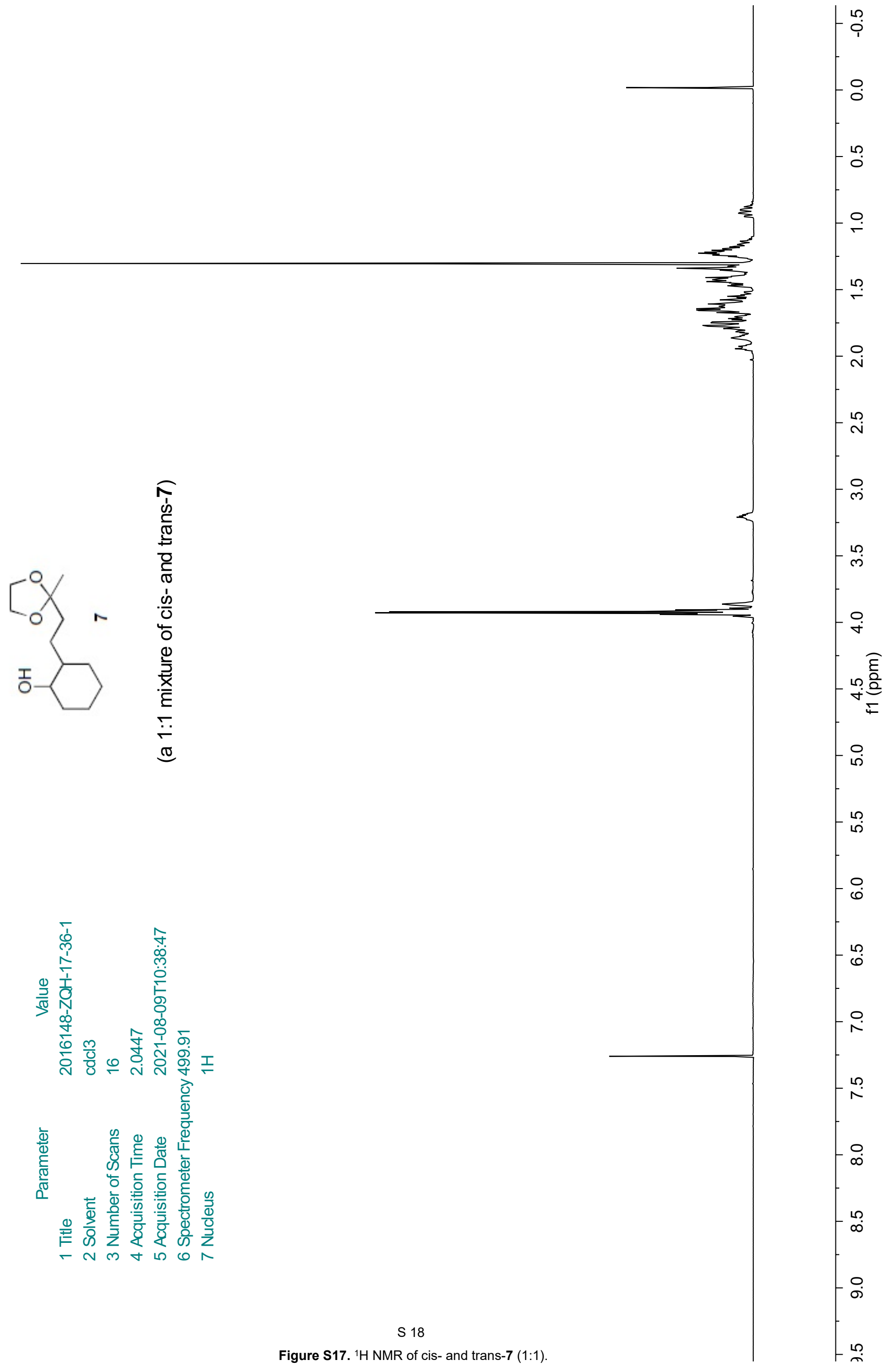


St06.0 -

S8Z6 $0^{\circ}-$

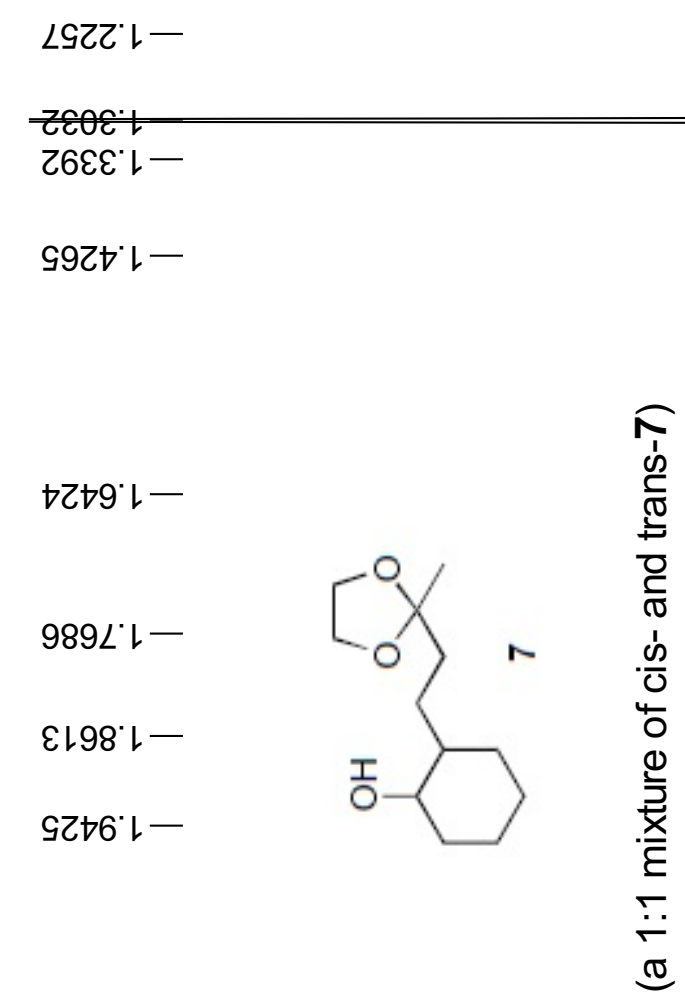

$\varepsilon\left\llcorner O Z^{\circ} \varepsilon>\right.$

$660 Z^{\prime} \varepsilon^{-}$

它

듬

$\dot{\omega}$

0

气

$\check{F}$

(2)

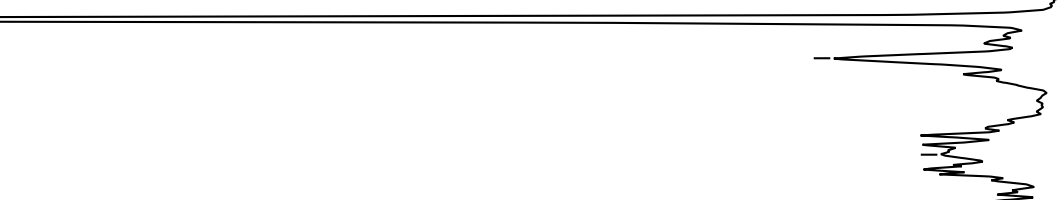




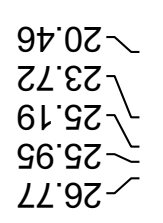

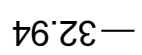

$0 \nabla^{\circ} 9 \varepsilon-$

6ฑ・レー

$69^{\circ}+9-$

L8'89-

$9 L 9 L$

$10 \angle L \frac{L}{5}$

$\angle Z \angle L$
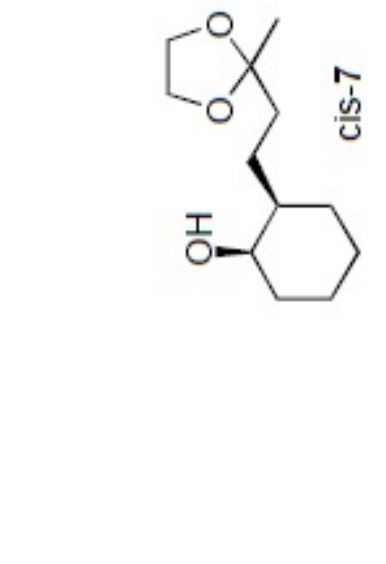

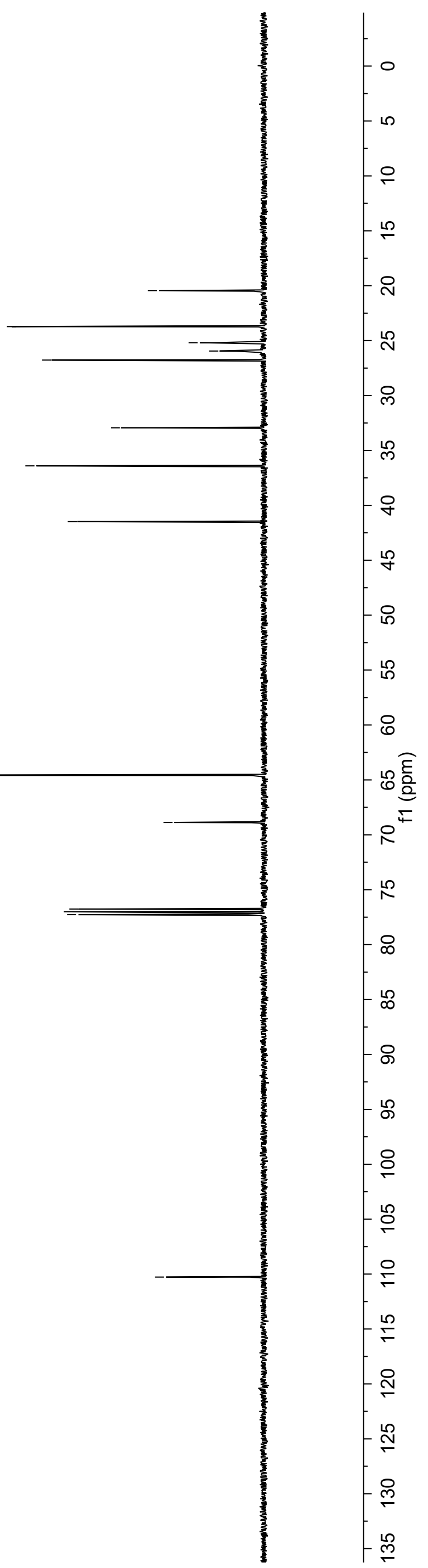

Figure S19. ${ }^{13} \mathrm{C}$ NMR of cis-7. 
ZL'EZ-

6L'Gน 96.9ZLL'9Z

${ }^{\circ} \succsim \varepsilon-$ $0{ }^{\circ} 9 \varepsilon-$ 6カ・レー $69^{\circ}+9-$ L8'89-

$9<9<>$ $10.2 L=$
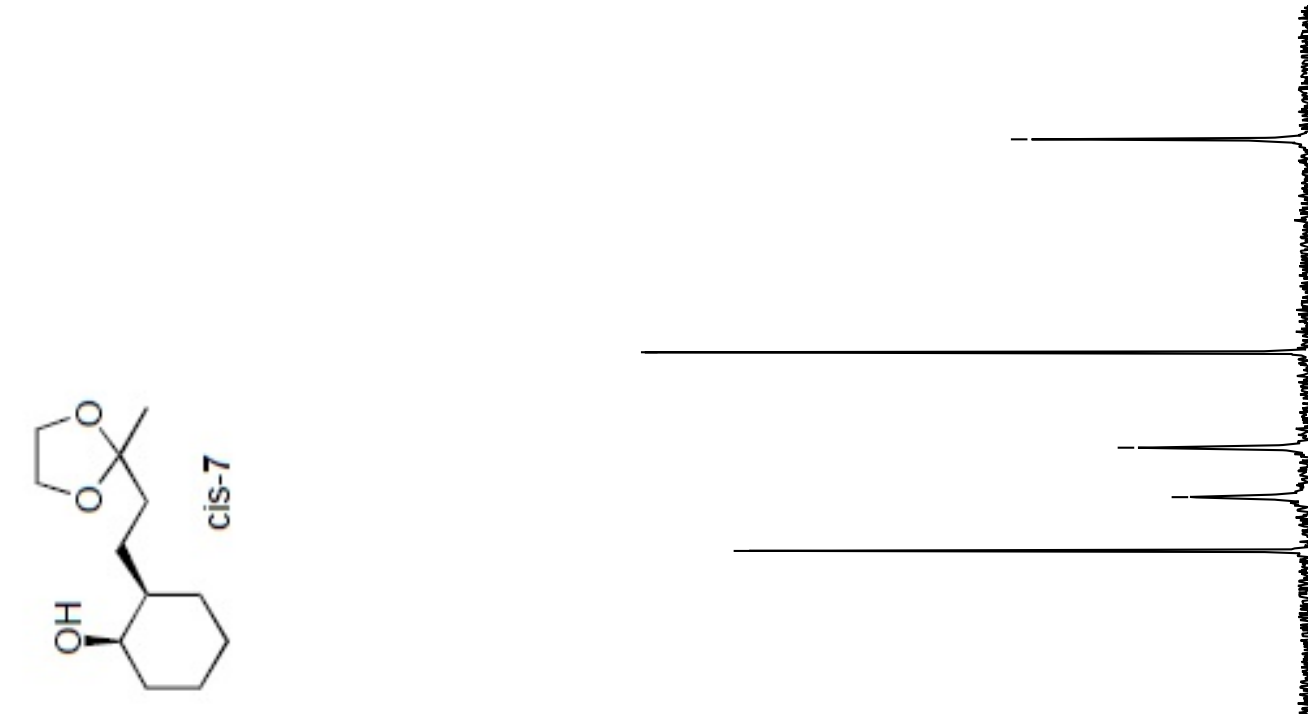

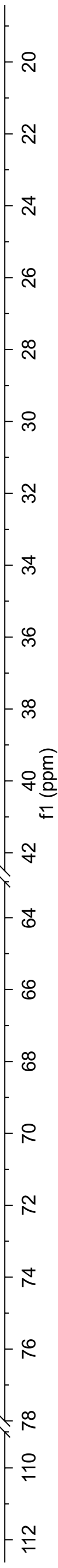




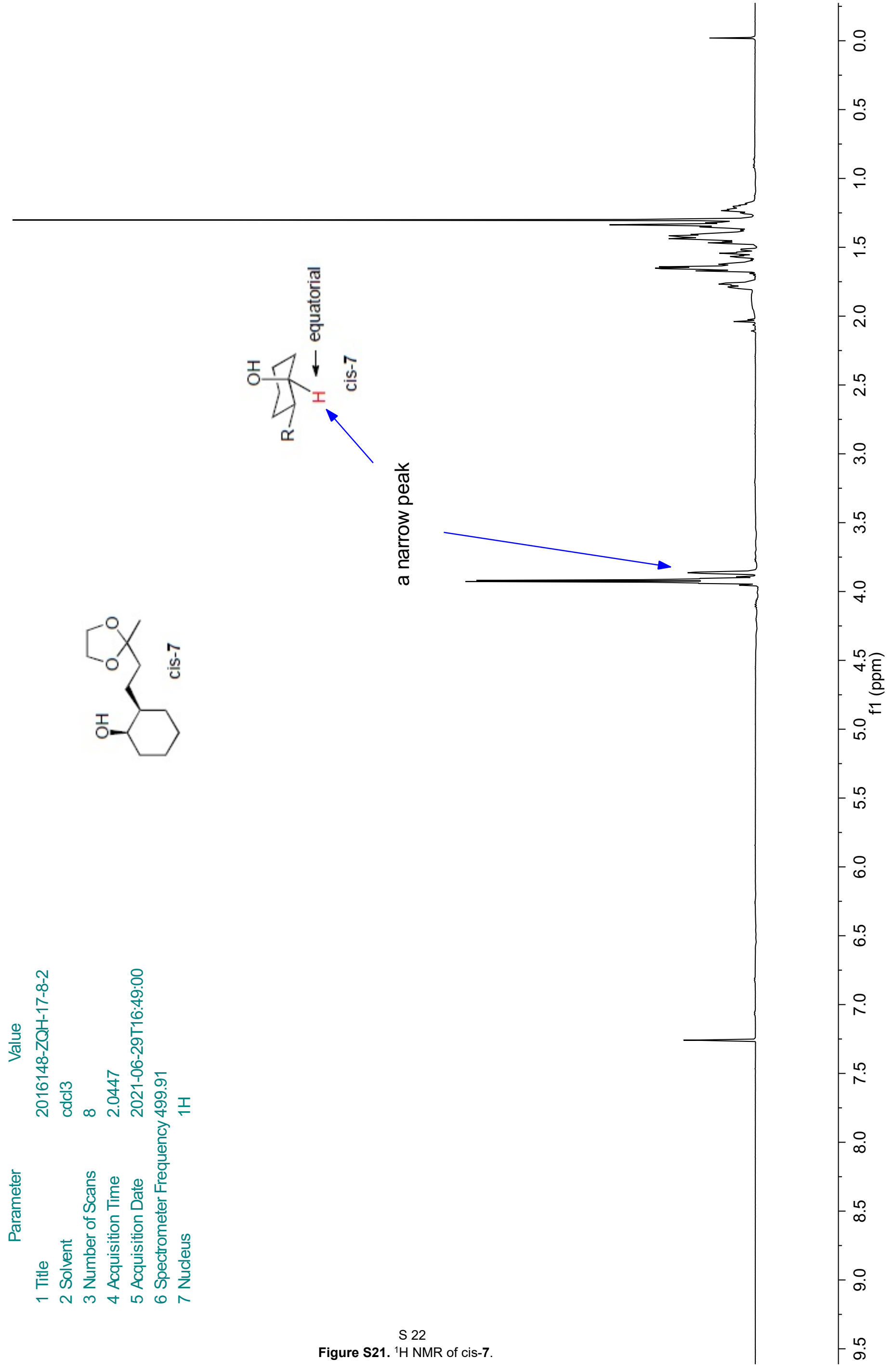




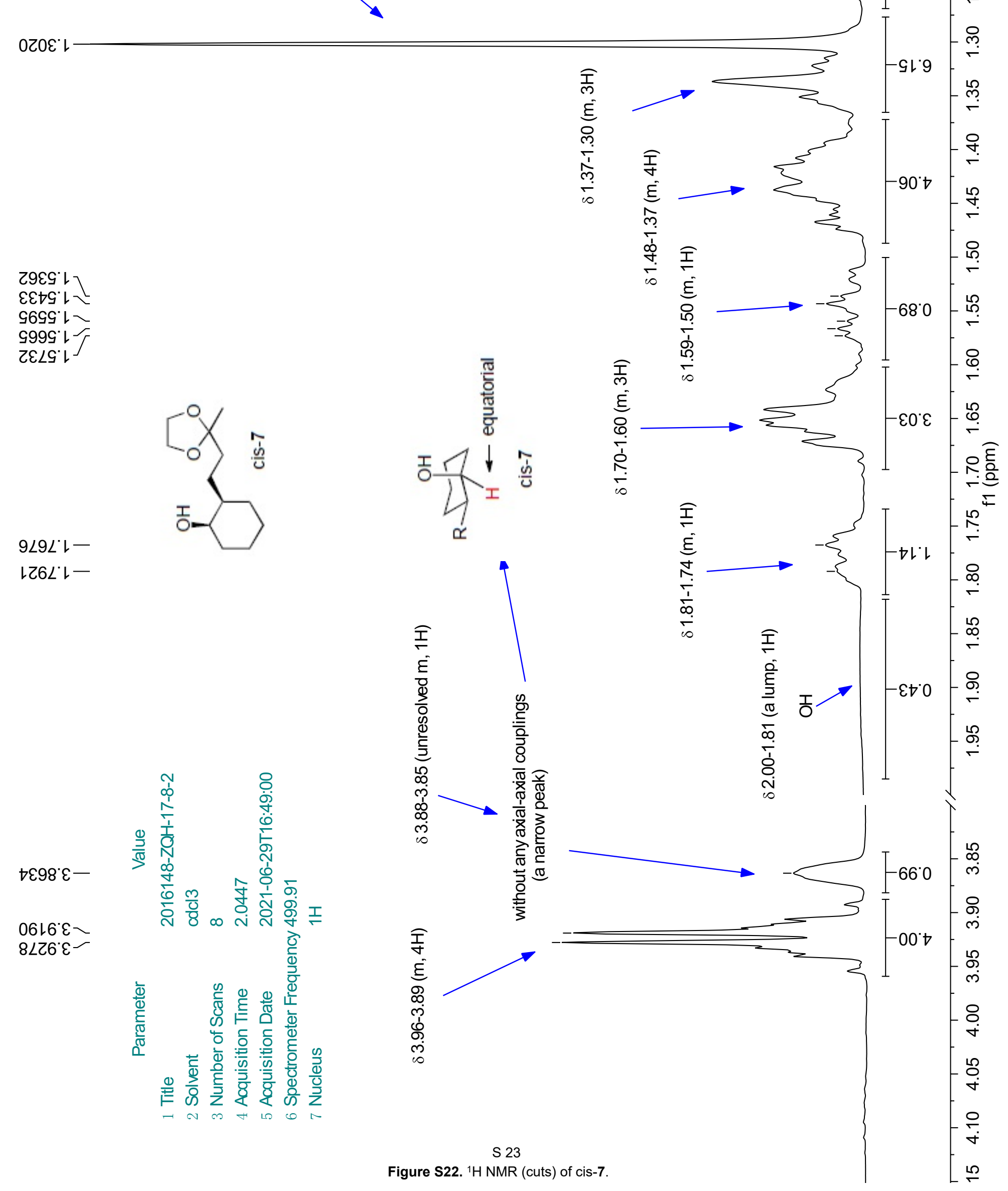




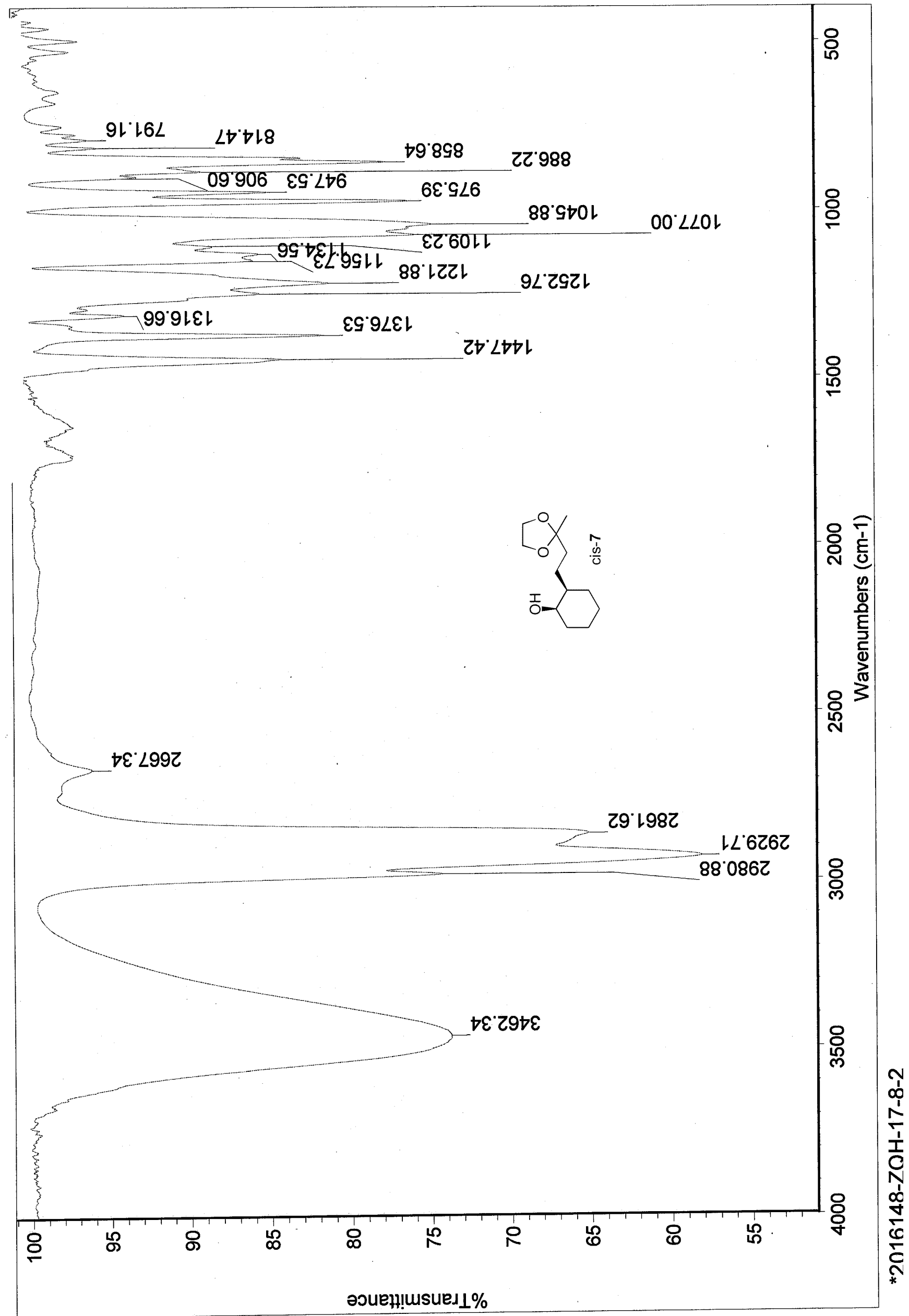

S 24

Figure S23. IR of cis-7. 
National Center for Organic Mass Spectrometry in Shanghai Shanghai Institute of Organic Chemistry

Chinese Academic of Sciences

High Resolution FI-MS Report

Low Resolution FI-MS Report

Instrument: JEOL-AccuTOF-GCv4G-GCT MS

Operation Mode:

FI Positive Ion Mode

(Counter Electrode: 10000V)

Card Serial Number: GCT-FI-T21-08-2212

Sample Serial Number: 2016148-ZQH-17-8-2

Operator:

$\mathrm{Li}$

Date:

$2021 / 08 / 17$

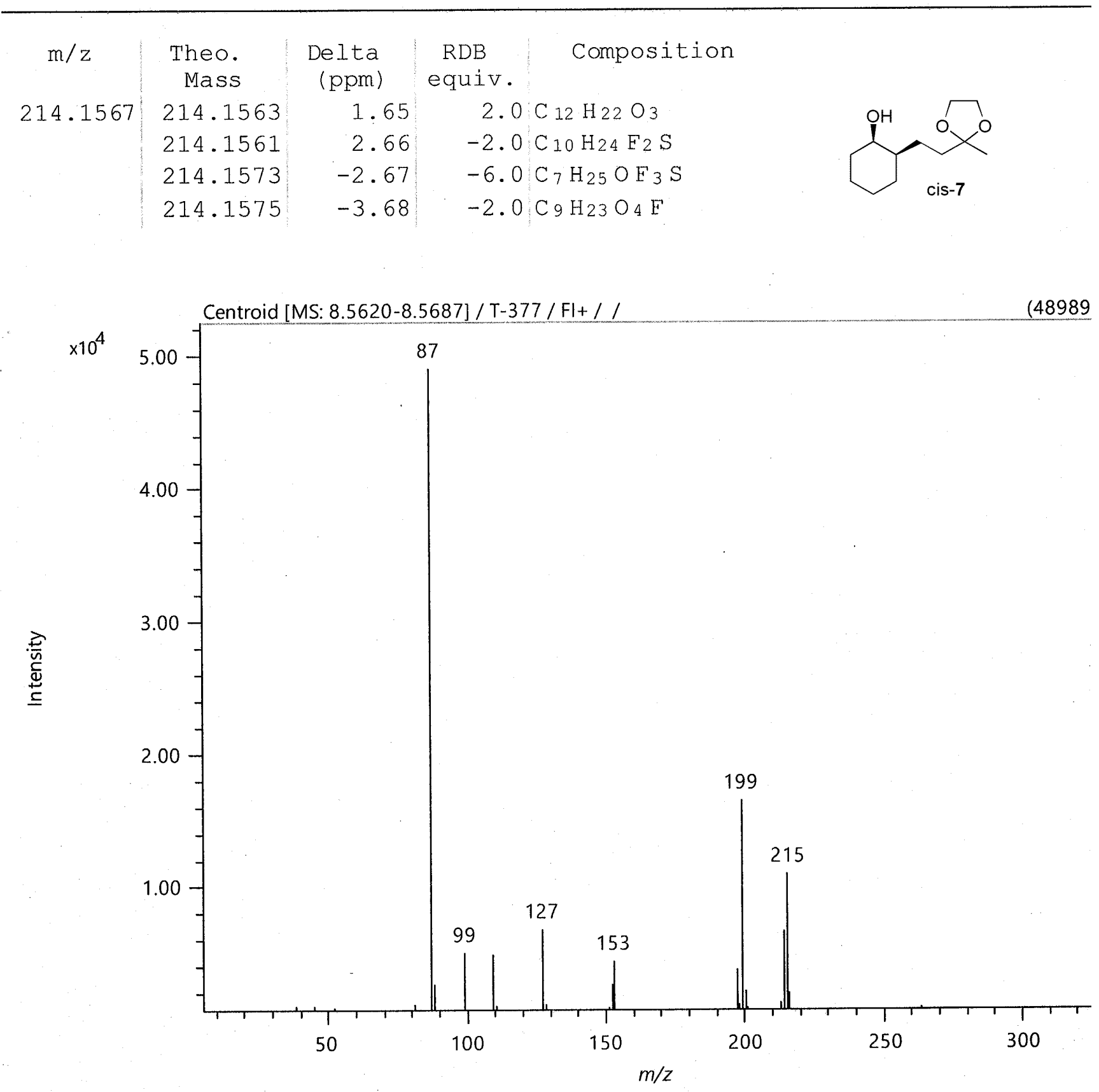


乙L८乙

$066^{\circ} \nabla 乙-$

GG'G乙

G乙'0

99. $9 \varepsilon$

18. $9 \varepsilon^{\gamma}$

ル・Sャー

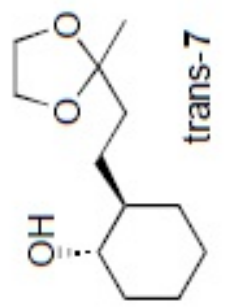

$89^{\circ}+9$

$6 G^{\circ}+9$

$8 \nabla^{\circ} \nabla L$

$\nabla L \cdot 9 L \backslash$

$00 \angle L \frac{1}{T}$

$G{ }^{\prime} L L$

98ㅇㄴ-

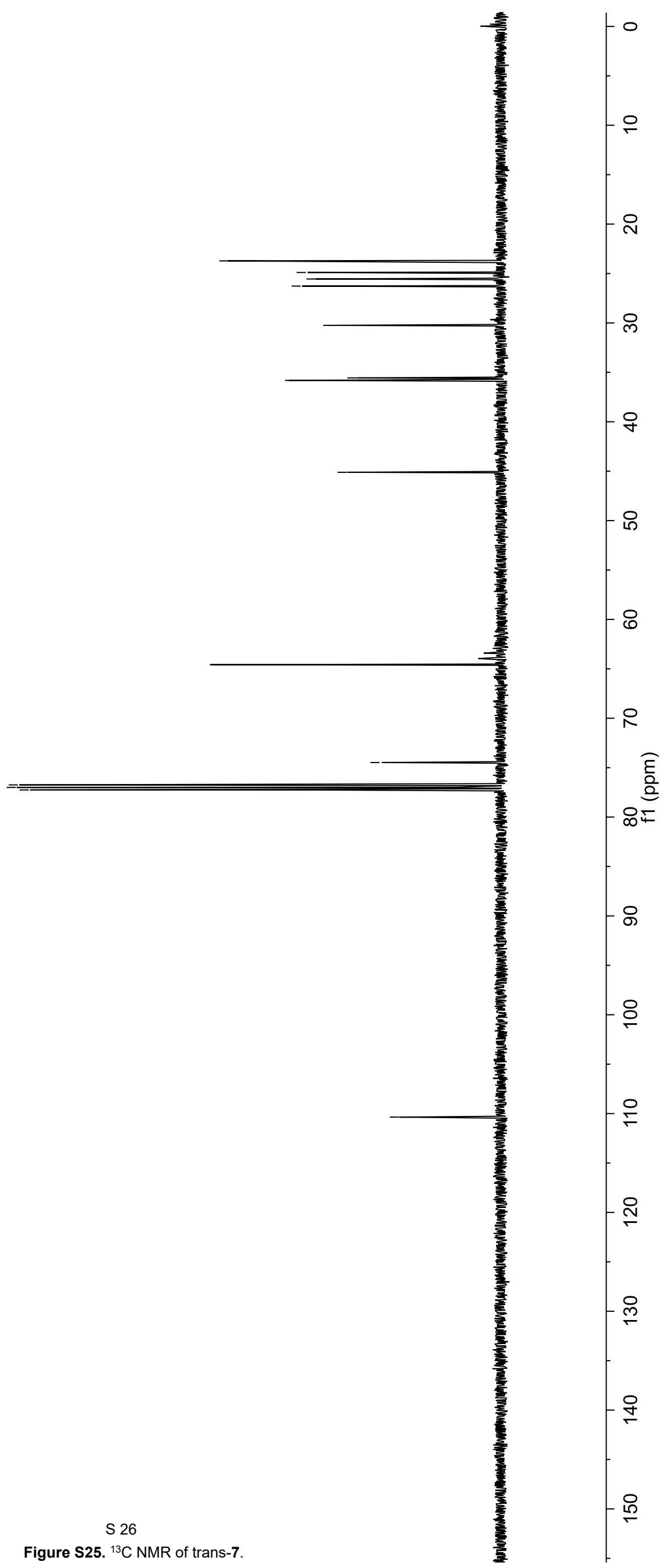

S 26

${ }^{3} \mathrm{C}$ NMR of trans-7. 
$06^{\circ} \circ \tau^{-}$

SG'GZ-

LZ'9Z乙

५Z $0 \varepsilon-$

99' $9 \mathcal{2} \sim$

18. $9 \varepsilon^{-}$
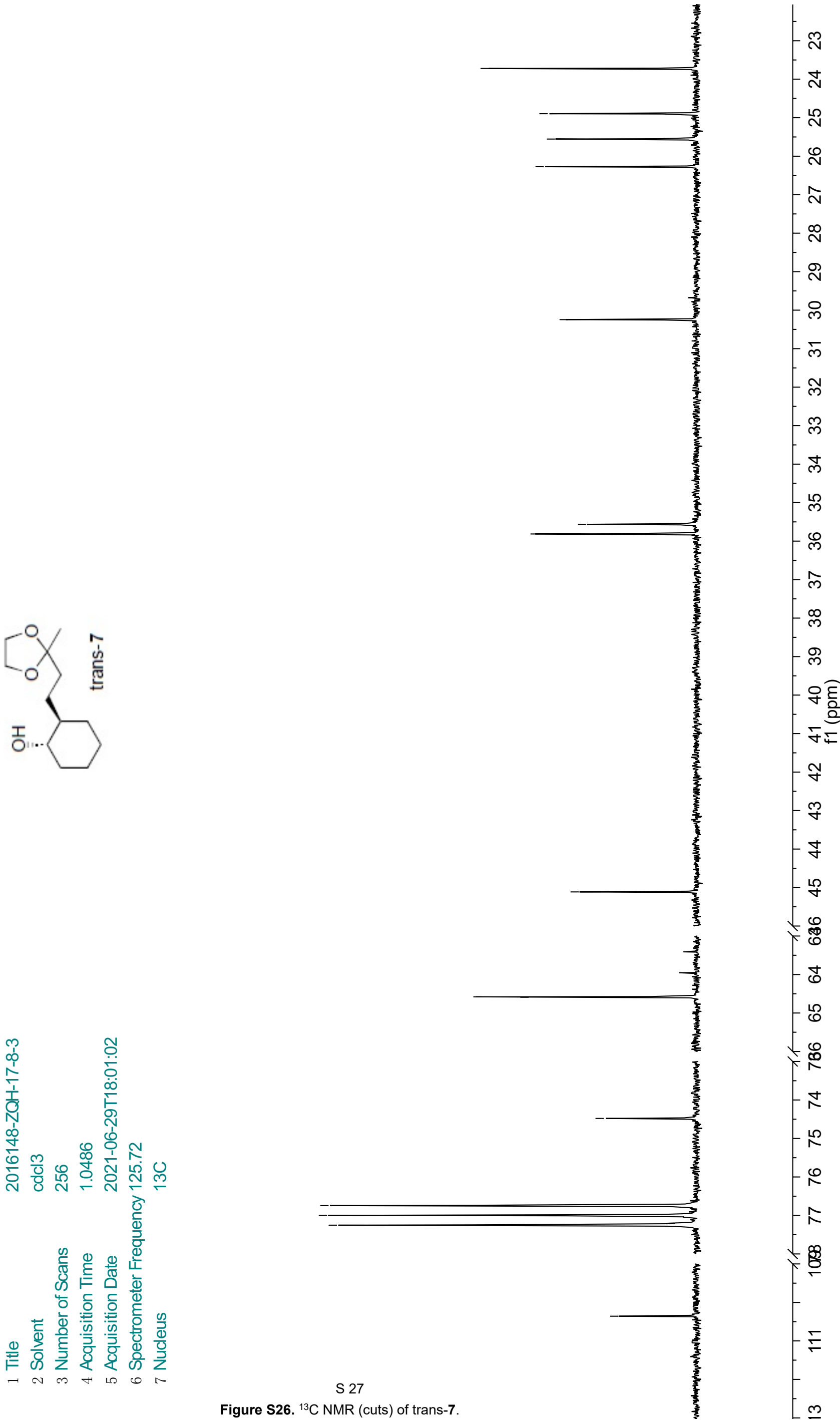

Figure S26. ${ }^{13} \mathrm{C}$ NMR (cuts) of trans-7.

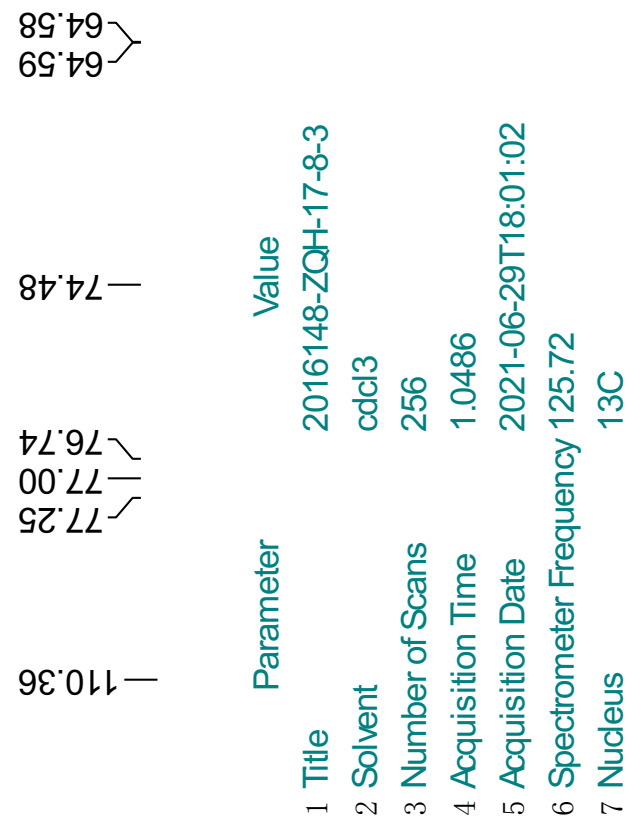




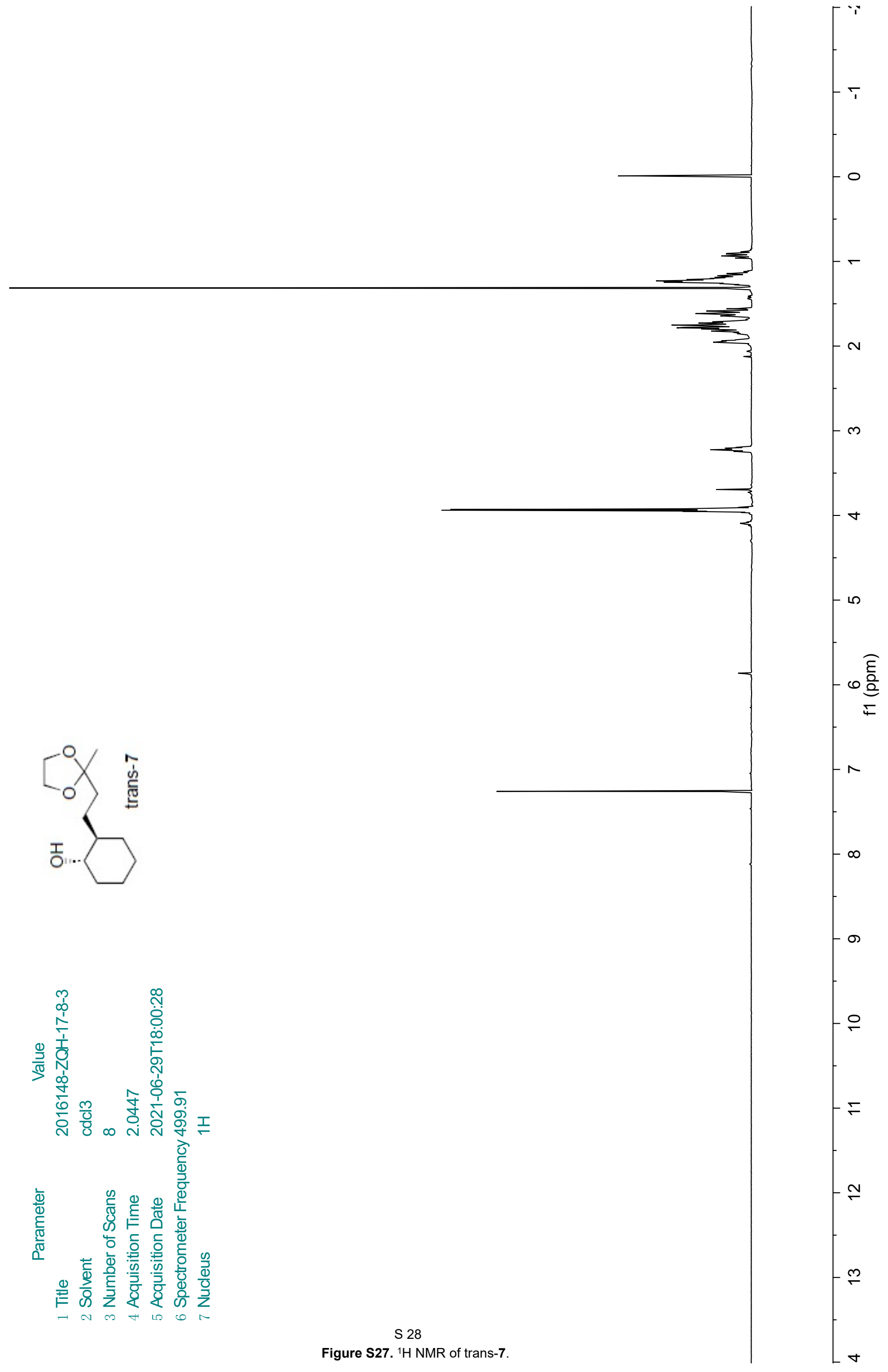


8L'ZST

งt๋ $๋ 97$

$\nabla S^{\circ} \angle 9 b-$

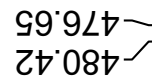

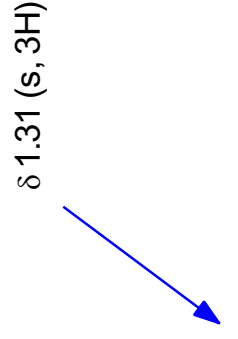

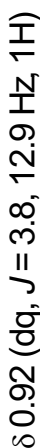

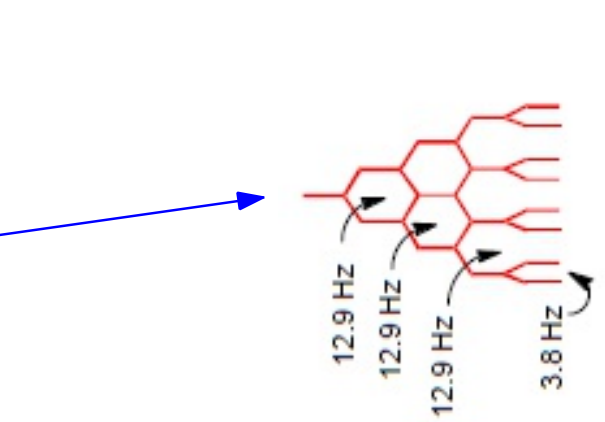

$-\infty$
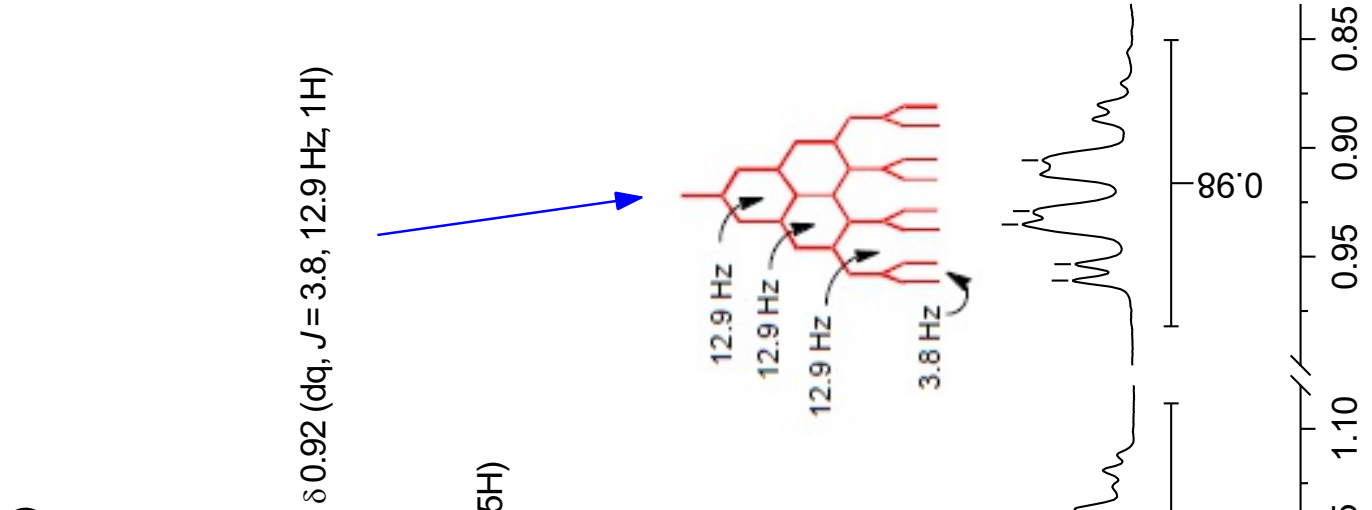

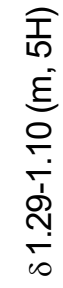

19. 2691$]$ $90.2091-$ 0tเレ9L Z6.0291 5

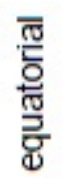

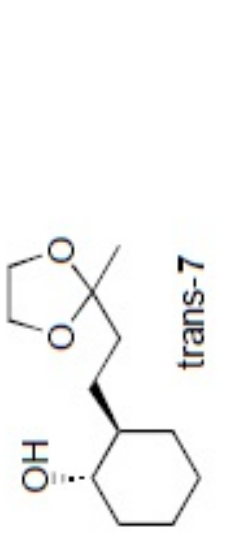

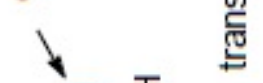

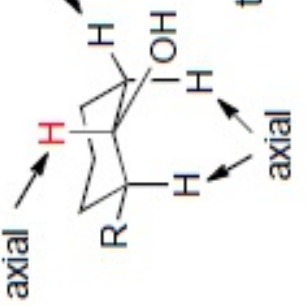

㐫

蛋

这

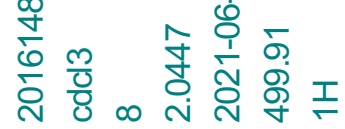

$\frac{\sqrt{0}}{\frac{\bar{d}}{0}}$

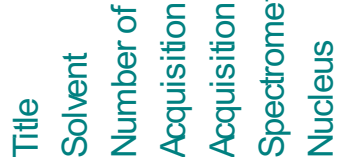
- $N$ \% 10 N
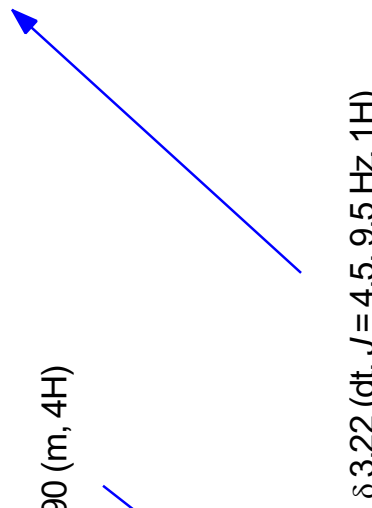

$\widehat{I}$
10
हे
8
0
$\dot{0}$
$\infty$
$\dot{0}$
$\overline{1}$

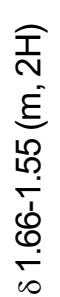

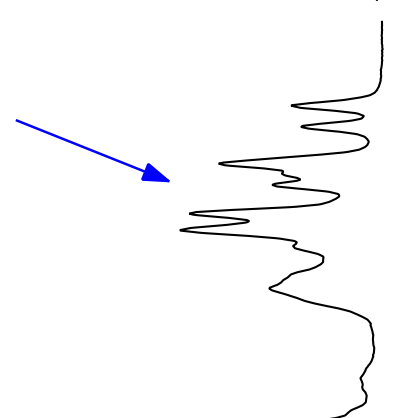

$-80^{\circ} 2$
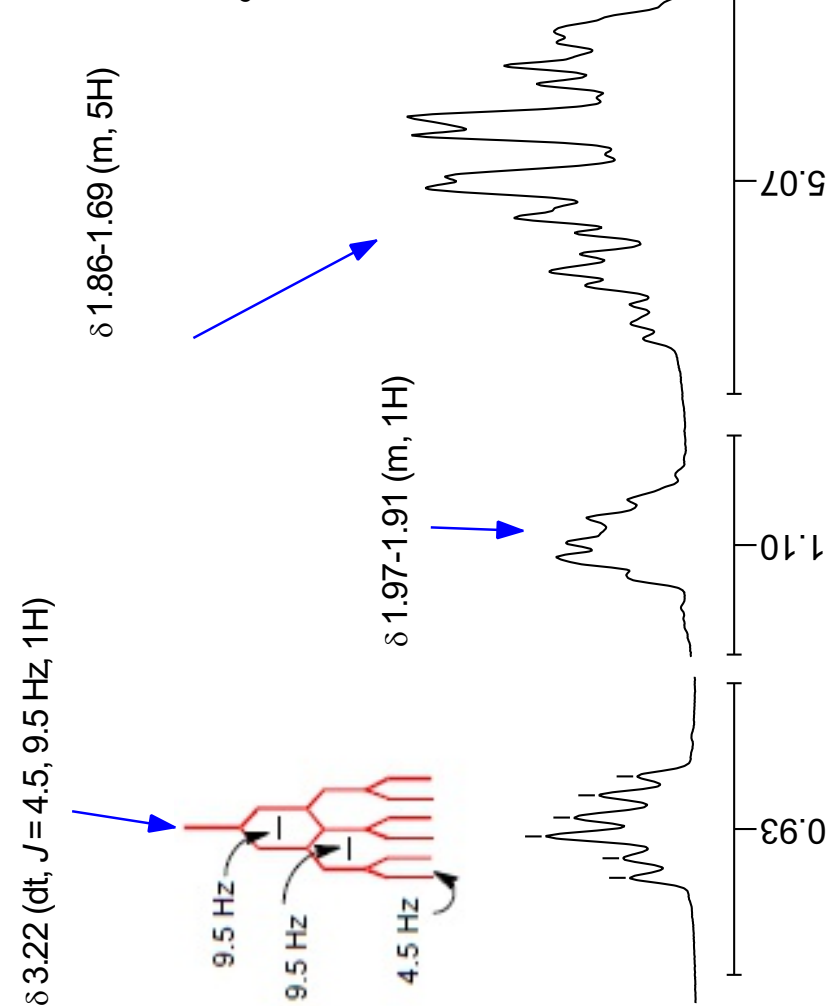

กิ

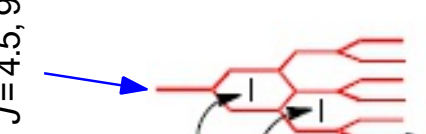

ثี

$\underset{\substack{\text { N } \\ \infty}}{\infty}$

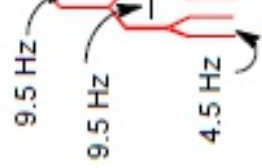

00

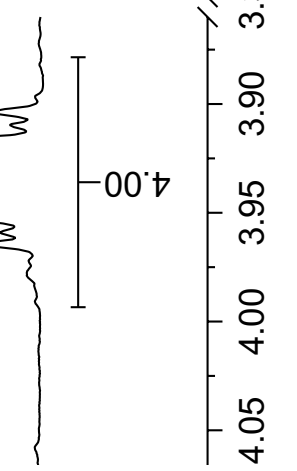

Figure S28. ${ }^{1} \mathrm{H}$ NMR (cuts) of trans-7. 


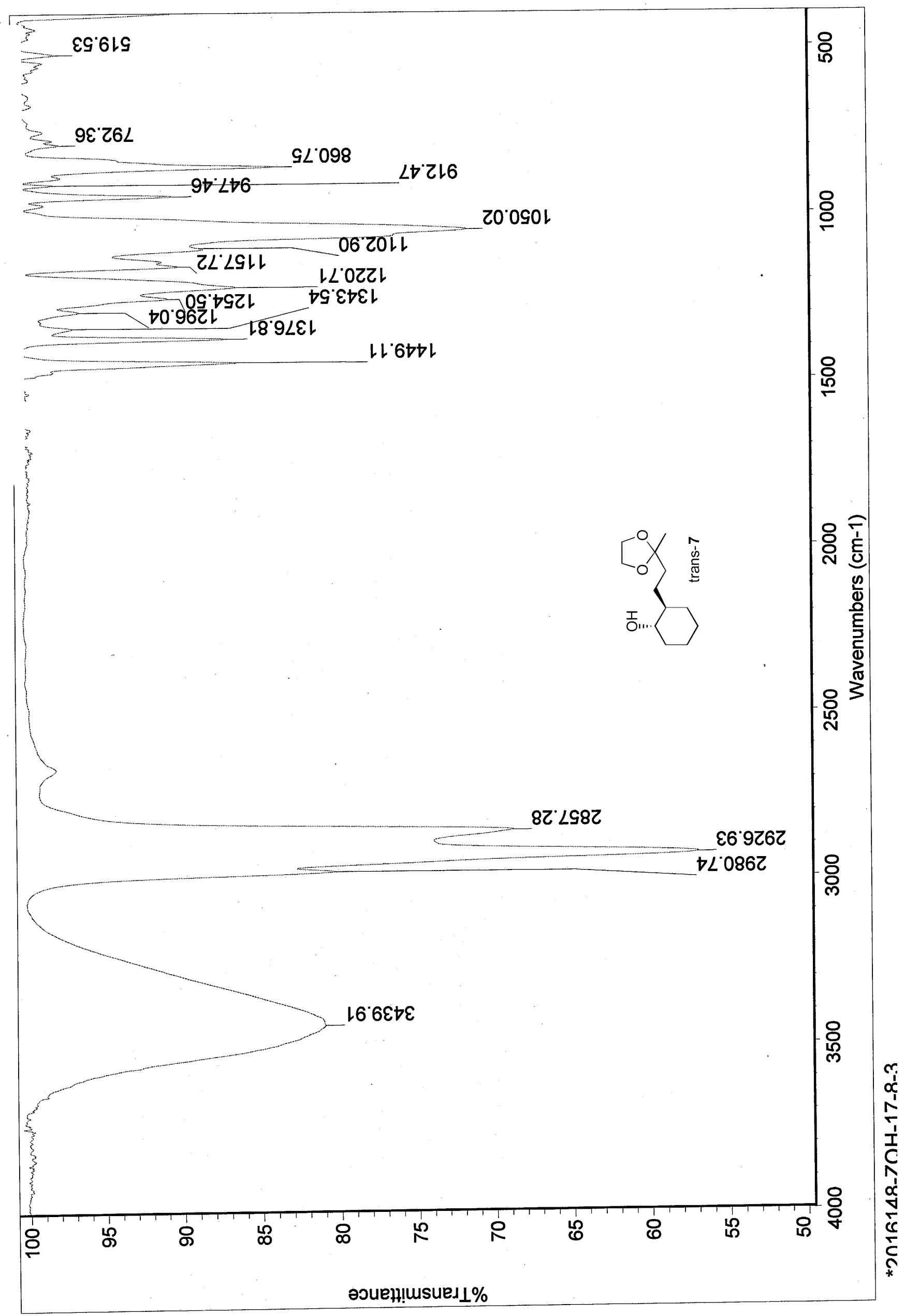

S 30

Figure S29. IR of trans-7. 
National Center for Organic Mass Spectrometry in Shanghai

Shanghai Institute of Organic Chemistry

Chinese Academic of Sciences

High Resolution FI-MS Report

Low Resolution FI-MS Report

Instrument:

JEOL-AccuTOF-GCv4G-GCT MS

Operation Mode:

FI Positive Ion Mode

(Counter Electrode: 10000V)

Card Serial Number: GCT-FI-T21-08-2213

Sample Serial Number: 2016148-ZQH-17-8-3

Operator:

Li

Date:

$2021 / 08 / 17$

\begin{tabular}{c|c|c|c|c|}
\hline $\mathrm{m} / \mathrm{z}$ & Theo. & Delta & RDB & Composition \\
& Mass & $(\mathrm{ppm})$ & equiv. & \\
214.1562 & 214.1561 & 0.33 & $-2.0 \mathrm{C}_{10} \mathrm{H}_{24} \mathrm{~F}_{2} \mathrm{~S}$ \\
& 214.1563 & -0.68 & $2.0 \mathrm{C}_{12} \mathrm{H}_{22} \mathrm{O}_{3}$ \\
& & &
\end{tabular}

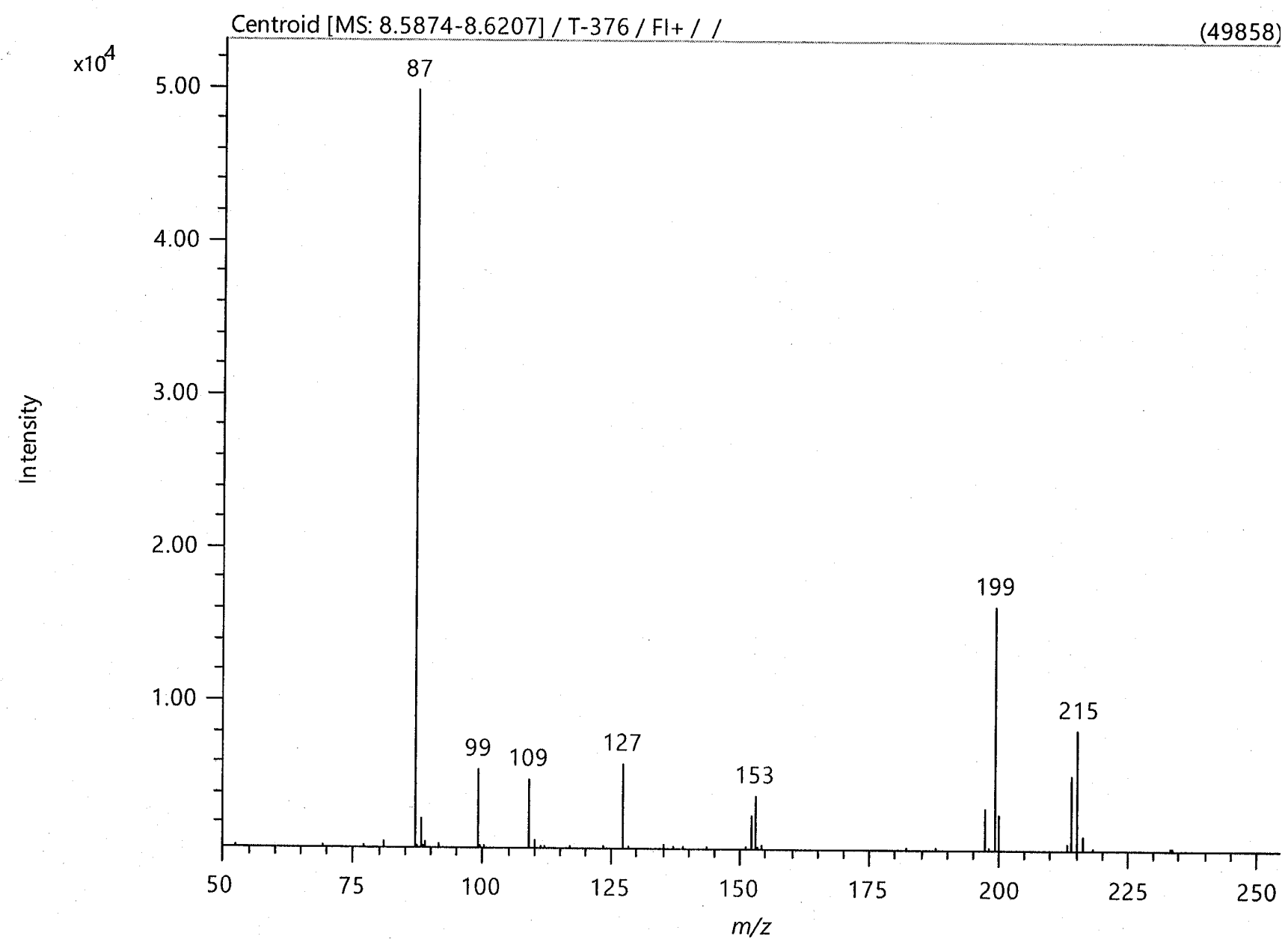




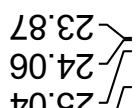

$$
\begin{aligned}
& \rightarrow 0.92] \\
& 61.82 \\
& \angle L^{\circ} \nabla \varepsilon \\
& 09^{\circ} 9 \varepsilon^{-} \\
& \text {GI'Z๐' } \\
& \text { 28.09- } \\
& \forall L^{\circ} \nabla 9- \\
& \begin{array}{l}
06^{\circ} 9 L \\
9 L \angle L J \\
07^{\circ} \angle L
\end{array}
\end{aligned}
$$

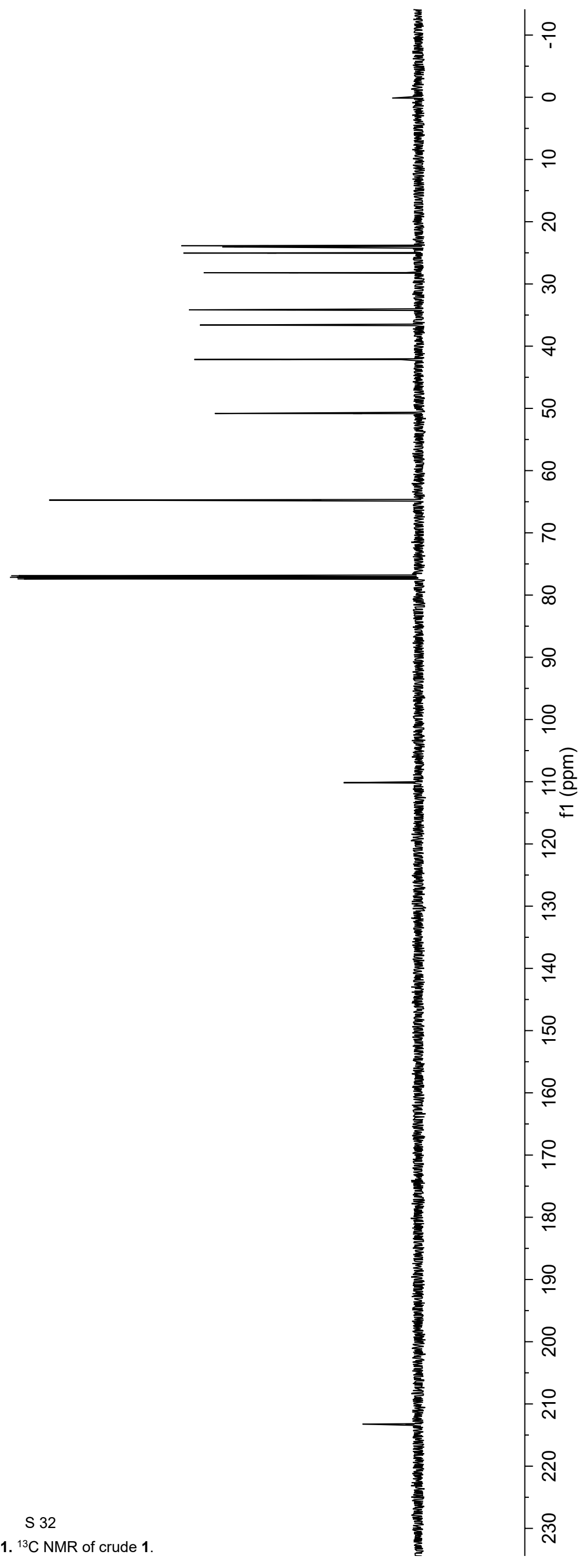




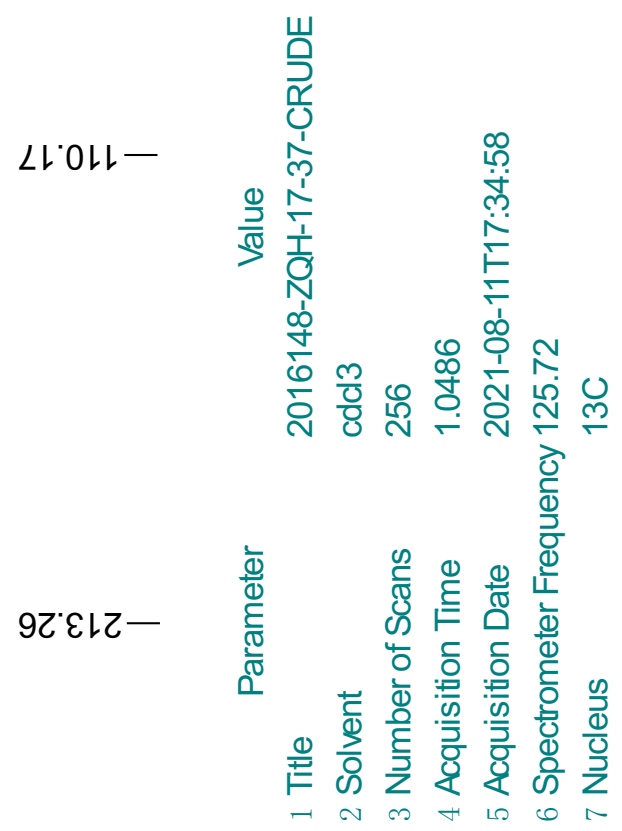




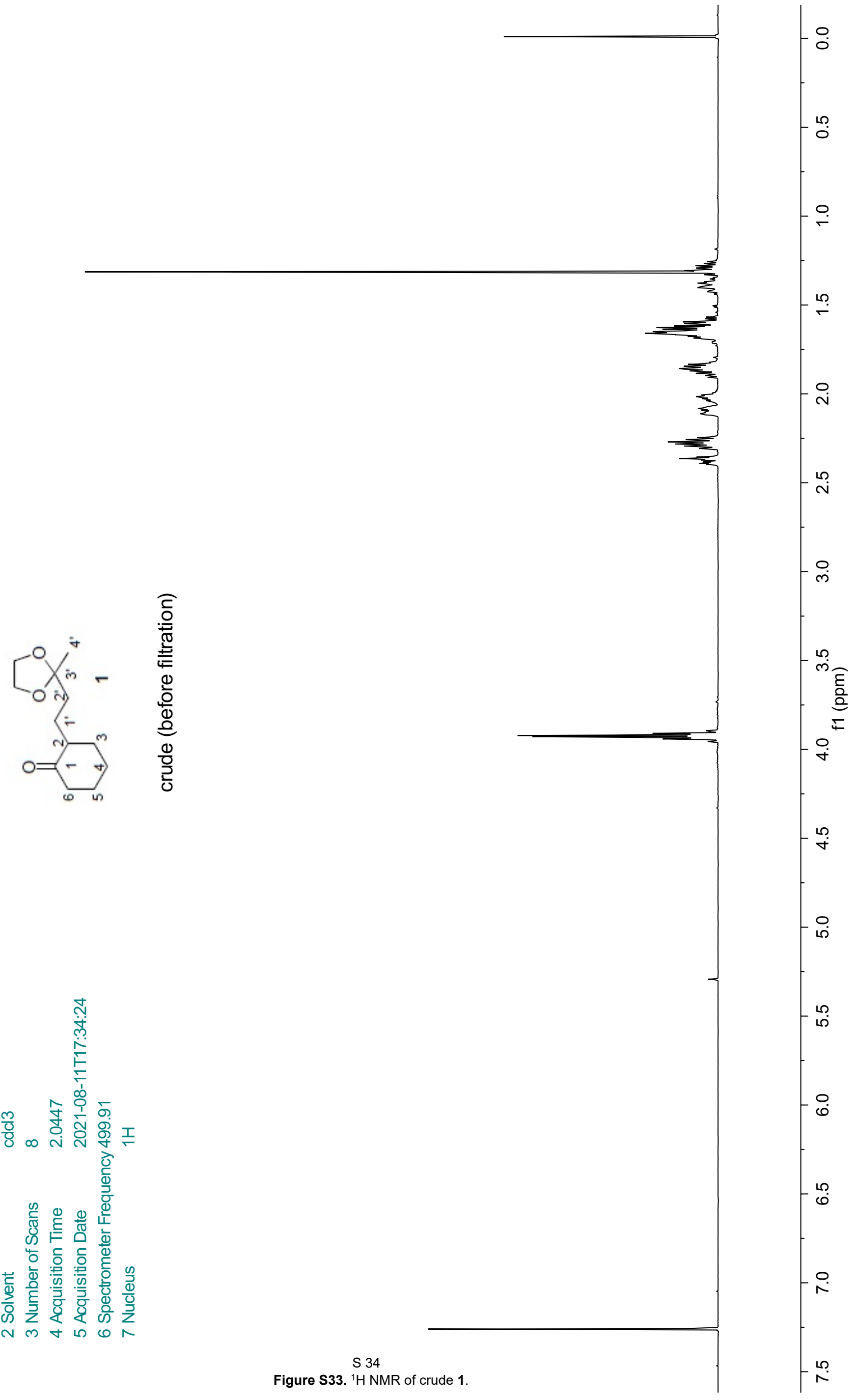




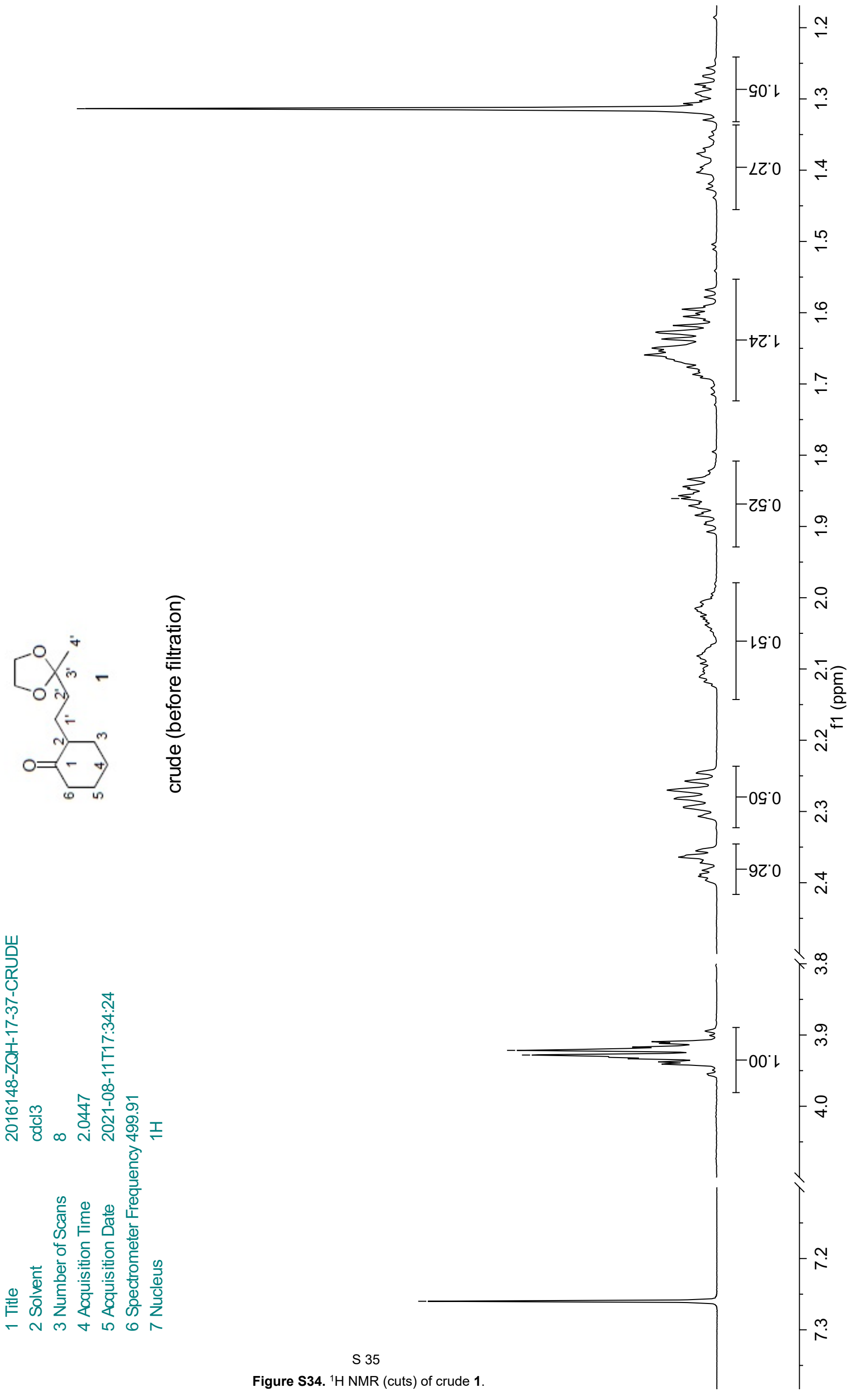



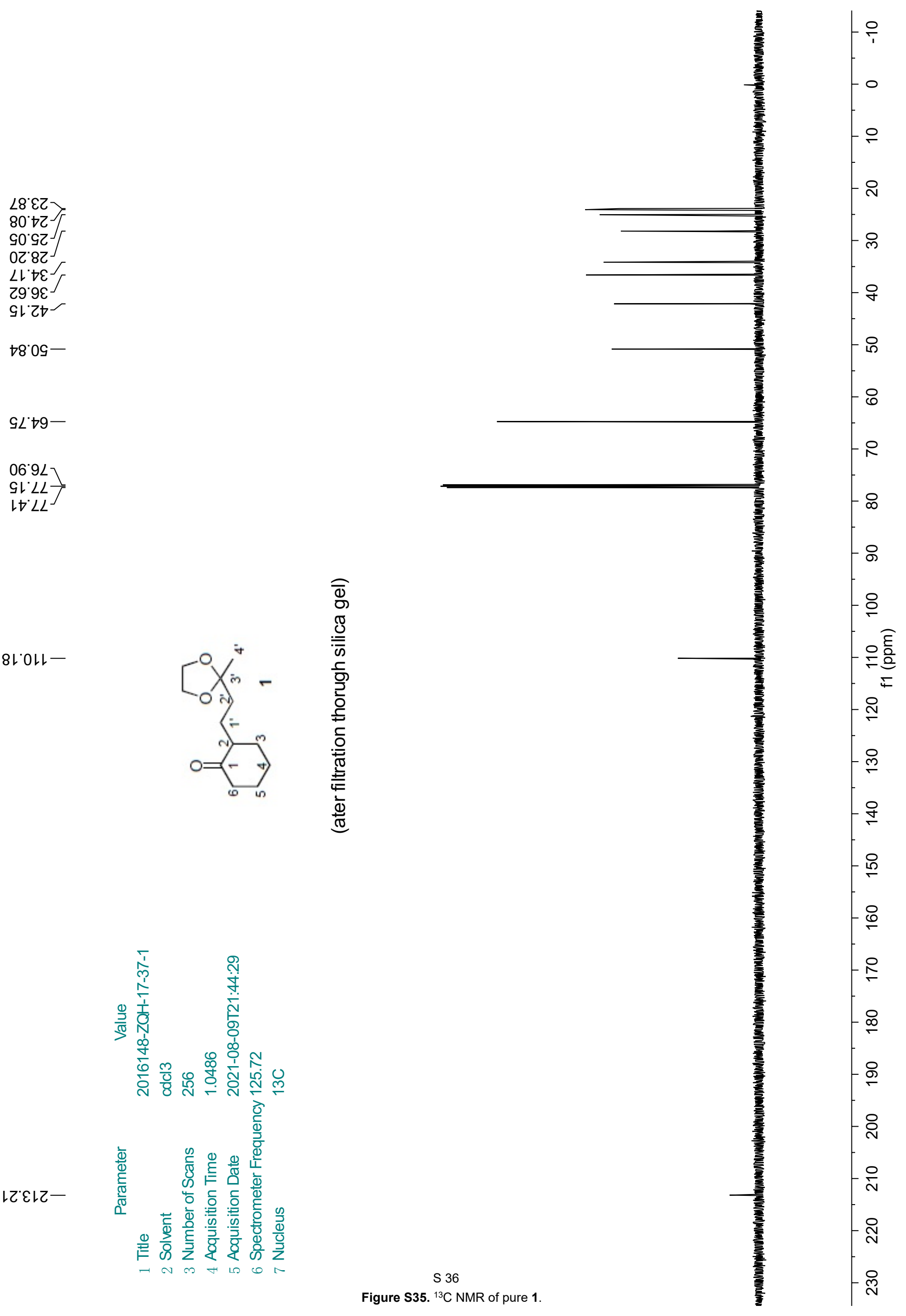


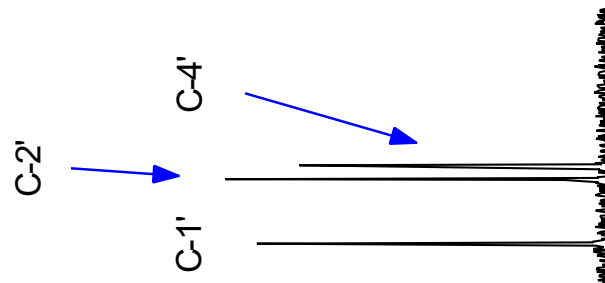

$02 \cdot 8 Z-$

$\angle L \nabla \varepsilon-$

$29^{\circ} 9 \varepsilon-$

GLて๖ー

$7809-$

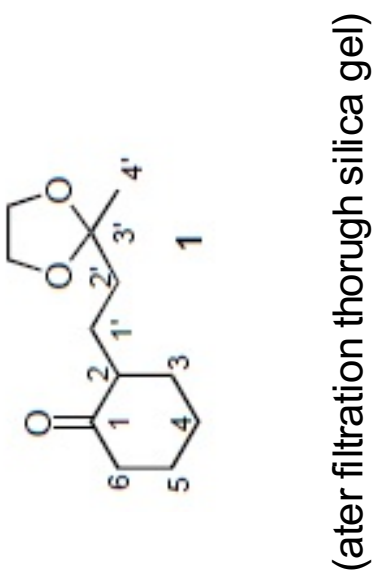

SL't9-

06.92 ר

$G L L L$
LV $L L$

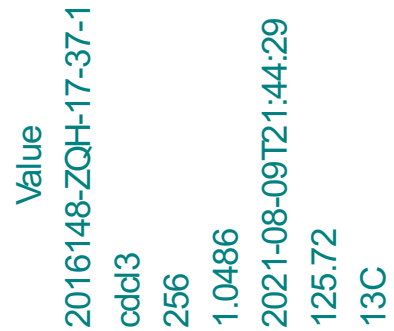

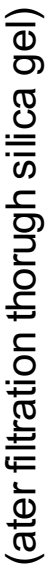

$-\approx$

N

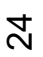

$\stackrel{\sim}{\sim}$

$-\stackrel{0}{ }$

ล

ปุ

$\stackrel{\infty}{N}$

군

요

ले

๙

m

0

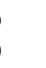

ल

-

J

요

우

チ

ư

ำ

-

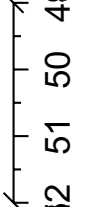

ชั

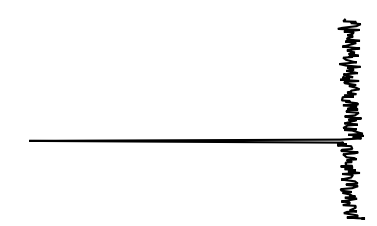

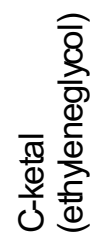

-

ष

-

$+\infty$

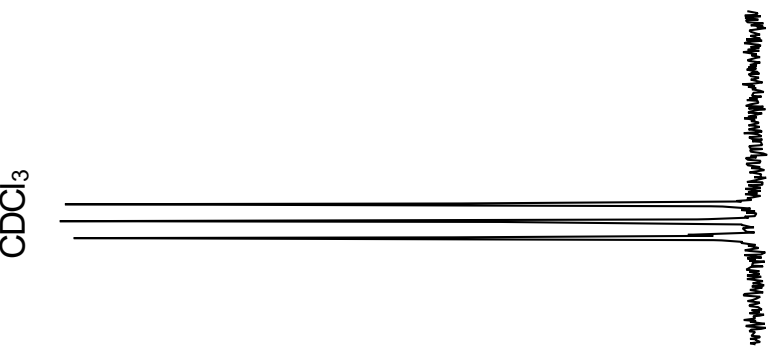

8เㄴㄴ

レてยเ乙-
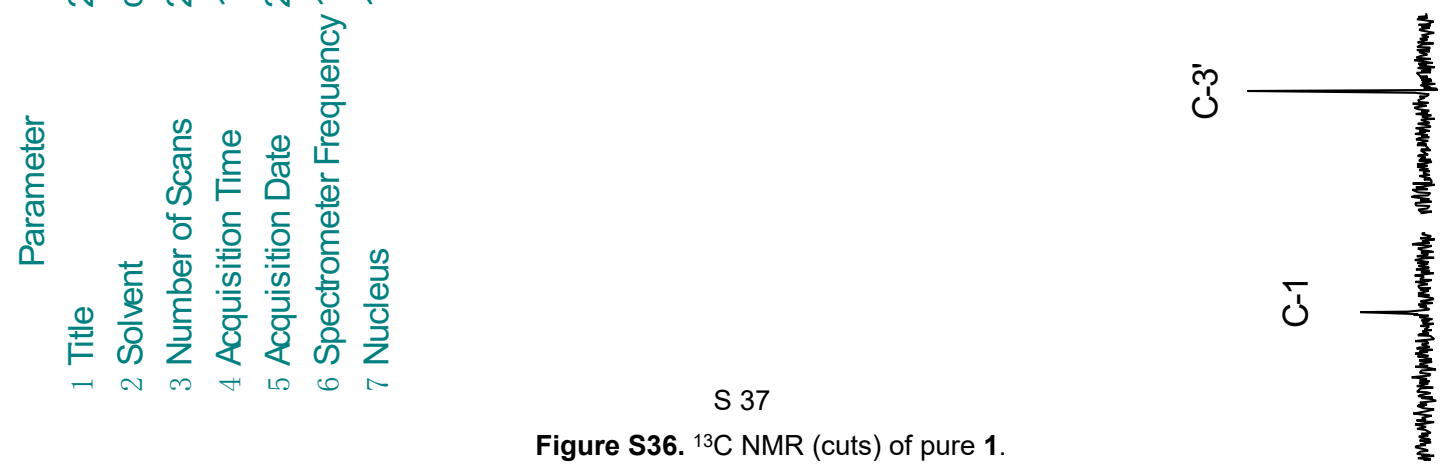

Figure S36. ${ }^{13} \mathrm{C}$ NMR (cuts) of pure 1. 
ปे

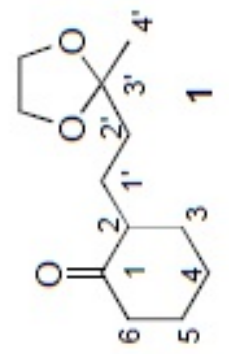

$19^{\circ} 9 \varepsilon-$

8เ๋ย-

9レてちー

\&8.09-

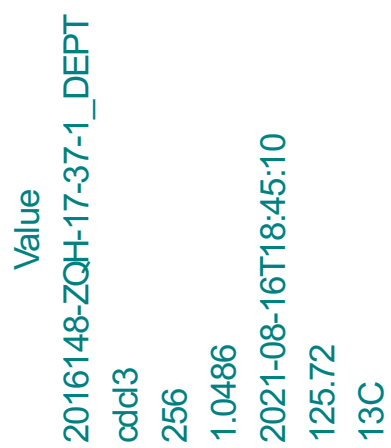

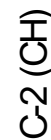

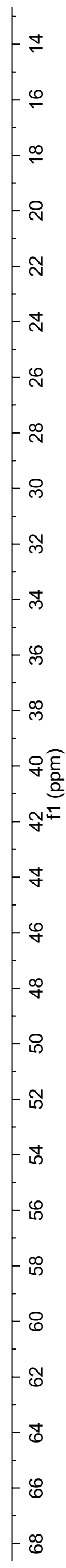




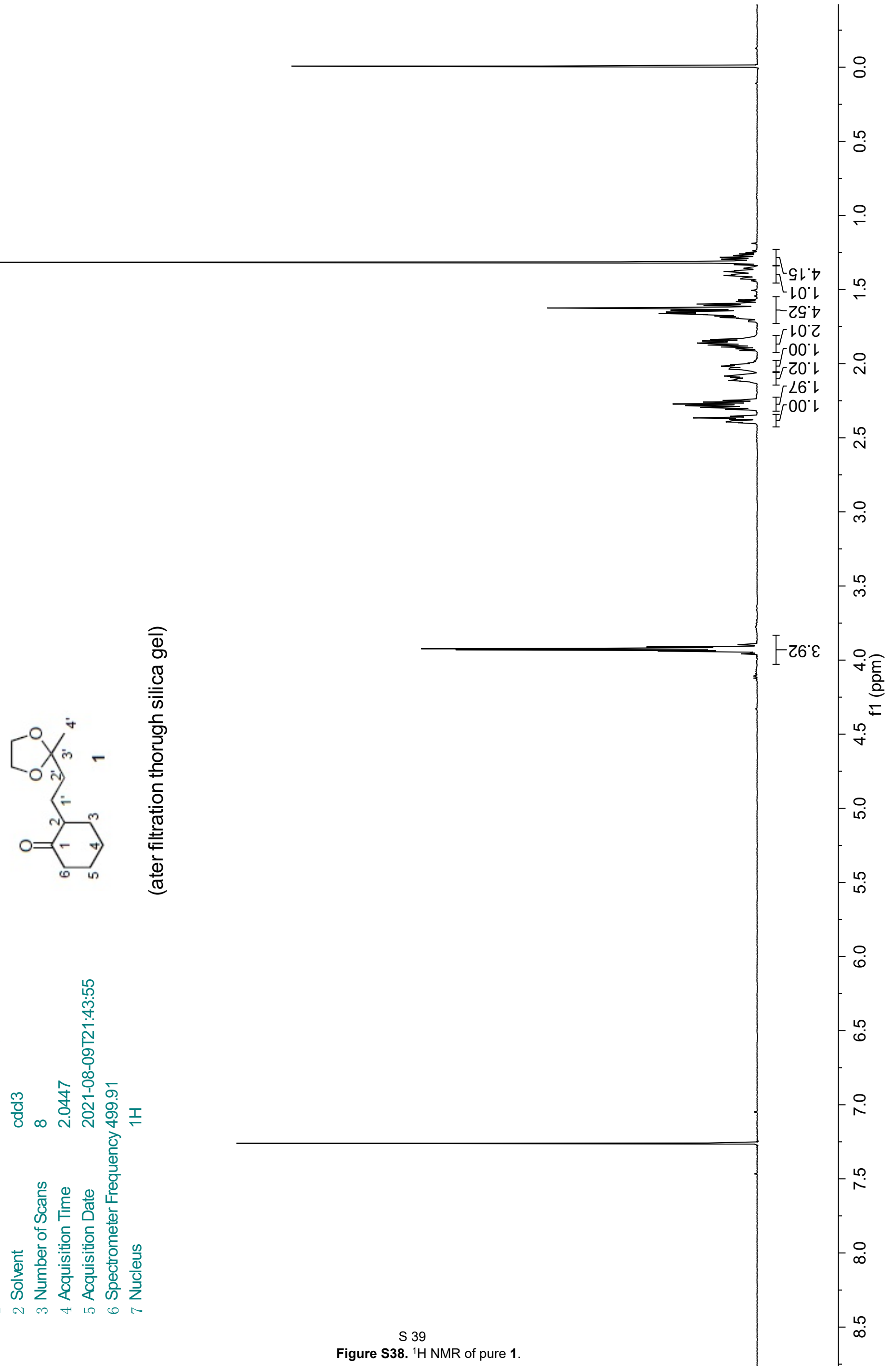




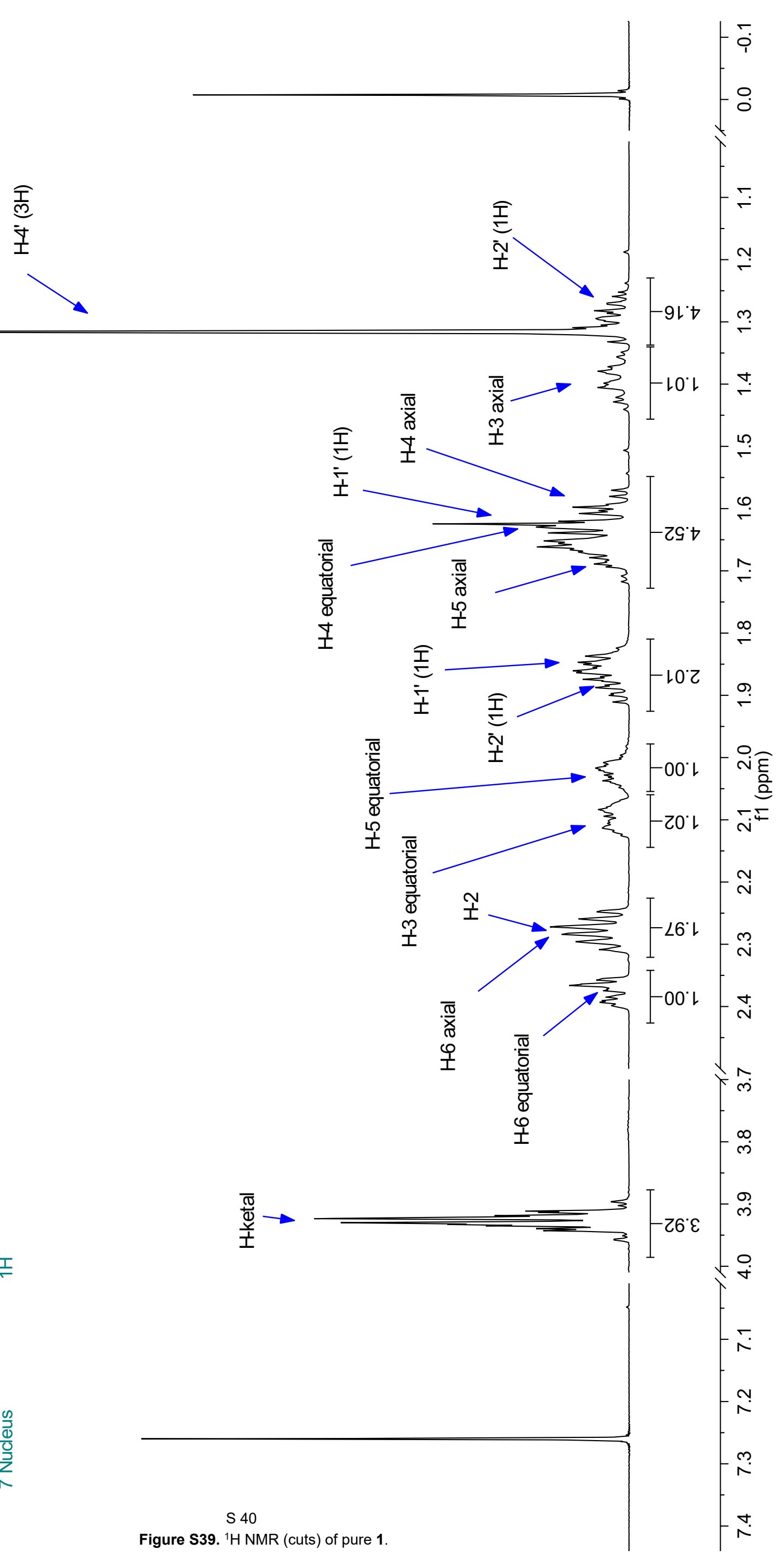


E966' ᄂ

$\angle 000^{\circ} \mathrm{Z}$

$0 \angle 00^{\circ} Z$

$\angle 10^{\circ} Z$

$\angle 910^{\circ} Z$

$\checkmark 0 Z 0^{\circ} Z$

LEZ0 Z -

1820 2

$\angle L E O 0^{\circ}-$

9980 25

$08+0{ }^{\circ} 乙$

$\angle 890^{\circ} Z$ -

99L0 Z

96L0'Z-

8280 '

$2 \angle 80^{\circ} \mathrm{J}$

$+7602^{\circ}$

$\angle 6600^{\circ}$

9901' $\mathrm{Z}^{-}$

0เLL乙

88L'Z-

ESZL'Z

6レจ乙てー

ย69Z'Z—

レてててー

0๖8Zてー

८S6ZZー

980๕乙— $\angle 6 \varepsilon 0^{\circ} \mathrm{T}$

$\angle \curlyvee \nabla 0^{\circ} 乙$

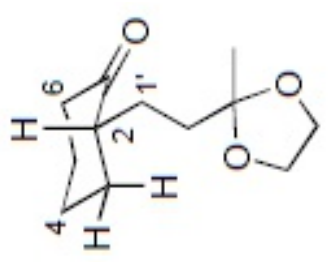

变

응

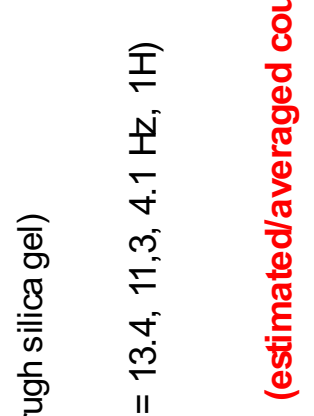

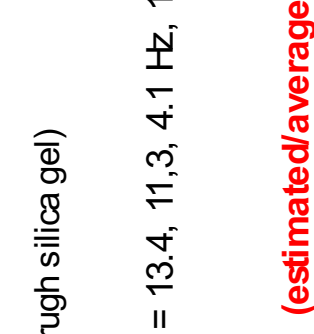

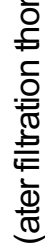

궁
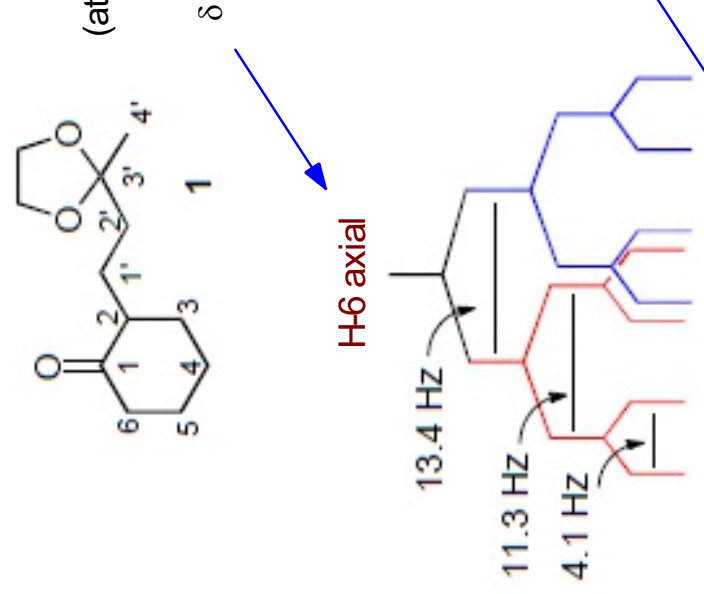

$\pi$

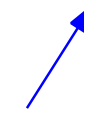

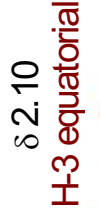
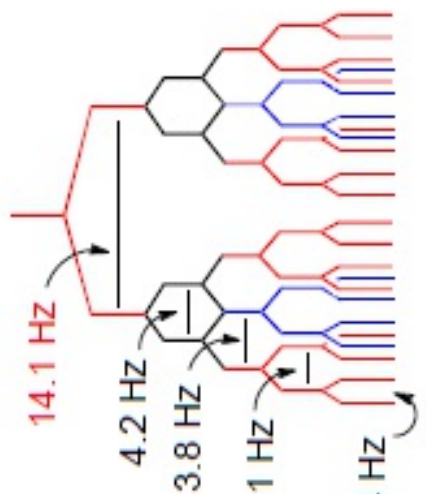

N. N

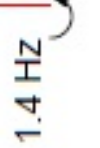

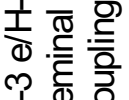

오행잉
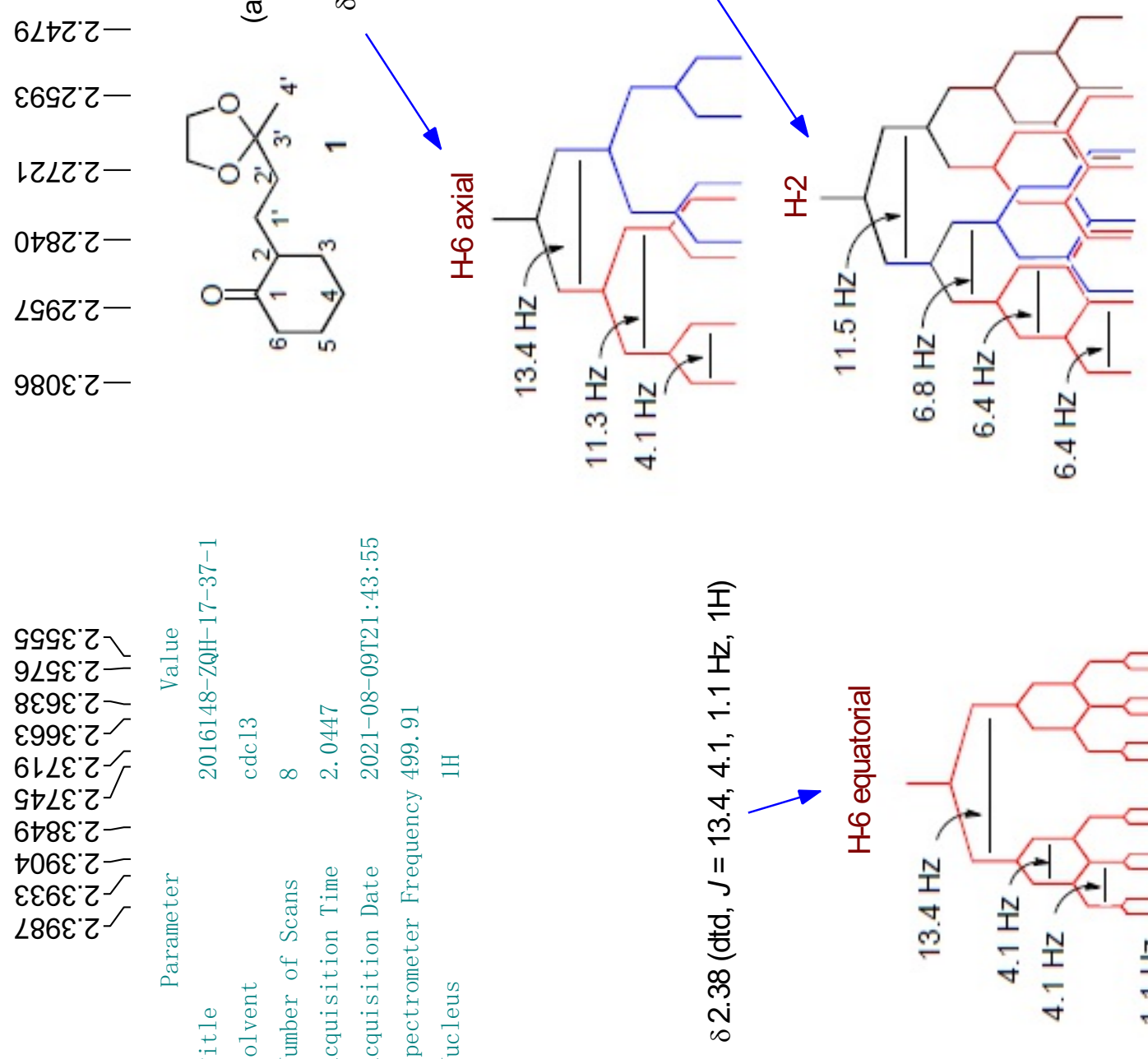

S 41

Figure S40. ${ }^{1} \mathrm{H}$ NMR (expansion 1) of pure 1. 


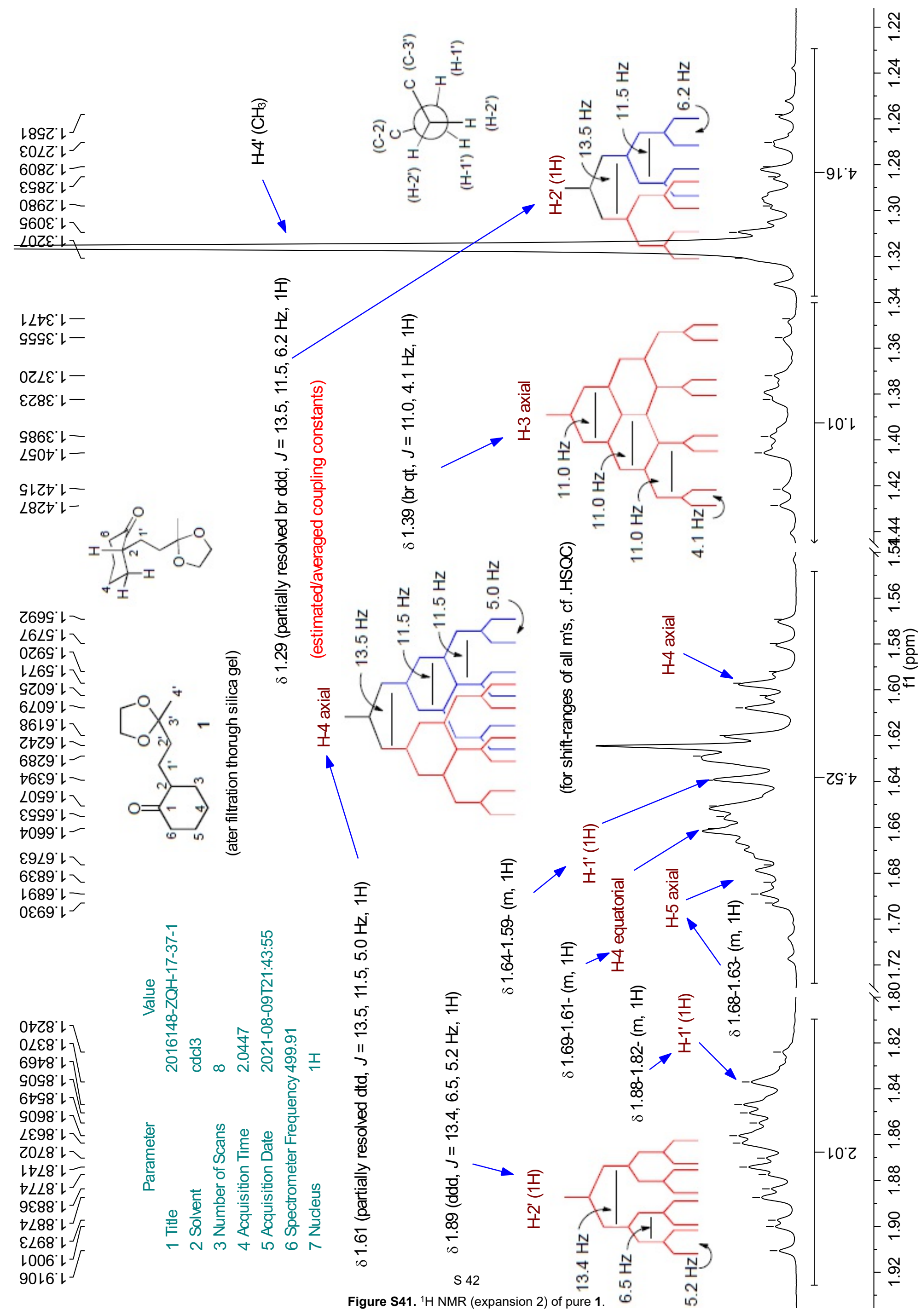


(mdd) $\mathrm{H}$
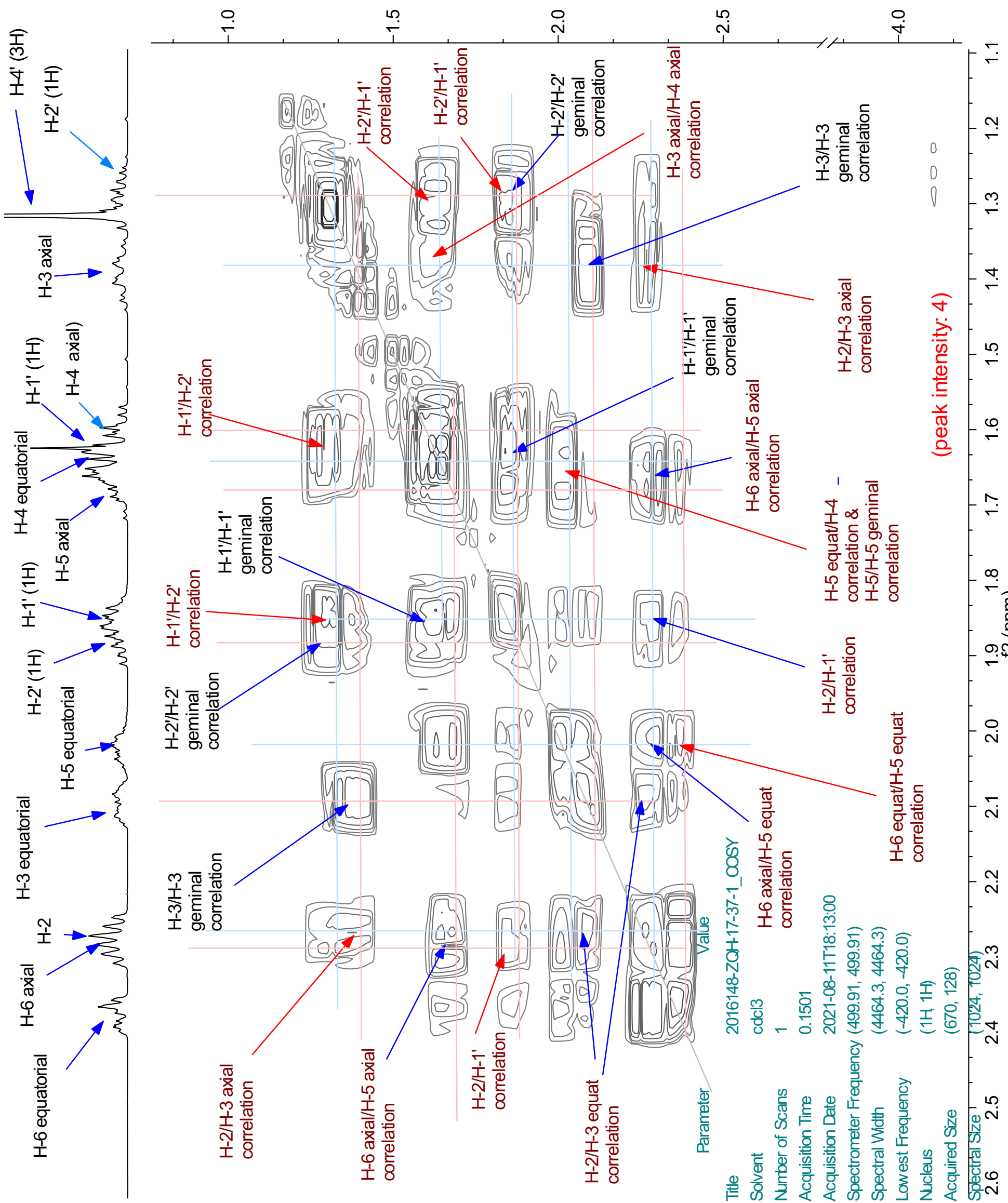

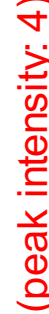

容亮
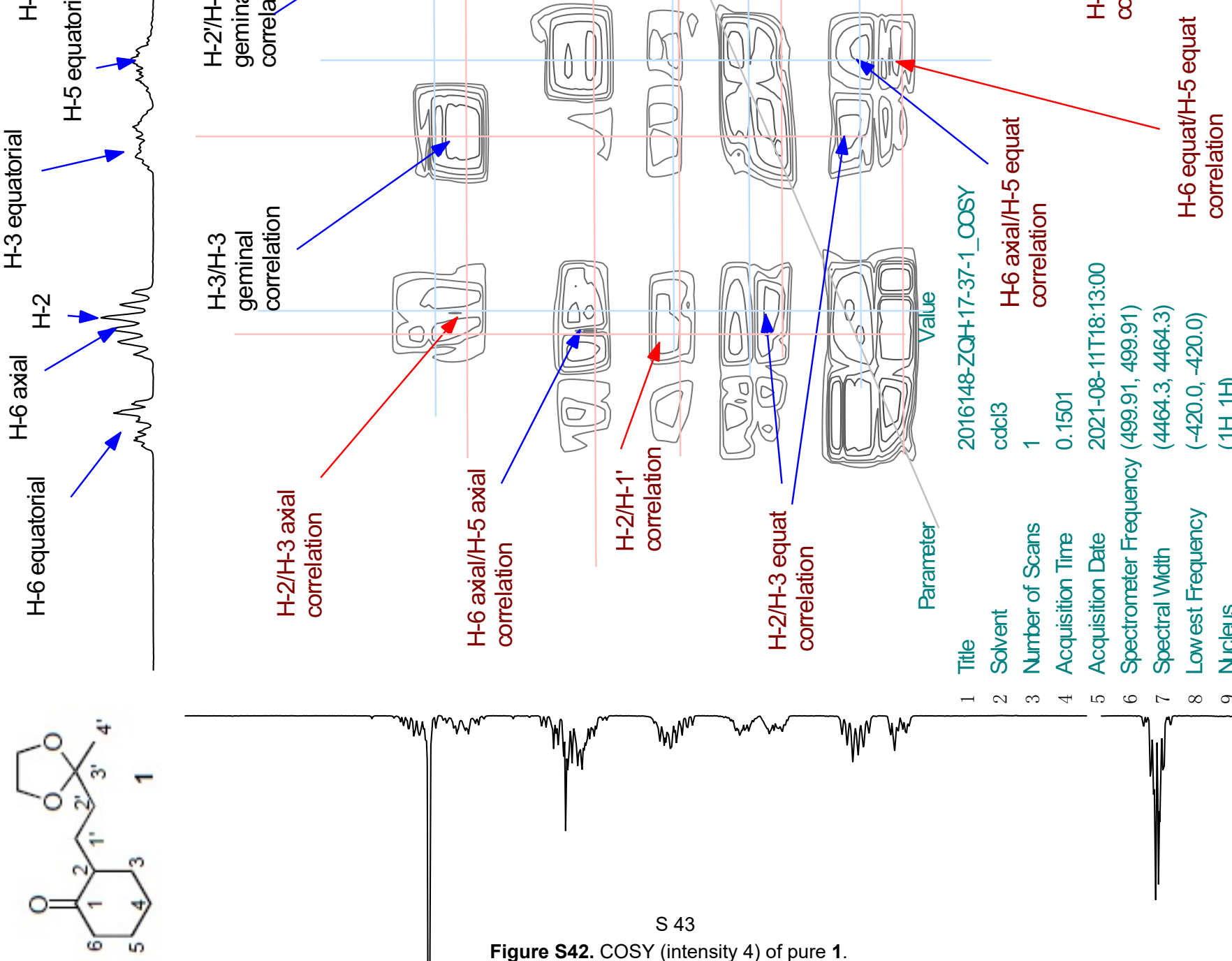
(mdd) if
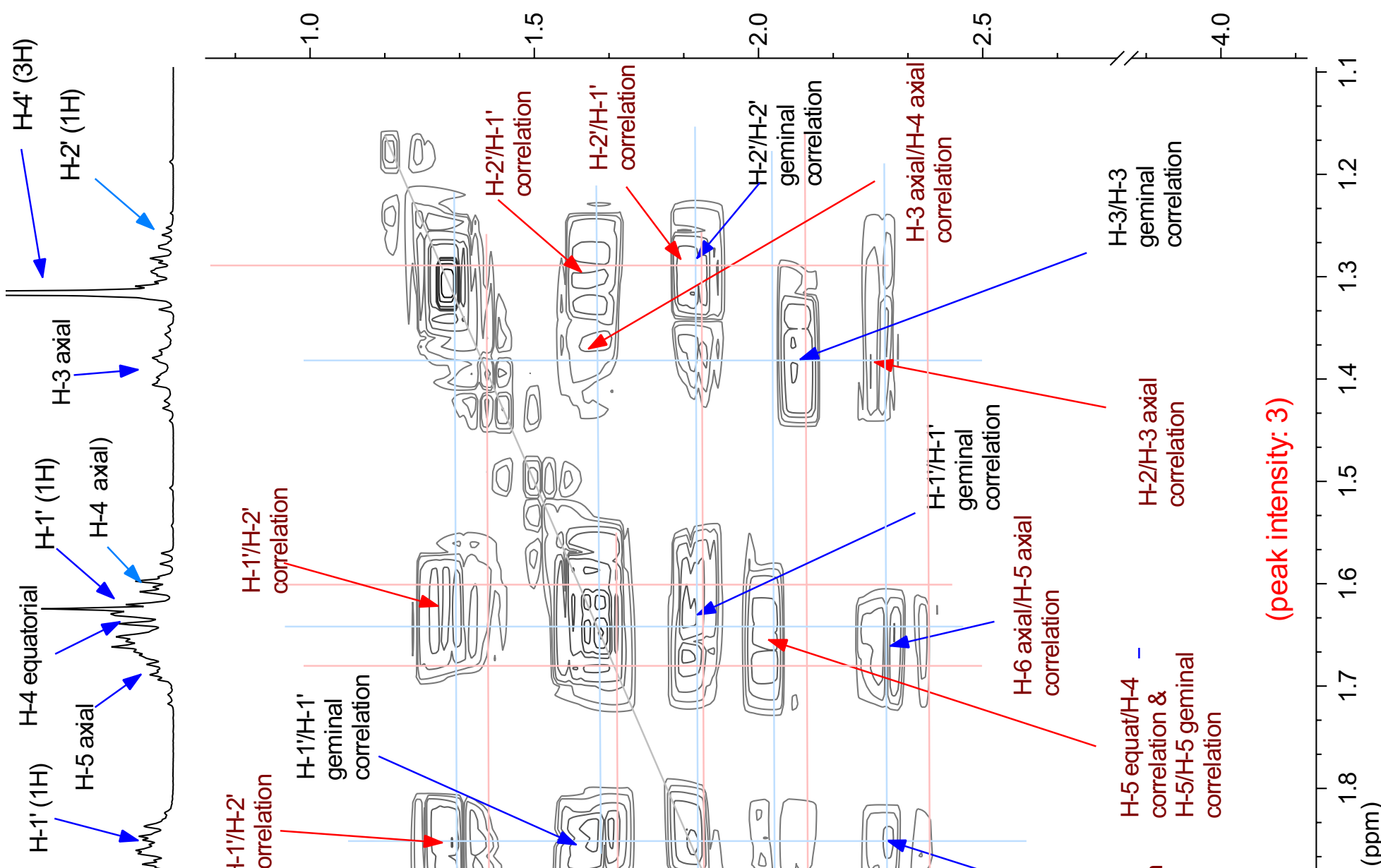

立

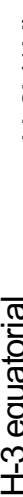
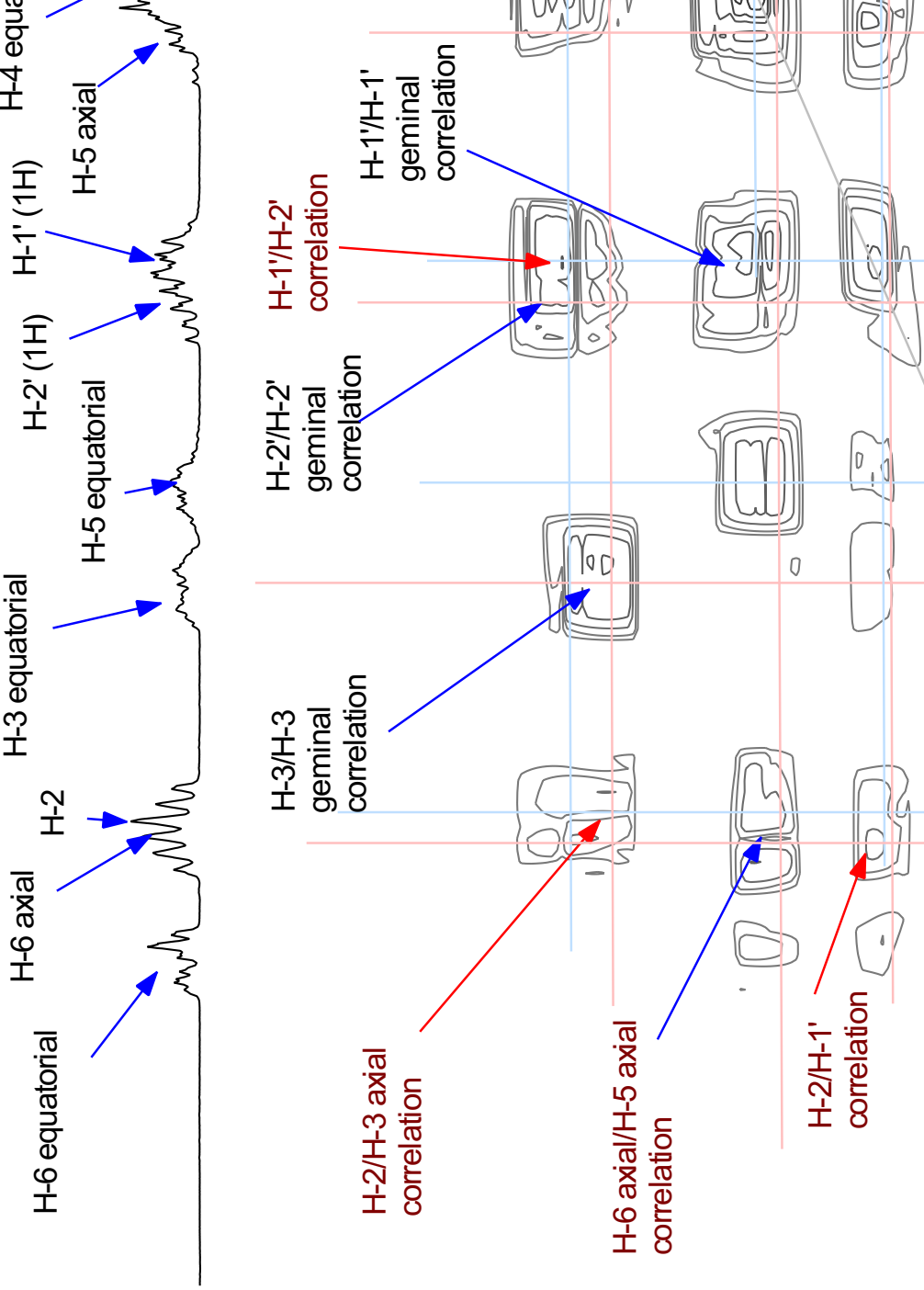

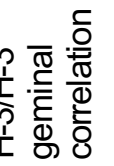
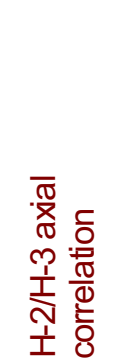
(mdd) $\mathrm{H}$
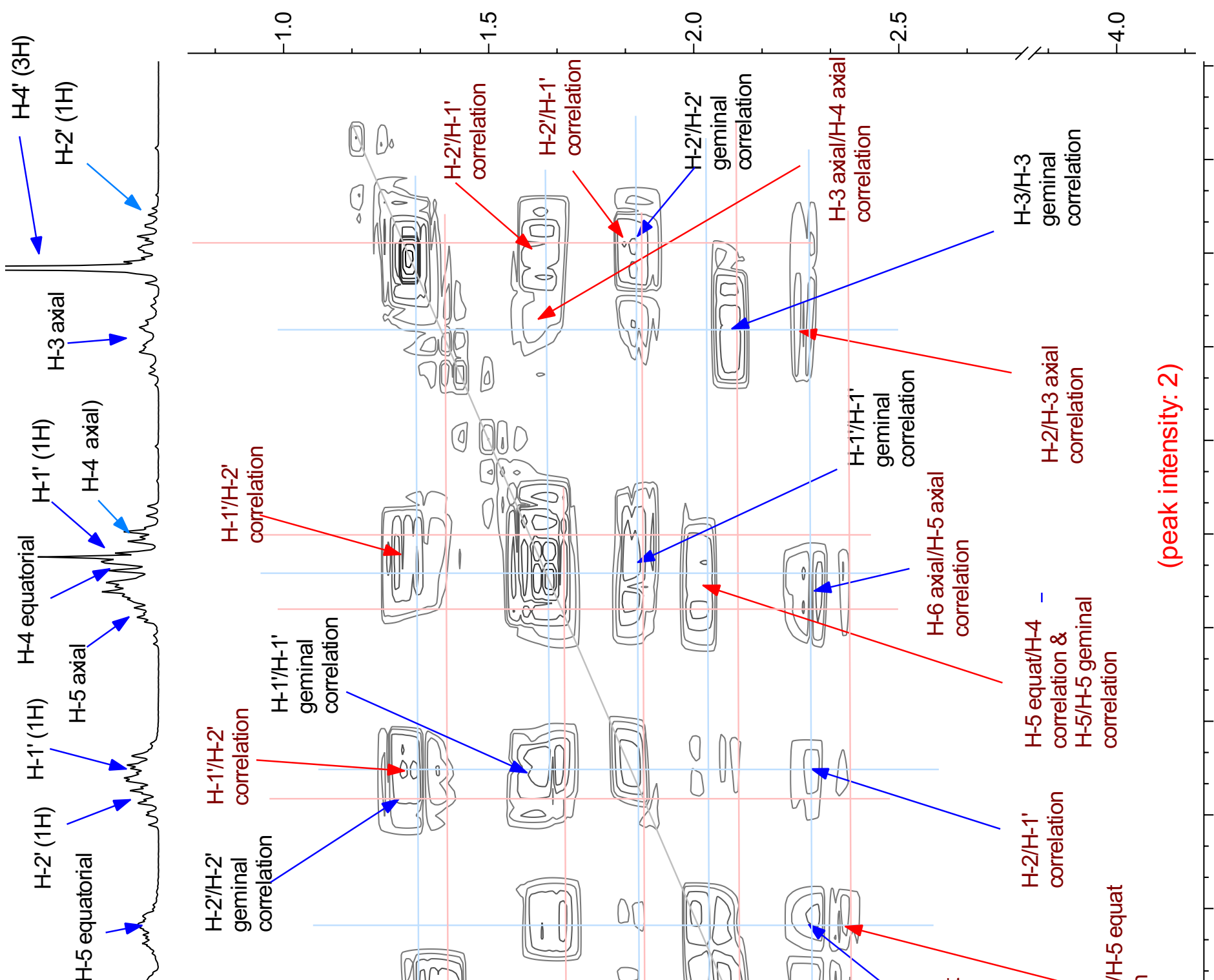

索彭

$\overline{0}$
$\frac{0}{9}$
$\frac{0}{0}$
$\overline{0}$
9
9
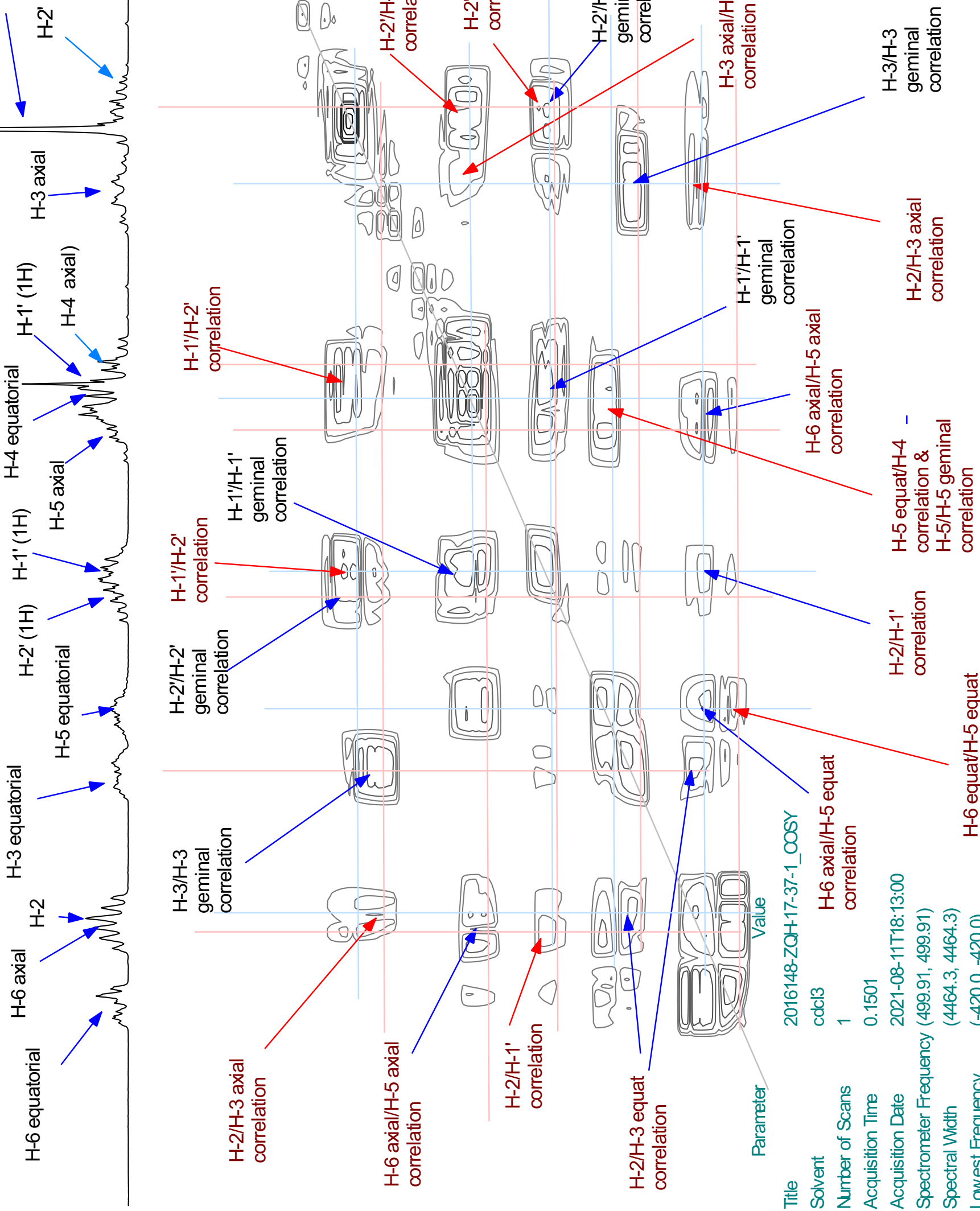

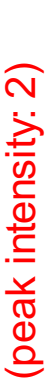
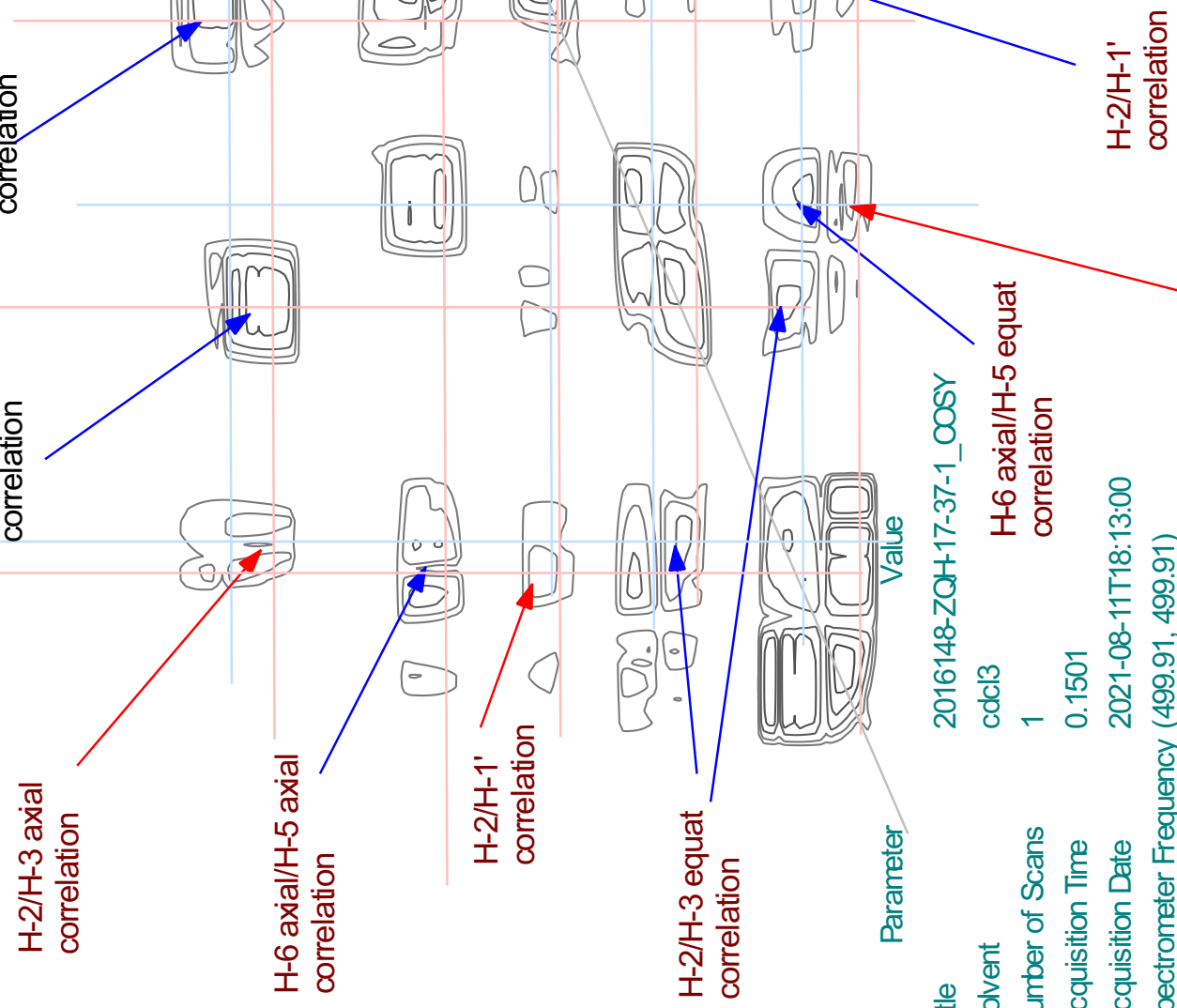

8

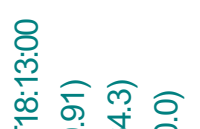

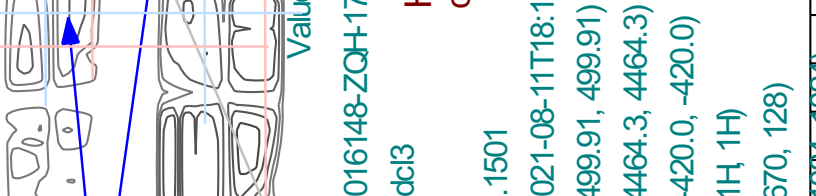

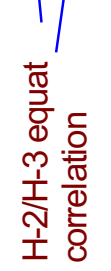

बे

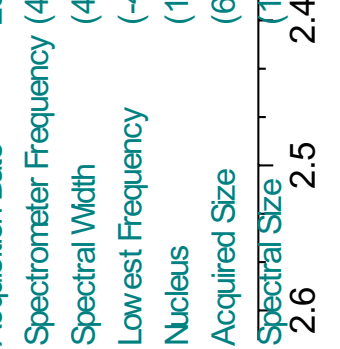

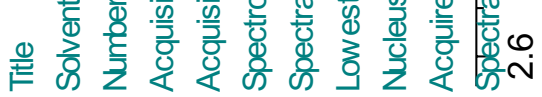

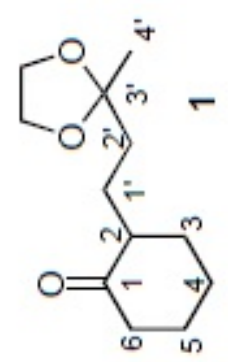


(udd) H
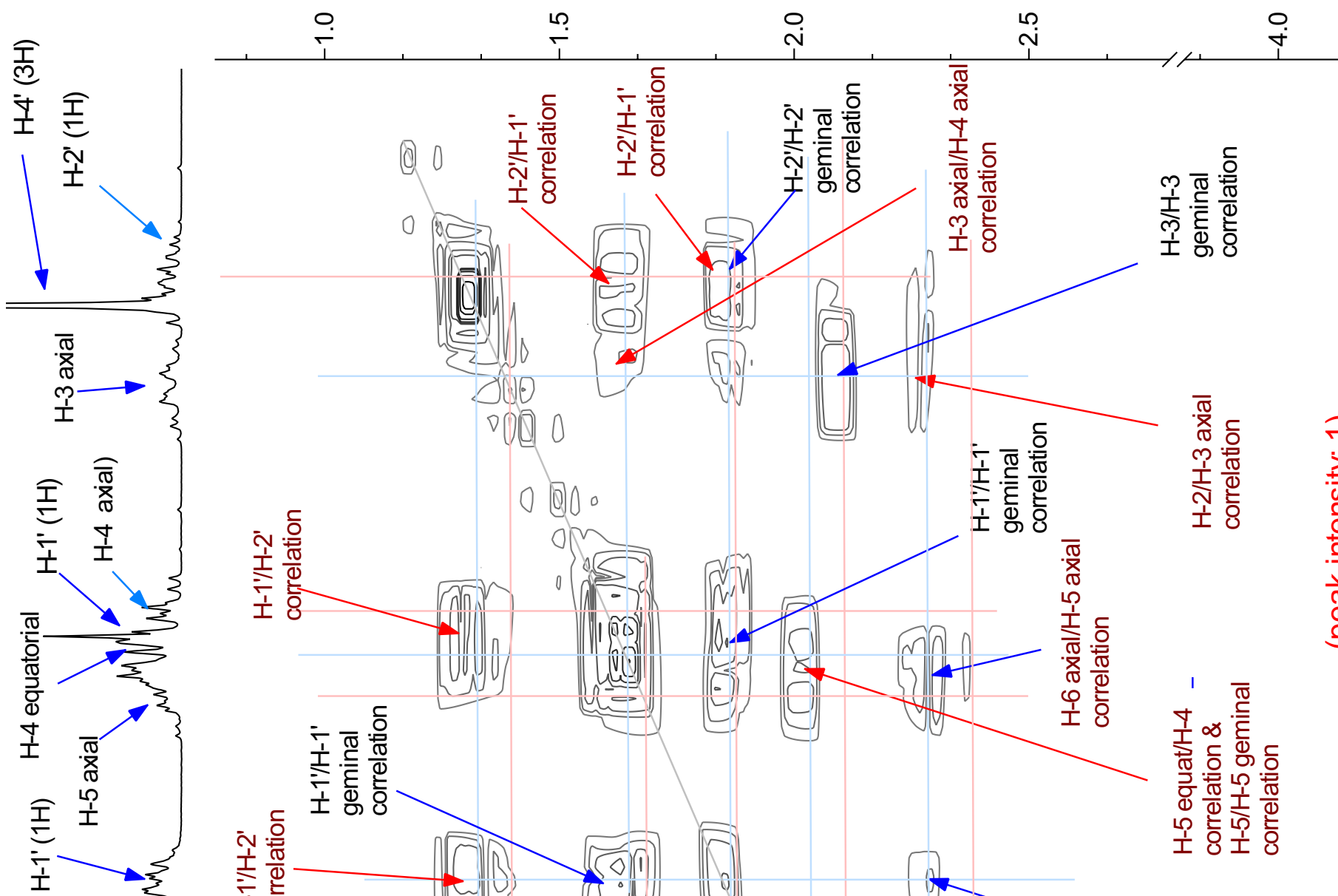$$
\text { . }
$$

(1)
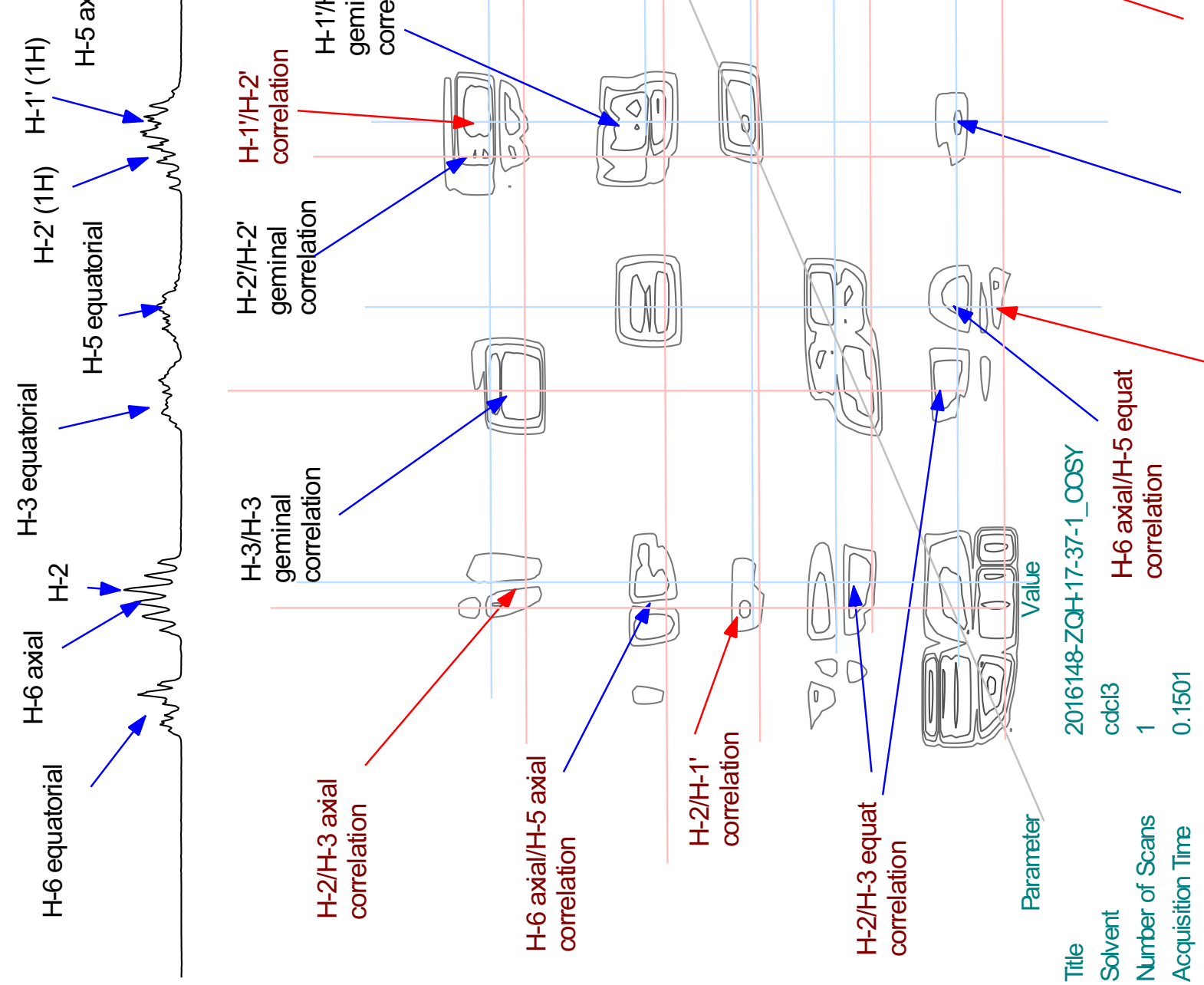

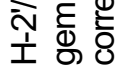
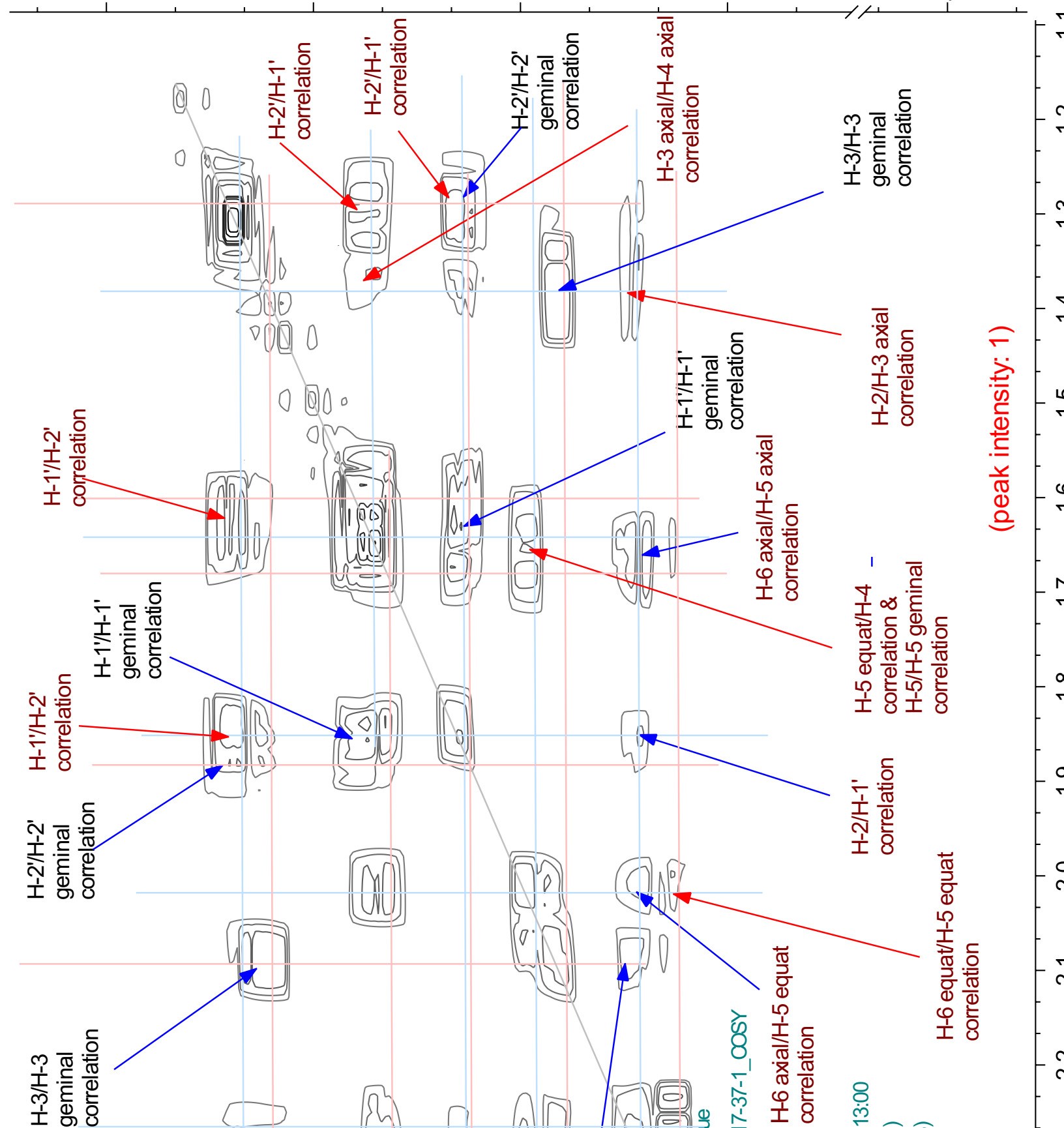

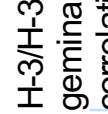

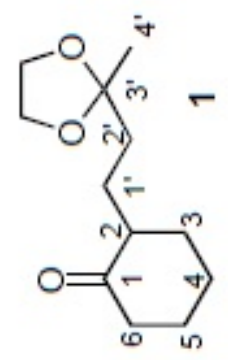


(mdd) if

오,
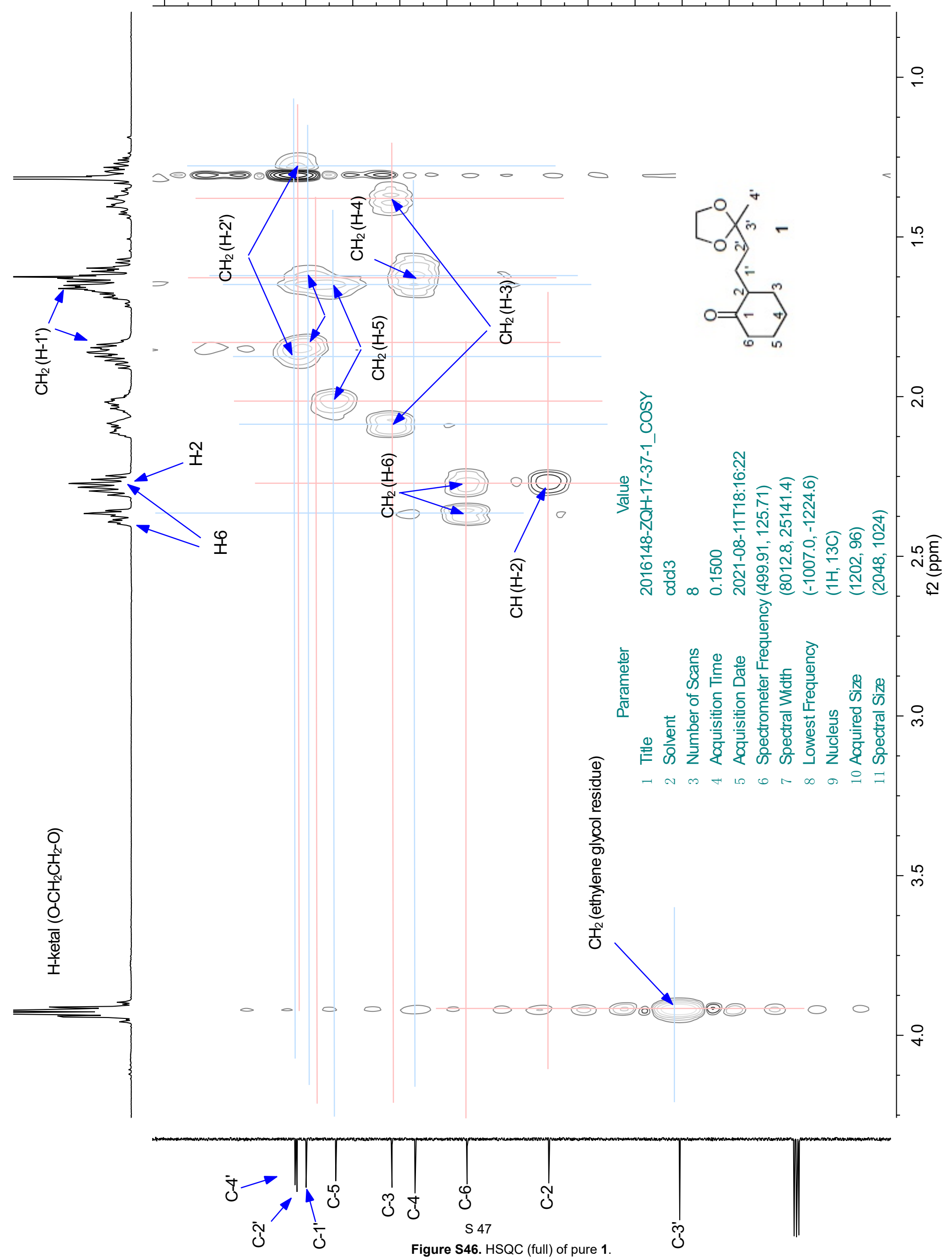
(mdd) if
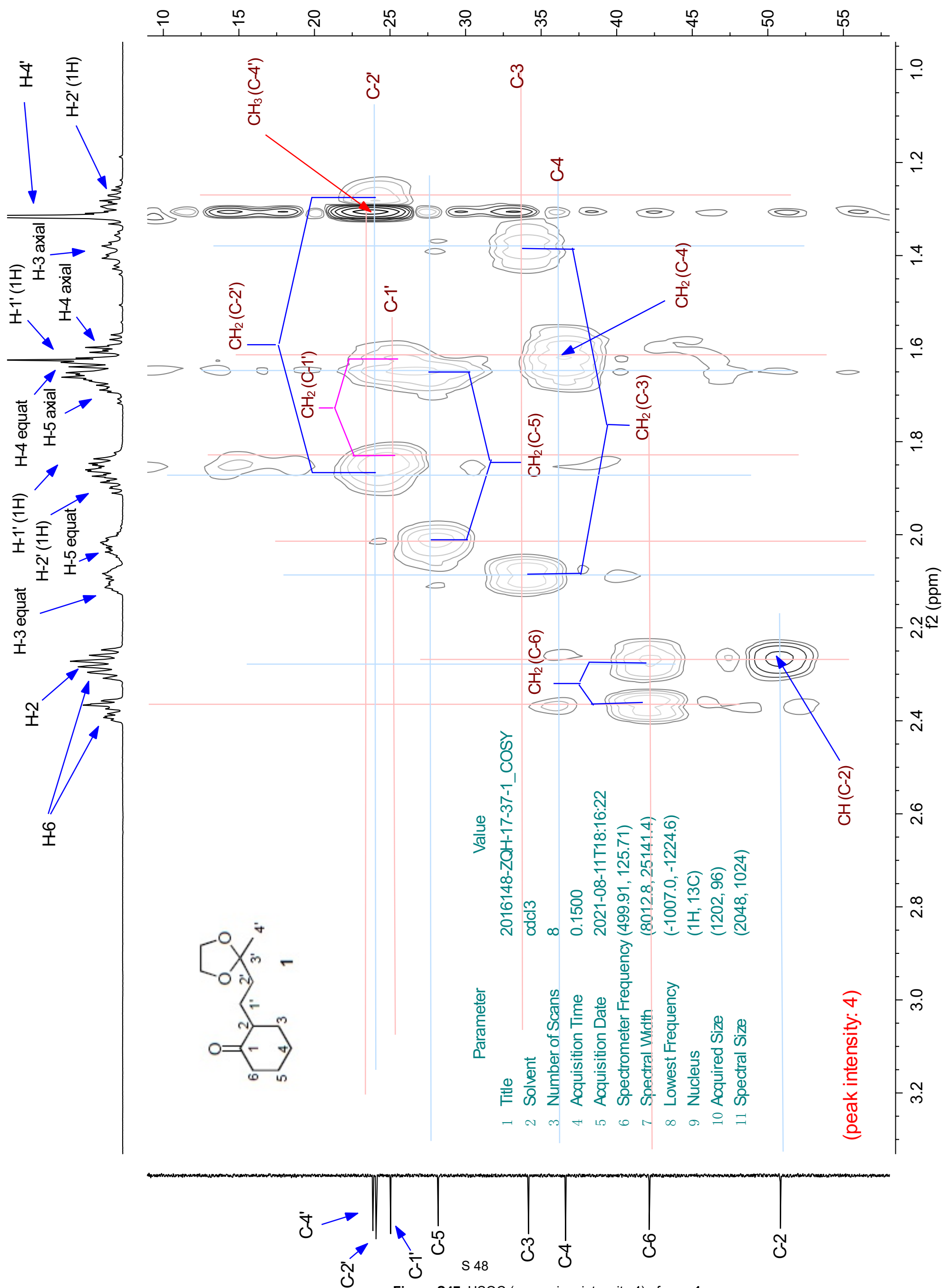

ชั 
(mdd) if

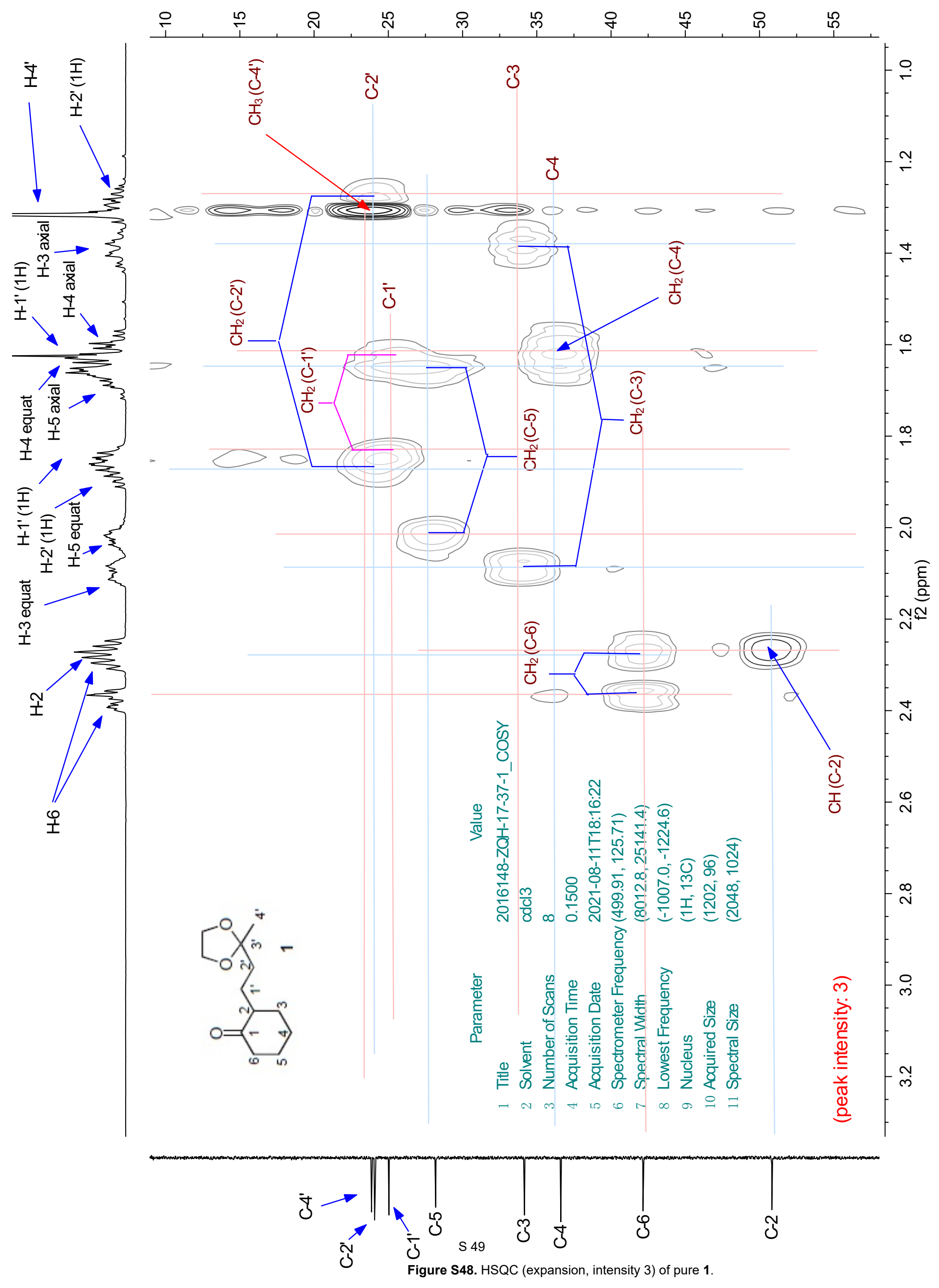


(mdd) if

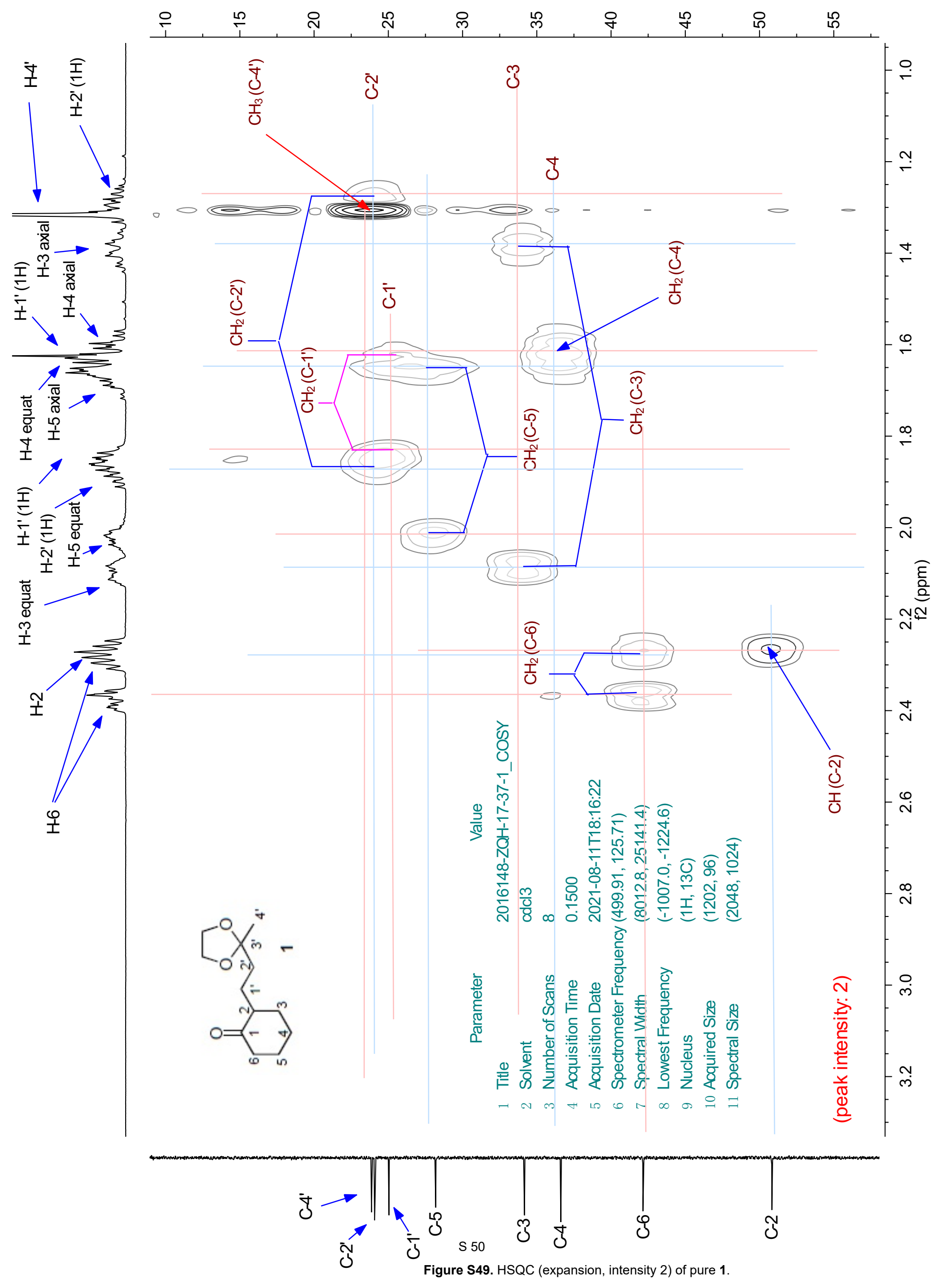


(mdd) if

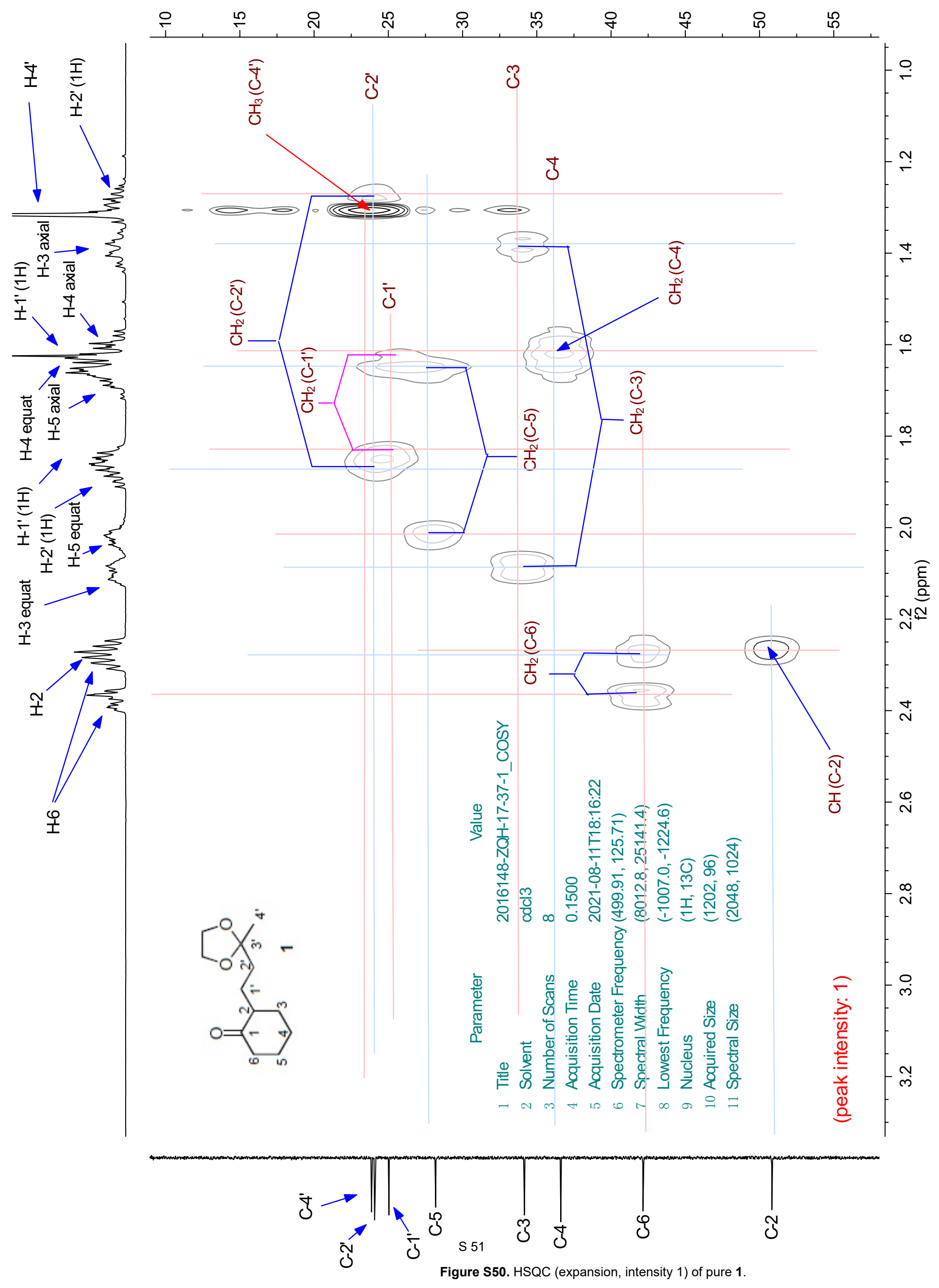


(urdd) IJ

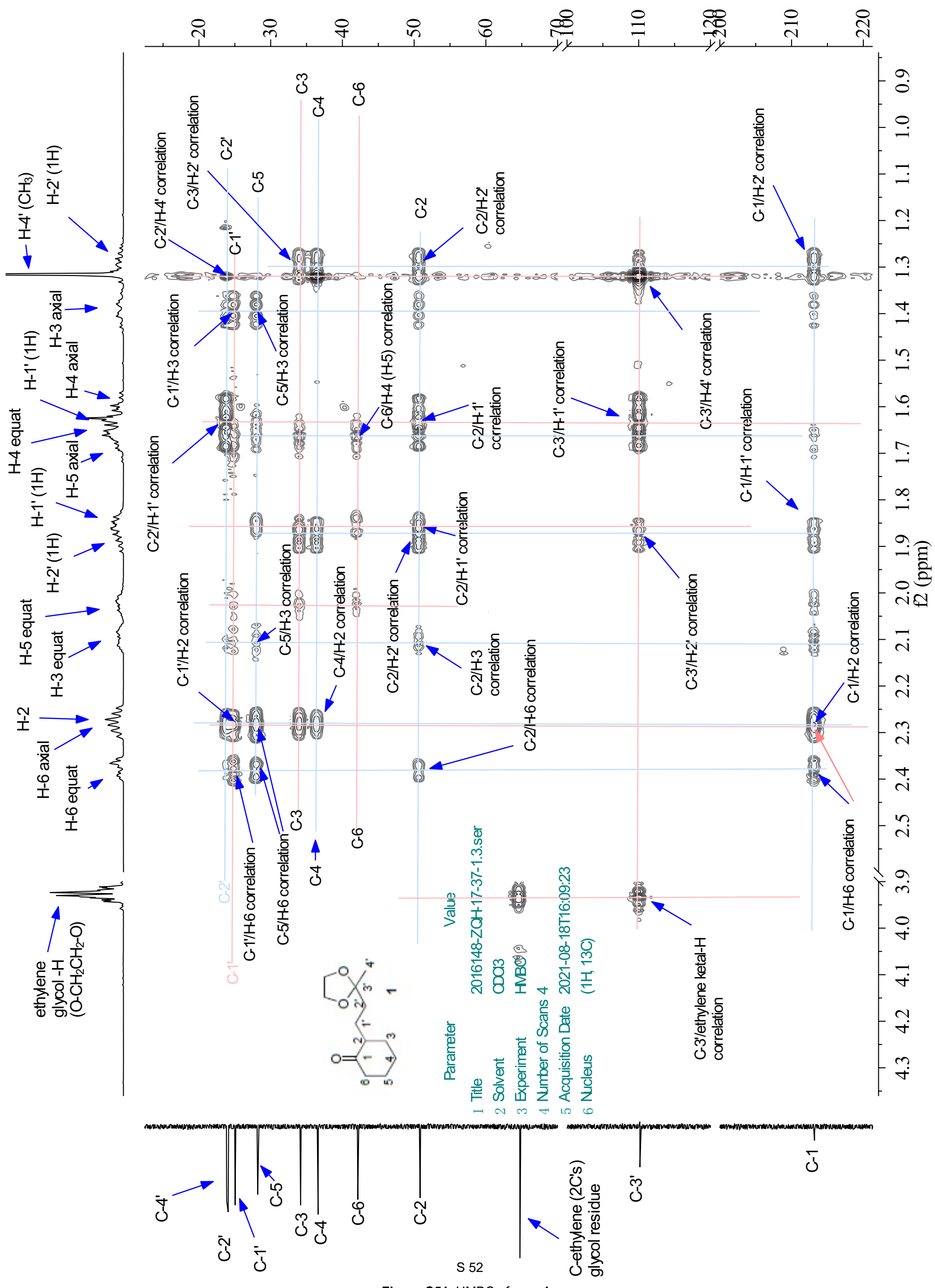

Figure S51. HMBC of pure 1. 